\title{
Late Neolithic and Late Bronze Age lithic assemblages associated with a cairn and other prehistoric features at Stoneyhill Farm, Longhaven, Peterhead, Aberdeenshire, 2002-03
}

\author{
by Ian Suddaby and Torben Ballin \\ with contributions by M Cressey, M Hastie, \\ A Jackson, \& M Johnson
}

CFA Archaeology Ltd, Old Engine House, Eskmills Park, Station Road, Musselburgh EH21 7PQ

Illustrations prepared by

Kevin Hicks, George Mudie and Leeanne Whitelaw

Scottish Archaeological Internet Report 45, 2010 www.sair.org.uk 
Published by the Society of Antiquaries of Scotland, www.socantscot.org.uk with Historic Scotland, www.historic-scotland.gov.uk and the Council for British Archaeology, www.britarch.ac.uk

Editor Helen Bleck

Produced by Archétype Informatique SARL, www.archetype-it.com

ISBN: 9780903903547

ISSN: $1773-3803$

Requests for permission to reproduce material from a $S A I R$ report should be sent to the Director of the Society of Antiquaries of Scotland, as well as to the author, illustrator, photographer or other copyright holder.

Copyright in any of the Scottish Archaeological Internet Reports series rests with the SAIR Consortium and the individual authors.

The maps are reproduced from Ordnance Survey material with the permission of Ordnance Survey on behalf of The Controller of Her Majesty's Stationery Office. (C) Crown copyright 2001. Any unauthorised reproduction infringes Crown copyright and may lead to prosecution or civil proceedings. Historic Scotland Licence No. GD 03032G, 2002.

The consent does not extend to copying for general distribution, advertising or promotional purposes, the creation of new collective works or resale. 


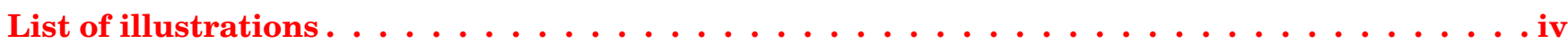

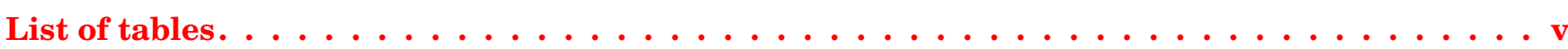

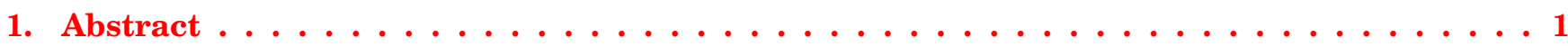

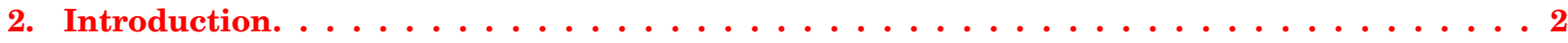

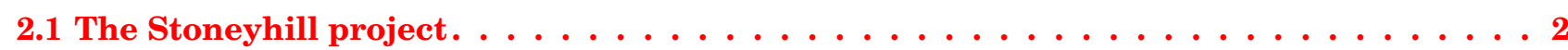

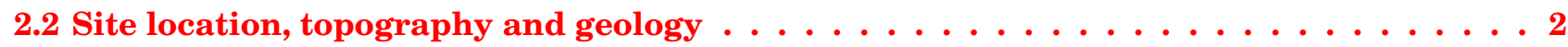

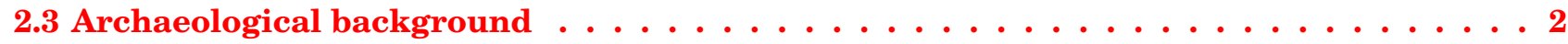

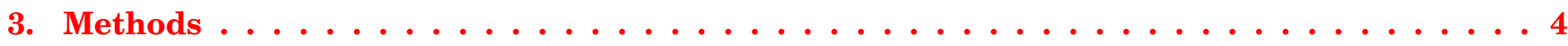

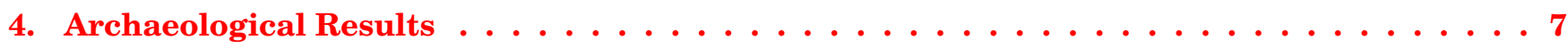

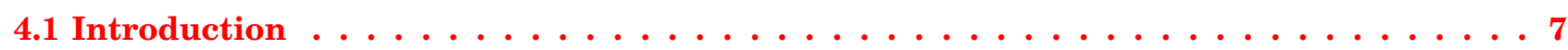

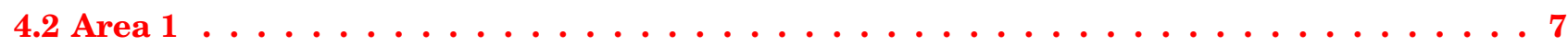

4.3 Area $2:$ investigation of previously recorded sites $\ldots \ldots \ldots \ldots$

4.4 Area 2: investigation of newly discovered prehistoric sites . . . . . . . . . . . . . 13

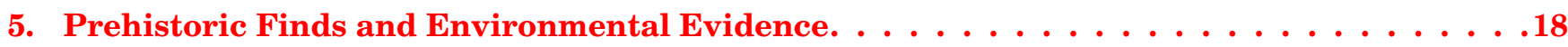

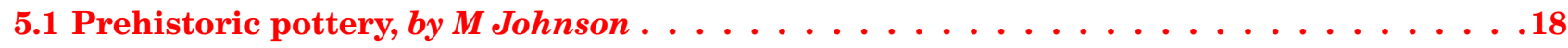

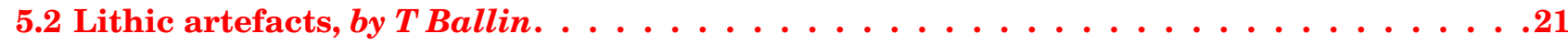

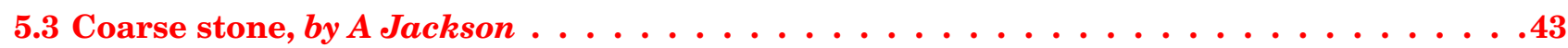

5.4 Charcoal and charred plant remains, by M Hastie \& M Cressey . . . . . . . . . . . . . .44

5.5 Radiocarbon dating . . . . . . . . . . . . . . . . . . . . . . . . . . . .

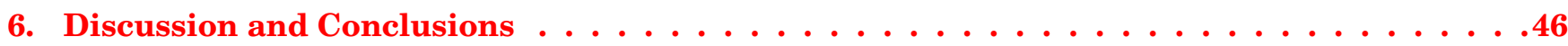

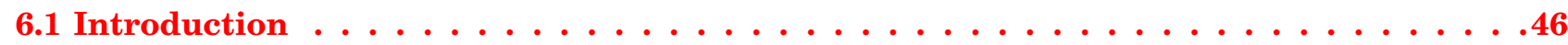

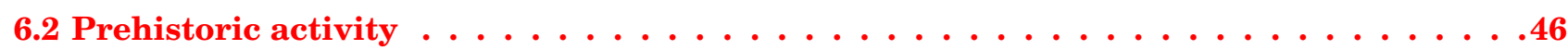

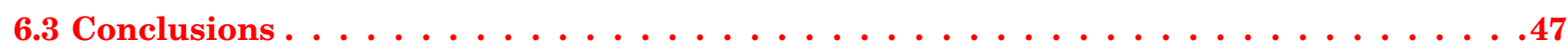

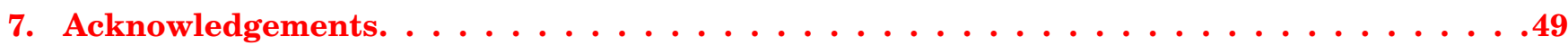

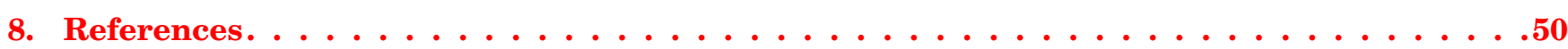

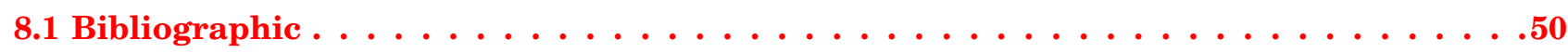

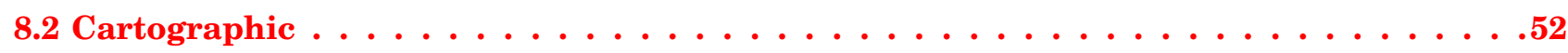




\section{LIST OF ILLUSTRATIONS}

Location maps showing the Stoneyhill Landfill development boundary and area of the study. . . . . . . . . . . . . . . . . . . . . . . . . . Area 1 plan with an inset showing the Ordnance Survey First Edition (Aberdeenshire Sheet XXXI 1872) . . . . . . . . . . . . . . . . . . . . . . . 4 Second Edition OS map (Aberdeenshire Sheet XXXI NE, 1901) $\ldots \ldots \ldots$ Clearance Cairn $7 / 4$ plan and section . . . . . . . . . . . . . . . . . . . . . 8 Plan and section of the lithic scatters in peat horizon 762 under modern Cairn $7 / 6 \ldots \ldots$ Plan of Cairn 7/17, with Pit 7181 shaded . . . . . . . . . . . . . . . . . . . . . . . 11

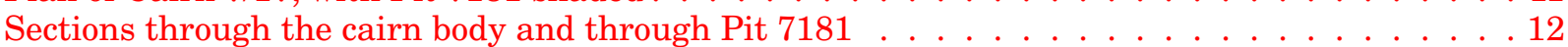
Plan of the post-arc and other prehistoric features, including pit F70, in the area. . . . . . . . 13 Post-arc F7-F11, 4402, 4407, plan and sections . . . . . . . . . . . . . . 14 The view from the post-arc, looking east towards Cairn $7 / 17$ on the horizon . . . . . . . . . . . 15 Sections through possible post-holes F5-F6, F12-F13 and F16 adjacent to the post-arc and through Pit F70 to the north . . . . . . . . . . . . . . . . 16

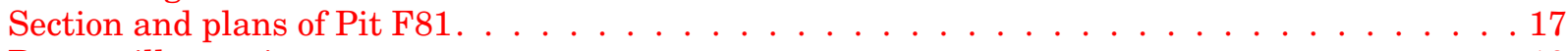
Pottery illustrations . . . . . . . . . . . . . . . . . . . . . . . . . . . . . 19 Lithic artefacts from Trench 9, Cairn 7/17 (7183) and Cairn 7/17 fill . . . . . . . . . . . . . . 26 Lithic artefacts from Dun na Cluaich and Grid J . . . . . . . . . . . . . . . . . . . 32 Lithic artefacts from Dun na Cluaich and Grid J . . . . . . . . . . . . . . . . . 36 


\section{LIST OF TABLES}

$1 \quad$ Baseline sites within the proposed development area (after Alexander 1999) _ . . . . . . . . .7

Quantification of pottery assemblage . . . . . . . . . . . . . . . . . . . . 18

Lithic artefacts by area . . . . . . . . . . . . . . . . . . . . . 22

Dates and characterisation of the various Stoneyhill sub-assemblages . . . . . . . . . . . . 39

Technological key-figures for the operational schemas of the assemblages from Trench 1 /

Grid J, Cairn 7/17 (7183), and Cairn 7/6 . . . . . . . . . . . . . . . . . . . . . 41

Composition of carbonised cereal remains and other plant remains . . . . . . . . . . 44

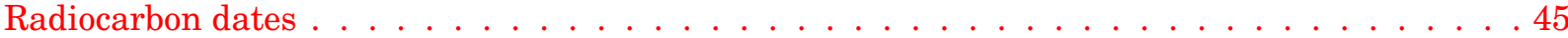




\section{$1 \quad$ ABSTRACT}

Prehistoric remains were recorded by CFA Archaeology Ltd (CFA) in 2002-03 during a programme of fieldwork at the landfill site within the boundaries of Stoneyhill Farm, which lies $7 \mathrm{~km}$ to the southwest of Peterhead in Aberdeenshire. These included a clearance cairn with a Late Bronze Age lithic assemblage and a burial cairn, with Late Neolithic and Early Bronze Age lithics and Beaker ceramics. Other lithic scatters of similar date had no certain associations, although pits containing near-contemporary Impressed Wares were nearby. Additional lithic assemblages included material dated to the
Mesolithic and Early Neolithic. What may be protoUnstan Wares in an isolated pit were associated with radiocarbon dates (barley) of the first half of the fourth millennium BC. These findings represent a substantial addition to the local area's archaeological record and form an important contribution to the understanding of lithic technology and ceramics in earlier prehistoric Scotland.

This paper is dedicated to the memory of Ian Shepherd, whose site visits enlightened this and other projects undertaken by one of the authors (IS). 


\section{INTRODUCTION}

\subsection{The Stoneyhill project}

Archaeological fieldwork at the Stoneyhill Landfill Site (illus 1) was carried out between July 2002 and May 2003. The project was commissioned and funded initially by Stoneyhill Waste Management (SWM) Ltd and latterly by SITA. It was overseen by Ian Shepherd of Aberdeenshire Council, Planning and Environment Services.

The project was initiated by a proposal for the expansion of an existing landfill site. A deskbased assessment and field survey of the proposed landfill extension (Alexander 1999) were carried out as part of an Environmental Impact Assessment (EIA) produced for SWM by BMT Cordah (SWM 2000). This work covered a wider area than that ultimately included in the landfill, but the site numbering used in the EIA has been retained to ease cross-referencing.

Following planning consent, work took place within a field to the east of the existing landfill and in the landfill extension, principally to the north and west of the existing site. The works included a survey and evaluation, followed by excavation of identified sites, and finally a watching brief within selected parts of the site during groundbreaking works.

This report covers mainly the prehistoric remains identified during the fieldwork, although later clearance cairns are also briefly described. More detailed information on the post-medieval remains is available in an archive report (Suddaby 2009).

\subsection{Site location, topography and geology}

Stoneyhill (NGR: NK 078 409, illus 1), lies 7km to the south-west of Peterhead on undulating agricultural land between $50 \mathrm{~m}$ and $75 \mathrm{~m}$ above OD. The farm is bisected by the Laeca Burn, which flows in a generally southerly direction towards Hatton and then east (as the Water of Cruden) to the sea at Cruden Bay. Flanking the burn within Stoneyhill Farm, there are areas of peat and steeper slopes on which modern cultivation is not possible. Many of the upstanding archaeological sites were preserved in these areas.

The development site lay entirely within the area between the River Ugie and the Burn (Water) of Cruden. A granite quarry at Stoneyhill Farm was the location of the initial landfill site and further exposures of similar rock were present in the south of the development site and under Cairn 7/17. Milne (1892) described the subsoil as containing much flint, and the local area, characterised by high proportions of quartzite and flint nodules, is now referred to as the Buchan Ridge Gravels (for a more detailed discussion of these gravel deposits, see Kesel \& Gemmell 1981; Bridgland et al 1997; Merritt et al 2000 and Merritt et al 2003).

The natural subsoil varies widely across the project area, with soft flint-rich clays and sandy clays containing granite cobbles and boulders dominating to the east of the Laeca Burn valley, with loose gravels, sandy gravels and sand on the valley floor and to the west. Flint cobbles and pebbles, rarely over $0.2 \mathrm{~m}$ diameter, of widely varying colours and qualities, dominated the gravel deposits, with granite, quartzite and sandstone also present. A thick iron-pan had formed within areas not under the plough.

Kesel \& Gemmell (1981, fig. 2) present a density map of the Buchan Ridge Gravels, and it clearly shows that the Stoneyhill area is near the most flintrich parts of the Gravels. Although the project area may not be directly on top of in situ gravel deposits, it is certainly within the richests parts of the surrounding glacial/fluvio-glacial deposits.

\subsection{Archaeological background}

The Peterhead area has a rich archaeological record, most notably in terms of upstanding field monuments and past artefact find-spots. Away from the coastal strip, little commercial development and hence archaeological work has taken place (Philips \& Bradley 2004), although recent work on a gas pipeline near Peterhead (Strachan \& Dunwell 2003) forms a notable exception.

Lithic-based research fieldwork has been conducted by Alan Saville and others (Saville 1995; Bridgland et al 1997) around the Den of Boddam, $4 \mathrm{~km}$ to the south of Peterhead and $4 \mathrm{~km}$ to the east of Stoneyhill (illus 1). This produced evidence for sub-surface mining of flint resources.

In 2002, a proposed windfarm to the west of the Laeca Burn, between Aldie Farm and Nether Kinmundy, led to an archaeological assessment and field survey (Cressey 2002). This identified twentyeight archaeological sites ranging from prehistoric cairns to modern quarries, and included four flint scatters. 

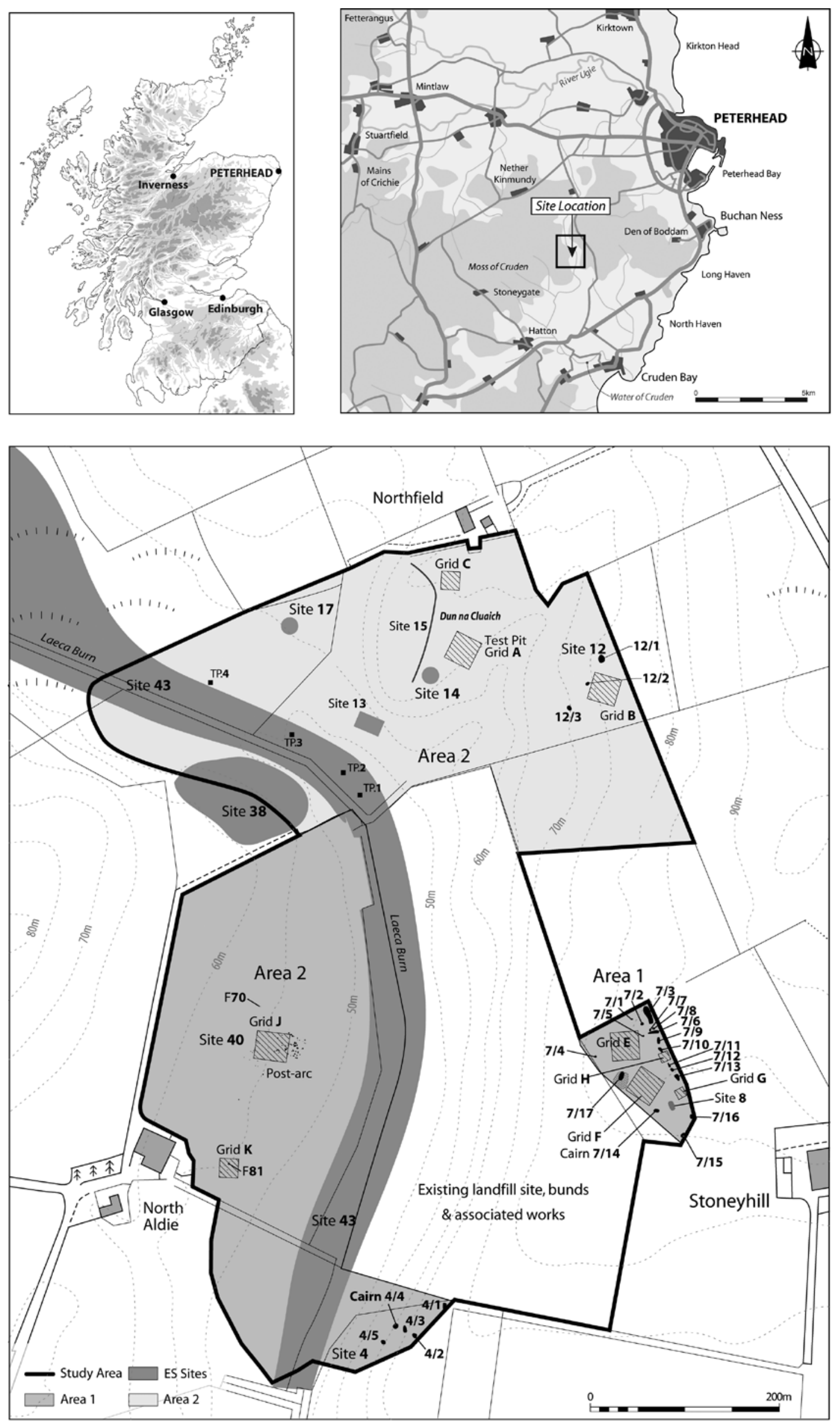

Illus 1 Location maps showing the Stoneyhill Landfill development boundary and area of the study 


\section{METHODS}

The aims of the project were to record those archaeological sites that would be destroyed in the course of the development, through a programme of surveying, evaluation, excavation, watching brief and publication.

Within Area 1, all upstanding cairns and quarry features were surveyed by total station equipment. These data were used to inform the subsequent evaluation strategy.
Evaluation took place within both Areas 1 and 2 , with methodological variation being employed to take account of the differing character of the recorded sites and the apparently blank areas between them. Hand-excavated trenches were positioned over clearance cairns forming Sites 4, 7 and 12 and over a quarry scoop (Site 8). Hand-excavation was also planned for Site 14, but the possible kiln was destroyed by gravel extraction on the

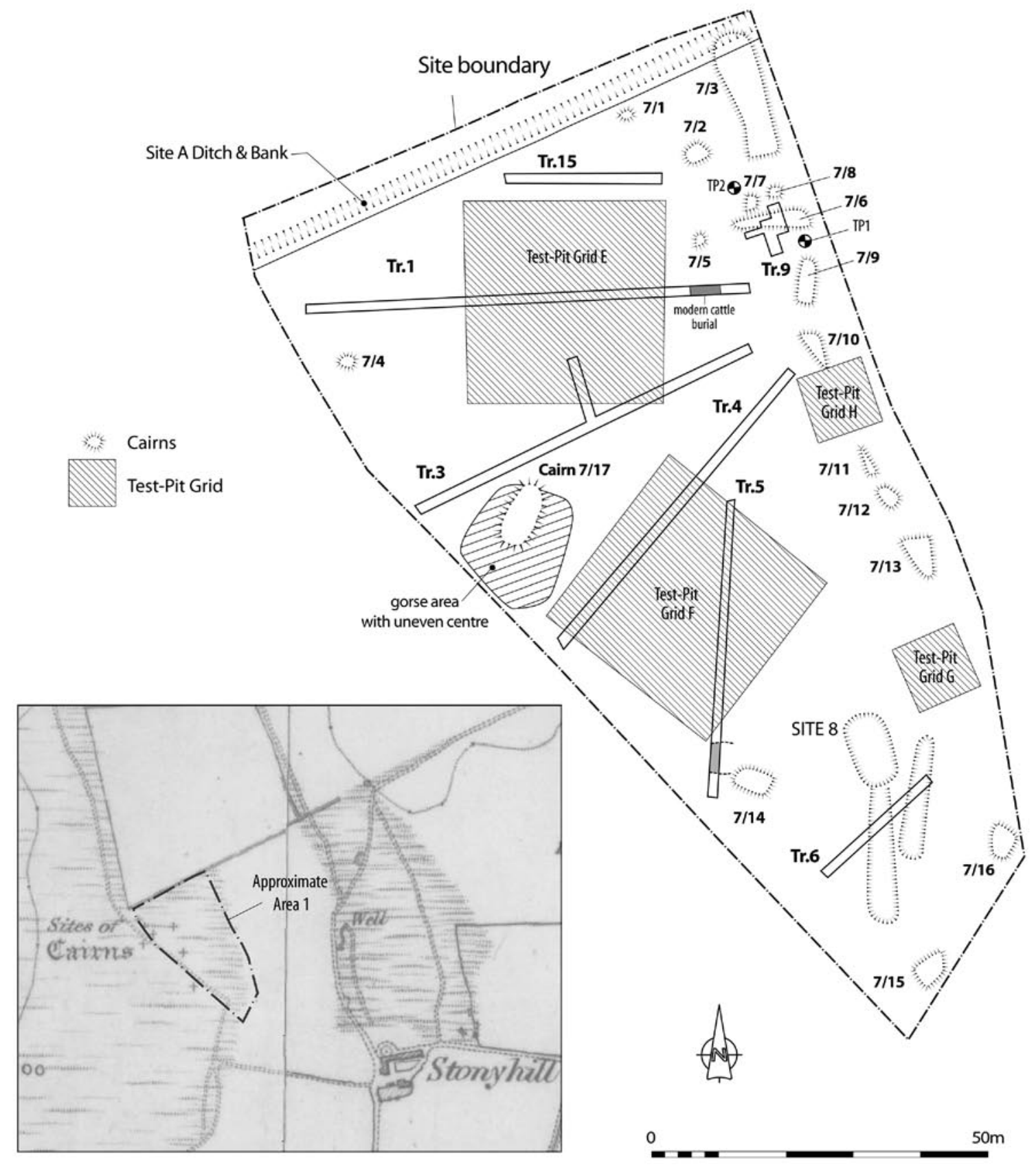

Illus 2 Area 1 plan with an inset showing the Ordnance Survey First Edition (Aberdeenshire Sheet XXXI 1872) 
summit of Dun na Cluaich before this was possible. Machine-trenching was used to evaluate Sites 15, 17 and apparently featureless zones within Areas 1 and 2. In Area 1, around 5\% (seven trenches, $383 \mathrm{~m}^{2}$ ) of the area was investigated (illus 2) and in Area 2, 58 trenches $\left(6407 \mathrm{~m}^{2}, 3.2 \%\right)$ were excavated in locations accessible by machine (illus 1 ). Within the alleged AD 1012-14 battle site, the excavated spoil was scanned by metal detector with the aim of recovering artefacts.

Hand-dug gridded test-pits with dimensions of $0.5 \mathrm{~m}^{2}$ were excavated during the evaluation in blank areas of Area 1 (illus 2) and around ES Sites 12, 14 and 43 in Area 2 (illus 1). A grid (Grid K, illus 1) was placed on the summit of a prominent knoll close to North Aldie Farm. The identification of numerous lithic artefacts on a second, slighter knoll led to test-pitting at that location (Grid J, illus 1) prior to topsoil removal during the excavation phase.

Following the evaluation, excavation of selected features took place. In Area 1, a lithic scatter (Trench 9 ) and cairn (Site 7/17) were recorded. At the lithic scatter, an overlying modern stone dump (Cairn 7/6) was removed by machine with the peaty topsoil below being removed by hand. At the cairn, gorse bushes were removed by machine prior to hand excavation. In Area 2, all topsoil was removed by machine prior to the hand-excavation of the post-arc.

A watching brief took place following the completion of excavations in both Areas 1 and 2. In Area 1, the whole of the area was monitored, with negative results, and in Area 2, monitoring in the field containing the battle site produced only a few pits. 


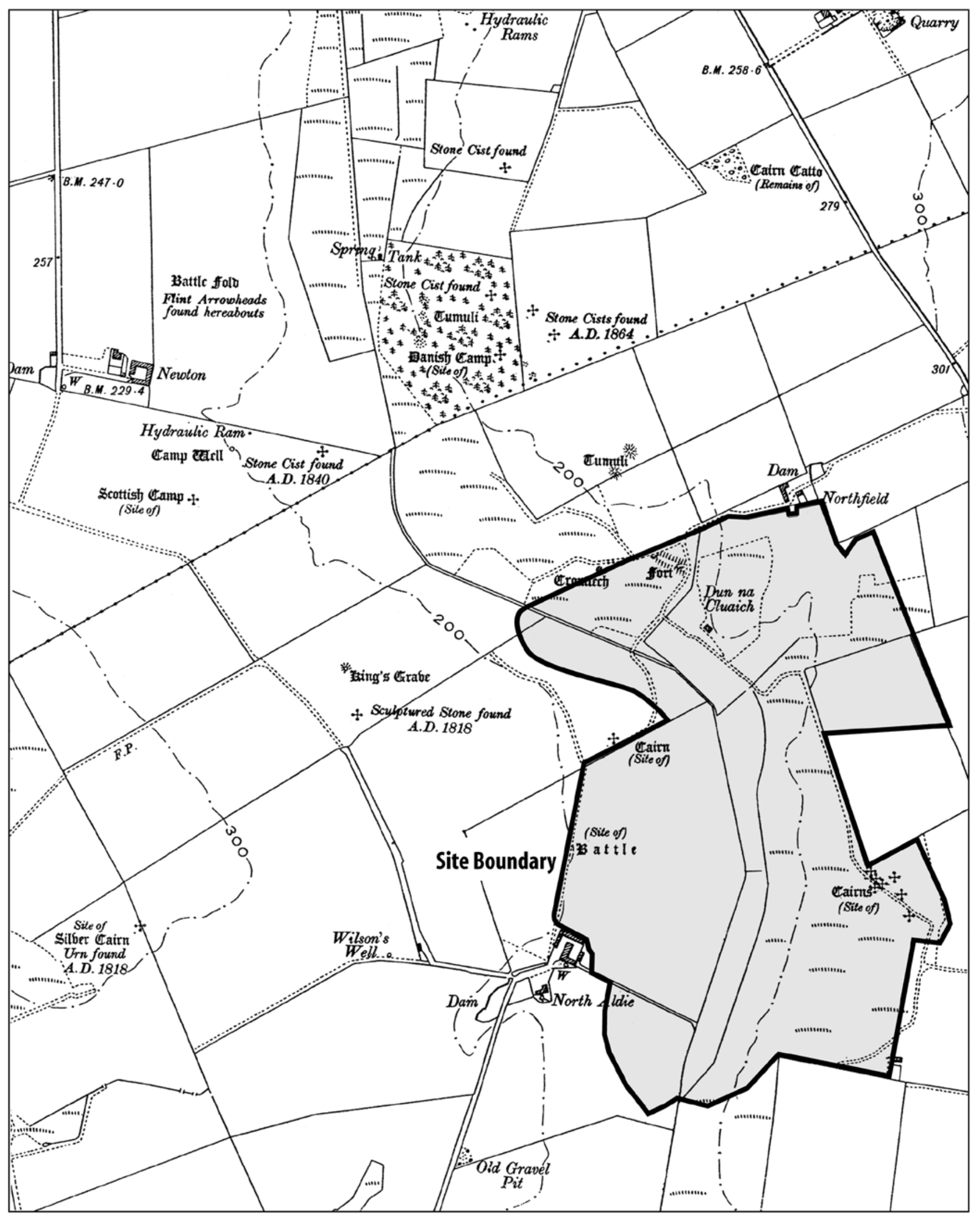

Illus 3 Second Edition OS map (Aberdeenshire Sheet XXXI NE, 1901) 


\section{ARCHAEOLOGICAL RESULTS}

\subsection{Introduction}

Eleven archaeological sites identified during the EIA work (illus 1, Table 1) were within the site boundary. These consisted of undated clearance and other cairns, post-medieval quarries, tracks and buildings, an alleged battle site between the Scots and the Danes dating from AD 1012-14, and a possible fort (determined by evaluation to be nonarchaeological; Suddaby 2009). Many of these are shown on the Ordnance Survey (OS) Second Edition Map of 1901 (illus 3).

\subsection{Area 1}

\subsubsection{Area 1 sites}

The Ordnance Survey First Edition 6-inch map (1872, illus 2 inset) shows the sites of seven cairns (Table 1, Site 7) in uncultivated ground on either side of an unfenced trackway. The Second Edition (1901, illus 3) also shows the cairns, although it is unclear whether the area remained uncultivated. Still surviving along the north side of the area, a bank and ditch may be the same one shown marking the boundary with an improved field to the north in 1872 and 1901.

The 1999 field survey recorded 'numerous spreads of stone' (Alexander 1999, 23) and in 2002 an instrument survey recorded 16 stone cairns (Cairns $7 / 1-16)$. These lay within a roughly triangular area measuring $150 \mathrm{~m}$ north to south by around $60 \mathrm{~m}$ east to west (illus 1,2) which corresponds approximately with the uncultivated area on the First Edition OS map. Of the 16 recorded cairns, 14 contained large boulders and this, combined with their distribution around the edge of the field, the rectangular form of several and the appearance of natural subsoil adhering to the lichen-free stones suggested a recent origin. Six cairns (Cairns 7/1, 7/4, 7/5, 7/6, 7/8, $7 / 11$, illus 2 ) were investigated by hand-excavated trenches. One trench, over Cairn 7/4, supported the surface indications that this site was of greater antiquity. A second, over Cairn 7/6, fortuitously located a lithic scatter within the underlying soil profile. Four grids of test-pits (illus 2, Grids E-H) recorded a scatter of over 150 lithic artefacts.

A sub-circular patch of gorse measuring around $15 \mathrm{~m}$ in diameter contained an uneven centre, and stones were apparent below the surface; this site was excavated in February 2003 and identified as Cairn 7/17.

Three surface stone quarries collectively formed Site 8; these were filled with stones and agricultural rubbish. Seven machine-excavated trenches revealed two features, one containing corrugated iron and the other the skeleton of a cow in a recent pit that was visible as a surface vegetation change. None of these sites is discussed further.

Area 1 fieldwork revealed that the surface vegetation overlay thin silty-peat topsoil with a depth of up to $0.3 \mathrm{~m}$, above a bioturbated and heavily iron-

Table 1 Baseline sites within the proposed development area (after Alexander 1999)

\begin{tabular}{lllll}
\hline Site No. & Site Type & Source & NMRS/AC SMR refs & Mitigation \\
\hline 4 & Clearance cairns & Field Survey & NK04SE0033 & Evaluation \\
7 & Cairns (sites of) \& clearance & 1st \& 2nd Ed OS maps; & NK04SE 14/ & Evaluation/Excavation \\
& cairns & Field Survey & NK04SE0010 & \\
8 & Quarry scoops & Field Survey & NK04SE0058 & Evaluation \\
12 & Clearance cairns & Field Survey & NK04SE0059 & Evaluation \\
13 & Structure & 2nd Ed OS map; Field & NK04SE0060 & None (Site destroyed) \\
& & Survey & & \\
14 & Kiln (possible) & Field Survey & NK04SE0061 & None (Site destroyed) \\
15 & Field Wall & Field Survey & NK04SE0062 & Evaluation \\
17 & Fort/Camp/Quarry & 1st \& 2nd Ed OS maps; & NK04SE 12/ & Evaluation \\
38 & Quarry & Field Survey & NK04SE 0042 & None \\
& & Aerial Photographs; & NK04SE0069 & \\
40 & Battle Site & Field Survey & NK04SE 27/ & Metal detecting \\
43 & Peat by Laeca Burn & Field Survey & NK04SE 0041 & \\
\end{tabular}


panned 'B' horizon with a depth of around $0.1 \mathrm{~m}$. The subsoil was gritty orange boulder clay.

\subsubsection{Clearance Cairn 7/4}

Cairn 7/4 was partially grassed over, with the stones being covered with turf, moss and lichen. It was located near the western side of the field, away from the concentration of modern cairns and close to the trackway shown on the First Edition OS map. A square trench measuring around $36 \mathrm{~m}^{2}$ was opened, which included the whole of the cairn (illus 4). Below turf and peaty soil (740) was a second, more humified peat formation (741) which contained lithic artefacts and overlay an iron-panned probable 'B' horizon (743). The stones formed a cairn $4 \mathrm{~m}$ in diameter and they had been dumped around a large natural boulder (744). There was no sign of any structure to these deposits. Disturbance in antiquity
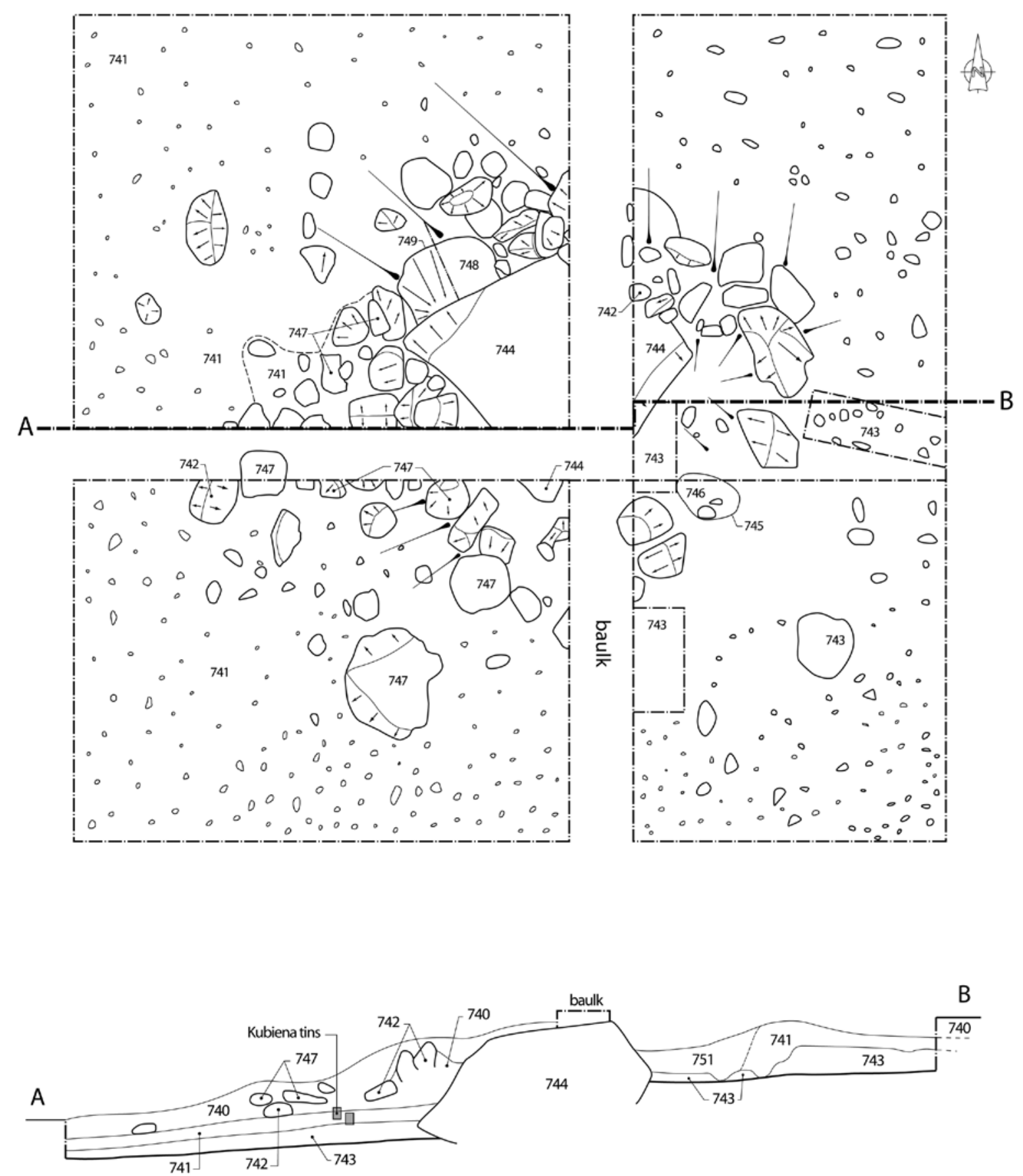

0 
was evidenced by peat-filled stone-holes (746). Both the presence of loose stones in the topsoil (747), and a modern cut (748-9) against the central boulder may be the result of unrecorded antiquarian investigations. An in situ domestic assemblage of 35 lithic objects provides a terminus post quem date for the cairn of Late Bronze Age (Section 5.2.4).

\subsubsection{Lithic scatter under modern Cairn 7/6}

A trench was hand-excavated to evaluate Cairn 7/6 (illus 5), which was rapidly established to be modern. Once the cairn stones (765) and the underlying sterile peat (761) were removed, 593 worked lithic artefacts were recovered from within a darker, more humified basal peat deposit (762) with a thickness of $0.05 \mathrm{~m}$. These had the character of an in situ domestic assemblage, but with few diagnostic pieces the assemblage could only be broadly dated to the Bronze Age (Section 5.2.5).

Subsequent excavations (Trench 9) entailed the removal by machine of the remaining cairn and of sterile peat by hand from an area of $25 \mathrm{~m}^{2}$. Once cleaned, three lithic scatters were identified (769, representing the initially discovered scatter, 770,
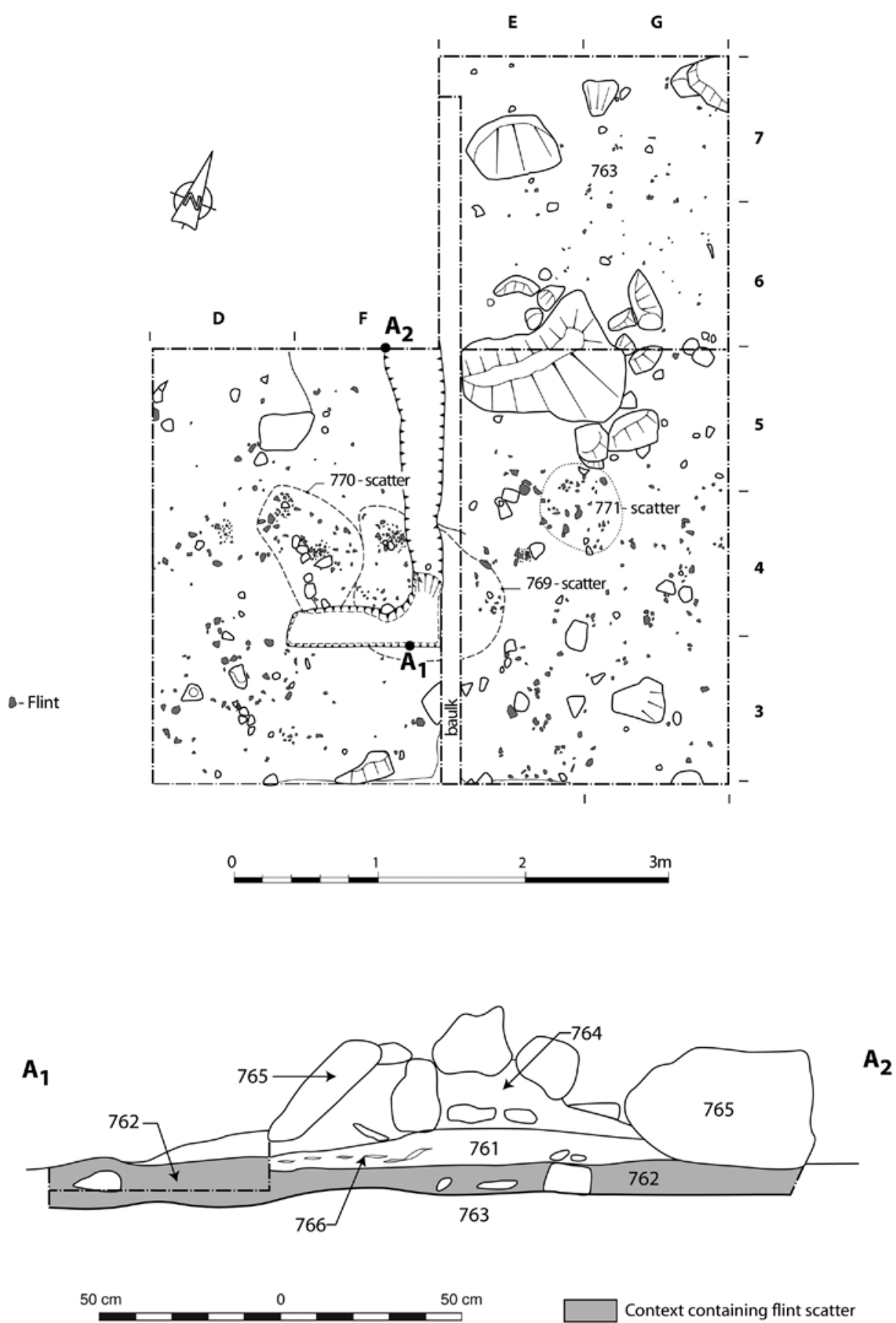

Context containing flint scatter

Illus 5 Plan and section of the lithic scatters in peat horizon 762 under modern Cairn 7/ 6 
771). All were within peaty deposit 762 or on the interface between it and the iron-panned B horizon (763) below. The scatters were hand-exposed and bagged within the $1 \mathrm{~m}^{2}$ trench grid. No structural remains or features were identified. A radiocarbon date (GU-13907, Table 12) using humic acid extracted from a Kubiena tin sample of deposit 762 within the area of the lithic scatter gave a determination of $155 \pm 35 \mathrm{BP}$, at variance with the date of the lithic objects and presumably reflecting recent contamination from the cairn above.

\subsubsection{Burial Cairn 7/17}

An area of gorse, approximating to the location of a cairn on the 1872 map, was removed by machine, revealing Cairn 7/17. Once cleaned, the remaining stones (7170) consisted of small and medium-sized cobbles, contrasting with the large stones and boulders of the modern cairns. The surviving cairn measured $8 \times 4.5 \mathrm{~m}$ and appeared to be generally oval, aligned NE-SW (illus 6). Illus 7 shows representative sections.

The cairn was shallow, rarely over two stones $(0.4 \mathrm{~m})$ deep and a maximum depth of $0.6 \mathrm{~m}$ was recorded around large natural upstanding boulders (7173). There was no clear indication of a kerb and it was uncertain whether several of the earth-fast boulders were of natural origin. A gritty humic matrix (7171), containing 187 lithic items (including a leaf-shaped arrowhead) and a few pottery fragments, was recorded between the stones and this overlay a thin peaty deposit (7172). A possible ard mark (7175-6) was exposed to the south-west of the cairn.

Discrete deposits of lithic artefacts (7177) and Beaker pottery (7174) were recovered from the north-east and centre of the cairn respectively. This assemblage spans the Neolithic period and extends into the Early Bronze Age (Sections 5.1.2 and 5.2.6-7).

A large boulder (7170) was present near the south end of the cairn and, close by, two distinct deposits $(7178,7179)$ of AOC Beaker pottery sherds representing two vessels and a cache of 167 lithic artefacts (7183) were recovered. Although not initially apparent, further removal of stones led to the identification of an egg-shaped cut feature (7181) with a length of $1.7 \mathrm{~m}$, a width of $1.1 \mathrm{~m}$ and a depth of $0.3 \mathrm{~m}$ (illus 7) which was aligned $\mathrm{NE}$ to SW and had been cut into bedrock. The feature was filled with granite blocks around which were a matrix of gritty peat and stone chips (7182). Underlying these, the bedrock base was covered with a thin deposit of manganese-stained clay (7185). Protruding natural squarish stone faces were present on both long sides which mimicked the side slabs on a cist. No finds were recovered from the base of the pit, and it may be that the contents were redeposited into the body of the cairn next to the pit in antiquity. In the light of modern root action, no radiocarbon dating was undertaken but the typological attributes of the flint assemblage place it in the Late Neolithic, while the Beaker pottery it was associated with conventionally dates to the end of the Late Neolithic, $c$ 2500/2400 BC to 2200/2100 BC. The position of the pit, within an apparently ancient cairn, and the character of the artefacts it contained, are sufficient to allow the inference that a much-abused grave was present.

\subsubsection{Test-pitting}

Four grids of test-pits (Grids E-H, illus 2) were laid out and excavated in spaces between the patches of gorse and broom. Grids E-F were $30 \times 30 \mathrm{~m}$ and, with a $5 \mathrm{~m}$ spacing between the $0.5 \mathrm{~m}^{2}$ test-pits, 49 were excavated in each grid. Grids $\mathrm{G}$ and $\mathrm{H}$ were smaller, $10 \times 10 \mathrm{~m}$ and, with the same spacing, nine test-pits were in each.

Grids $\mathrm{E}$ and $\mathrm{F}$ produced 50 and 87 lithic artefacts respectively, but the low density of the artefacts and the lack of any features in the area suggests merely natural loss and discard. Grids $\mathrm{G}$ and $\mathrm{H}$ produced no significant numbers of finds, which may indicate a drop-off of activity away from Cairn 7/17.

\subsection{Area 2: investigation of previously recorded sites}

An initial lack of communication between the office of the developer and the landfill site contractors led to the loss of Sites 13 and 14 before they could be investigated. Aerial photographs indicated that gravel quarry Site 38 (illus 1) post-dated 1959 and no work was undertaken within it.

Sites 4 and 12 cairns were investigated. Excavations showed the cairns to be largely structureless concentrations of cobbles, and machine-dug trenches in the two areas revealed no archaeological features. None of the investigated cairns could be dated, but all may be interpreted as the product of stone clearance, quite possibly dumped a few at a time, as opposed to bulk tipping by trailer, and may derive from the nearby cultivated fields. A date in the 18th/19th-century may be suggested.

Lithic artefacts representing lost or discarded domestic material from the Late Neolithic to the Late Bronze Age (Section 5.2.11) were recovered from the soil profile in trenches at Site 4, and 118 lithic items dating mainly to the Late Neolithic (Section 5.2.12) were evenly distributed within Test-pit Grid B and the three hand-dug trenches at Site 12.

Sites $13-15$ on Dun na Cluaich, and Site 17 at its foot, are presumed to be post-medieval and are discussed in the archive report (Suddaby 2009). Site 13 was a rectangular building, Site 14 was a possible kiln, Site 15 was a wall and Site 17 was a gravel quarry. Numerous lithic artefacts were recovered from the soil layers underlying and abutting Site 15.

A battle between the Danes, led by Sueno and 


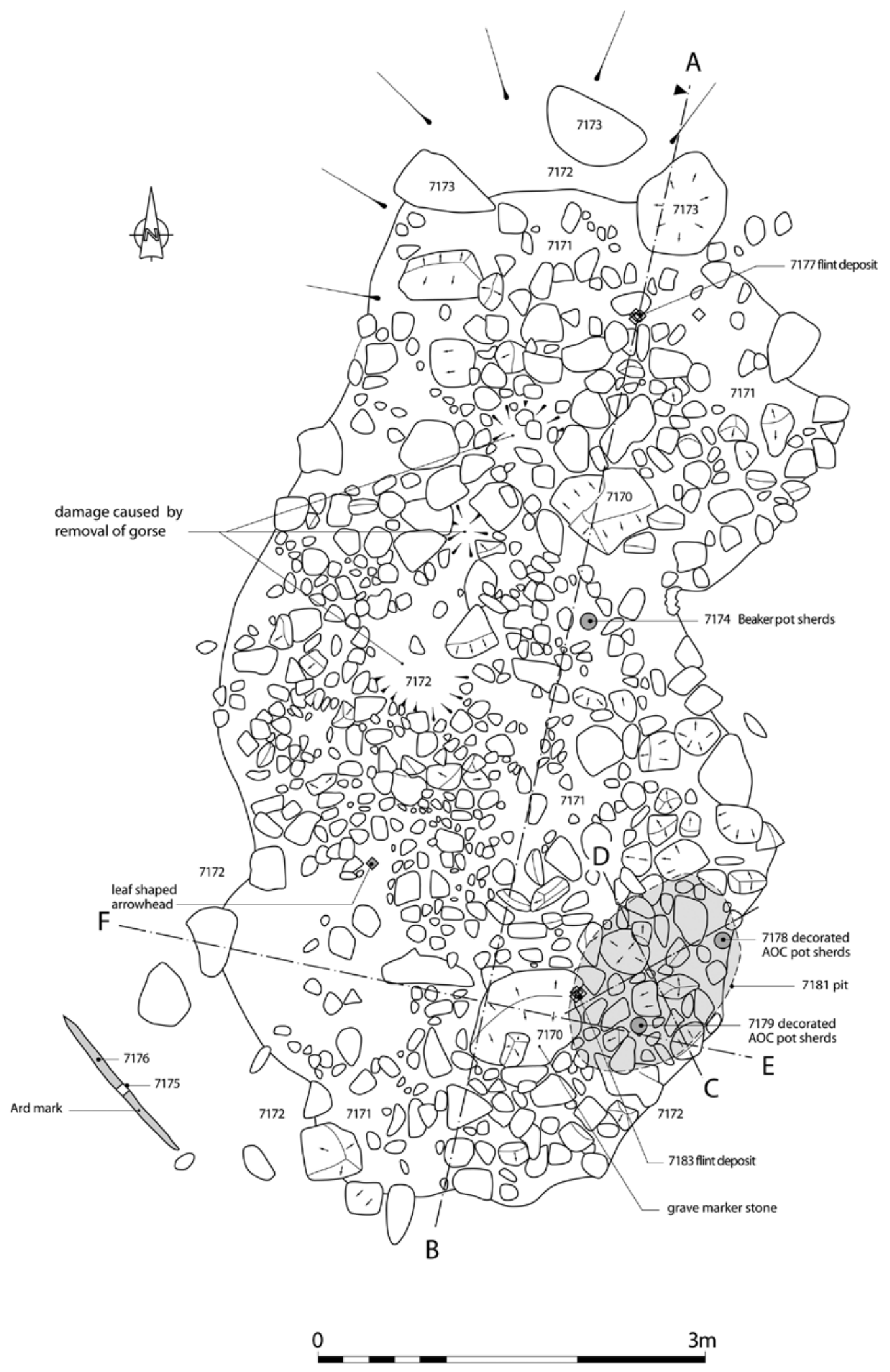

Illus 6 Plan of Cairn 7/17, with Pit 7181 shaded

Canute, and the Scots, under Malcolm II, is alleged to have taken place in the field to the north-east of North Aldie Farm in AD 1012 or 1014. Part of the wider Battle of Cruden, the background to this is fully described by Alexander (1999, 37), who records references to plundering by Earl Sigurd and others in Scotland at this time (Abercromby 1711; Anderson 1922, 529-30) but also their lack of geographical precision. John B Pratt, minister of Cruden Episcopal Church from 1825, recounts the history of Buchan and provides the main account of the battle (Pratt 1856, 32-42) which extended for 


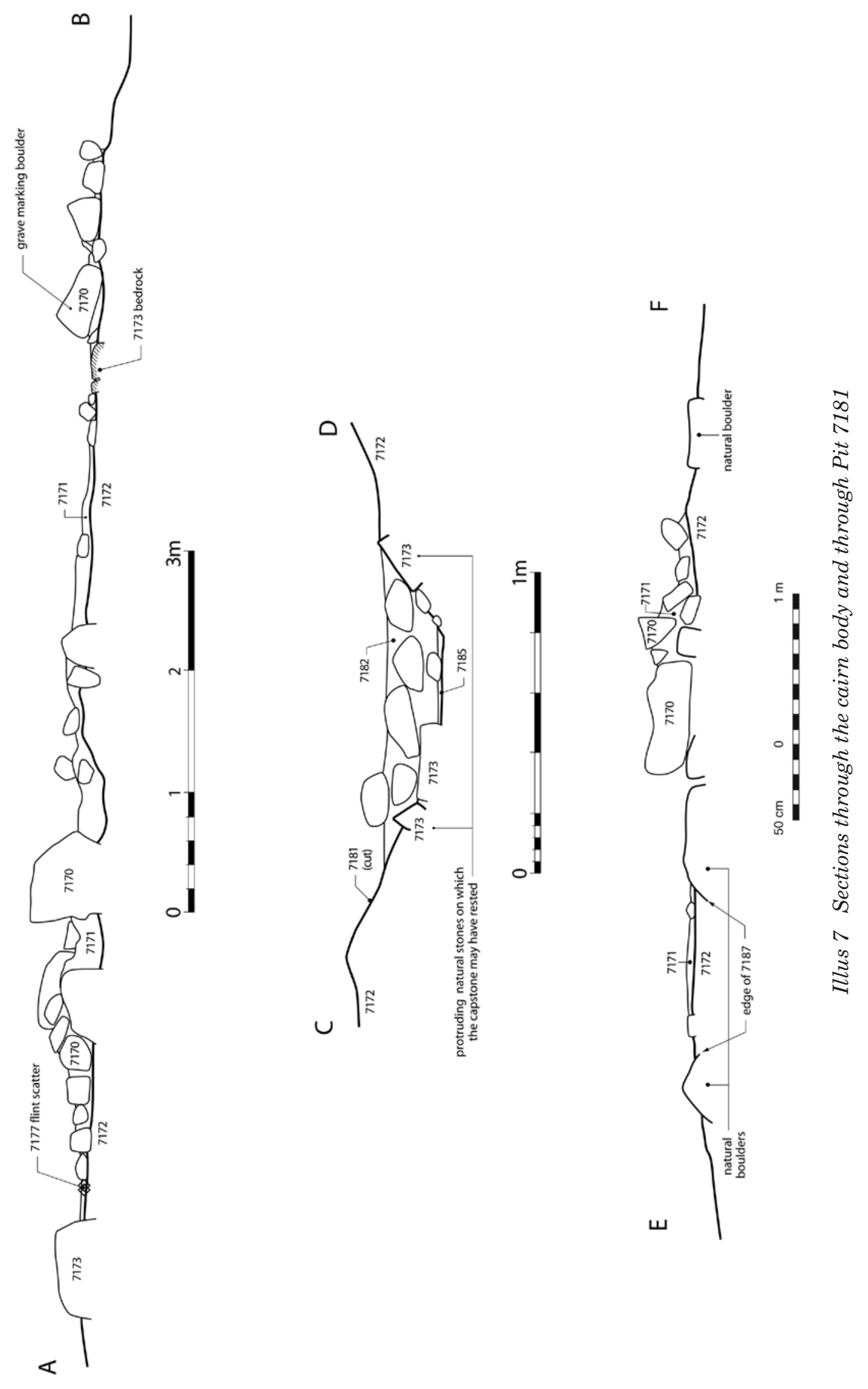




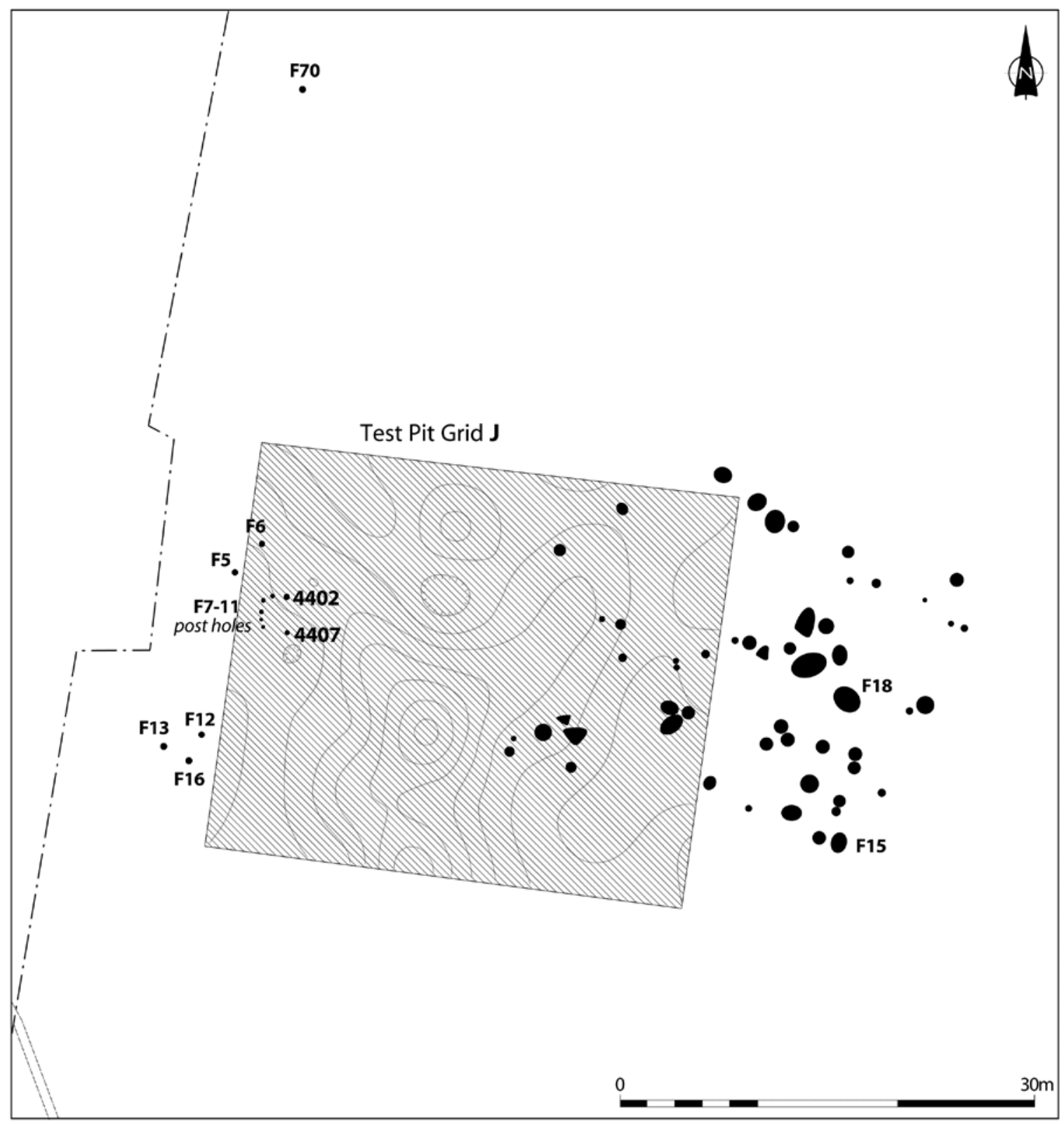

Illus 8 Plan of the post-arc and other prehistoric features, including Pit F70, in the area. The distribution of lithic artefacts recovered from Test-pit Grid $J$ is superimposed.

4 miles inland from the sea and left a trail of relics half a mile wide. Nevertheless substantive evidence is lacking. The spoil heaps of the evaluation trial trenches in the field around Site 40 were metaldetected; only modern agricultural metalwork was recovered.

An extensive area of peat lay on flat ground to the east of the Laeca Burn (Site 43). The deepest peat $(1.1 \mathrm{~m})$ in the north of the area was investigated by four machine-dug test-pits (TP1-4, illus 1) which revealed that the upper levels were penetrated by modern roots and field drains. Branchwood was preserved in the lower levels and the peat merged into the underlying waterlogged stained gravels. An evaluation trench across a now-disused trackway shown on the OS Second
Edition map (1901, illus 3) showed that $0.15 \mathrm{~m}$ of peat had accumulated over the trackway, indicating ongoing peat formation.

\subsection{Area 2: investigation of newly discovered prehistoric sites}

\subsubsection{Dun na Cluaich lithic scatter}

Prior to recent quarrying, the topsoil had been removed by machine from an area of $c 40 \times 40 \mathrm{~m}$ and bunded around the edge of the summit plateau. Although this process had destroyed Site 14 (above), repeated searching of these bunds, most profitably after rain, led to the recovery of one of the most 


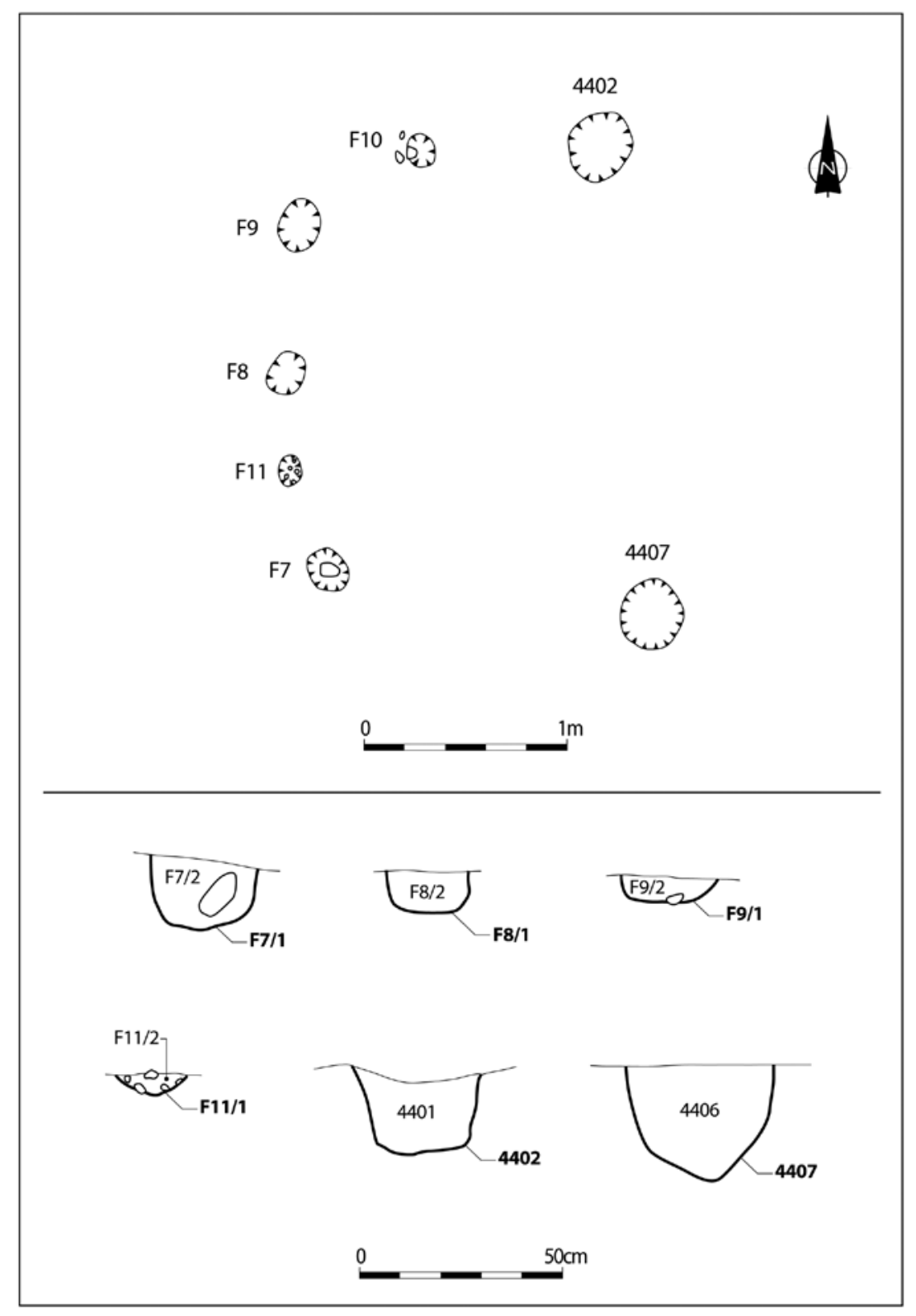

Illus 9 Post-arc F7-F11, 4402, 4407, plan and sections

important lithic assemblages from Stoneyhill. This assemblage is interpreted as redeposited material dating to the Mesolithic and Early Neolithic (Section 5.2.13). The nearby Test-pit Grids A and C produced just 22 and 12 lithic objects respectively, confirming lithic material was concentrated on the summit.

\subsubsection{North Aldie Farm, pits, post-holes and lithic scatter}

An evaluation trench across a slight, but prominent, elongated knoll in the centre of the field to the north-east of North Aldie (illus 1) revealed three plough-truncated features. One (4405) was $0.1 \mathrm{~m}$ deep and contained no artefacts. Excavation of this feature had apparently been discontinued after encountering impenetrable natural subsoil. The other two $(4402,4407)$ were more substantial and included pottery and lithic artefacts in their fills. The identification of substantial quantities of similar material on the spoil heaps led to a programme of test-pitting (Grid J, illus 8).

Sixty test-pits (Grid J) were excavated and 850 lithic artefacts were recovered. The test-pitting indicated that the lithic artefacts were distributed across a restricted area and there was an apparent lack of dispersal of the material. The centre of the lithic distribution (illus 8) did not coincide with the post-arc or other negative features in the area, but fell on the lip of the elongated knoll and on the slope to the east.

Following test-pitting, the topsoil was removed from an area measuring $65 \times 25 \mathrm{~m}$ by machine. Twelve plough-truncated features (including 4402, 4407) were revealed. These consisted of a U-shaped setting of seven features (F7-F11, 4402, 4407, illus 9-11), two pits or post-holes to the north-west (F5- 


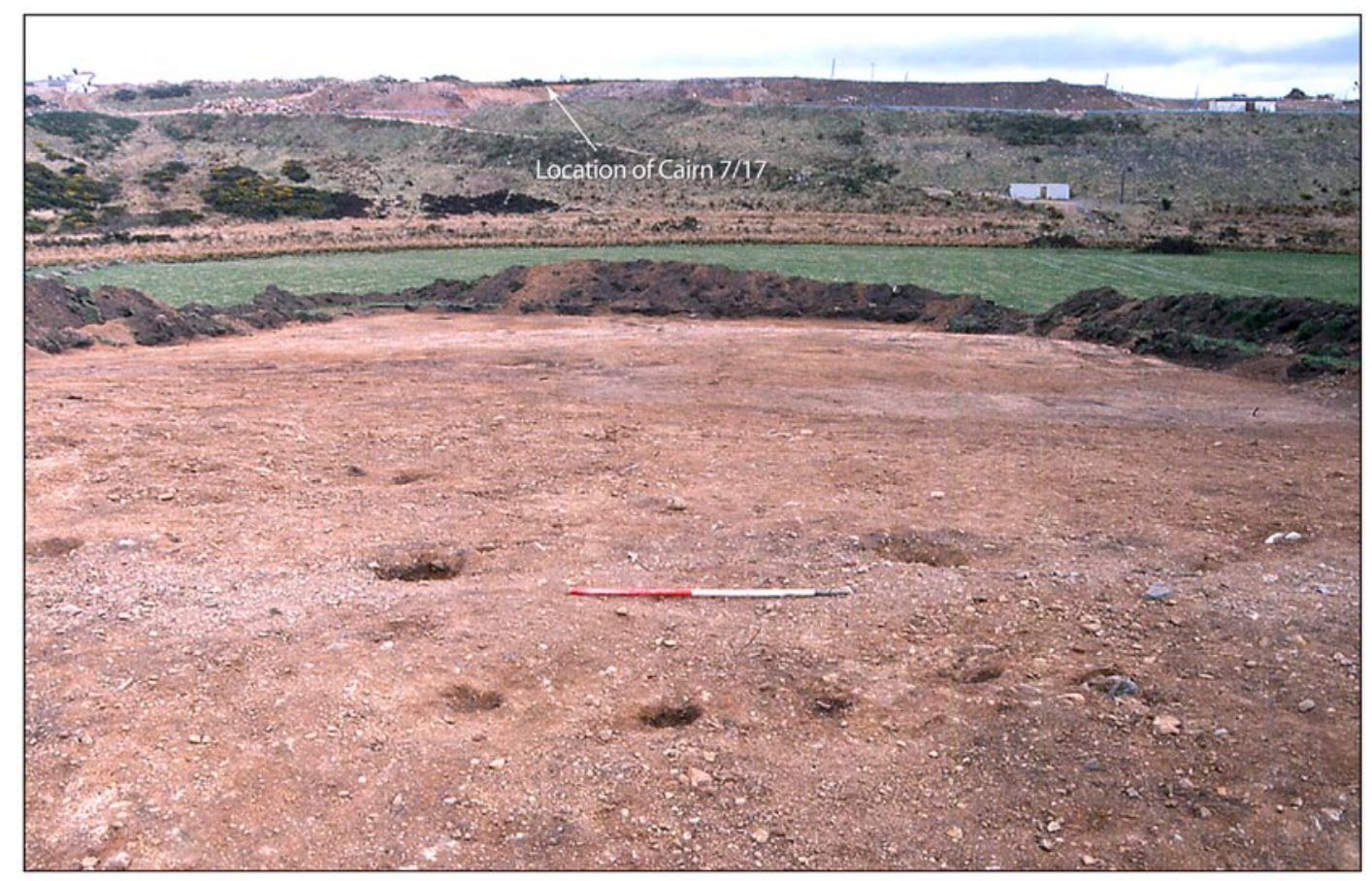

Illus 10 The view from the post-arc, looking east towards Cairn 7/17 on the horizon

6 , illus 9,11 ) and a group of three deeper assumed post-holes (F12, F13, F16, illus 8, 11), to the southwest. Below the knoll to the east, 54 features (illus 8) appeared to be stone extraction pits (Suddaby 2009).

Whilst none of the seven features forming the Ushaped setting contained either a post-pipe or in situ packing stones, all are assumed to be post-holes due to their vertical sides and generally fairly flat bases (illus 9). Some plough-truncation of the features is likely to have occurred, and originally they may have held substantial posts of around $0.2 \mathrm{~m}$ diameter.

With its open end facing east across the valley directly towards Cairn 7/17 (illus 11), the postsetting was $2 \mathrm{~m}$ in length and width. The post-holes at the terminals of the arc $(4402,4407)$ were the most substantial, being $0.3 \mathrm{~m}$ in width and depth. Both contained compacted gravelly fills that included prehistoric pottery and charcoal. Thirty-six sherds equating to parts of ten vessels were recovered from the fill (4401) of 4402. The fill (4406) of feature 4407 only contained five sherds, all from the same vessel, but included two hammerstones. Fifty lithic items were also found in these features. The remainder were around $0.2 \mathrm{~m}$ in width and $0.1-0.2 \mathrm{~m}$ in depth, with single fills of compact sand, grit and angular gravel with charcoal. No further pottery was recovered from these features, but lithic artefacts were recovered. Whilst some of the pottery in 4402 and 4407 is abraded, the charcoal was not, and the contemporaneous nature of these fill elements must be questioned.

Located around $4 \mathrm{~m}$ to the north-west, features F5 and F6 contained no depositional evidence with which to interpret their function. F5 was oval,
$0.3 \times 0.2 \mathrm{~m}$, with the sides sloping to a convex base at a depth of $0.1 \mathrm{~m}$. F6 was sub-circular, with a width of $0.45 \mathrm{~m}$ and vertical sides over a flat base, $0.2 \mathrm{~m}$ deep. The fills were similar in nature to those in the post-arc. Three lithic artefacts were recovered from F5 and four from F6.

Around $10 \mathrm{~m}$ to the south-west of the post-setting, features F12, F13 and F16 (illus 8, 11) were more substantial. All were near-circular in plan and were cut through compact angular gravels. F12 and F13 were $0.3 \mathrm{~m}$ wide and $0.3-0.4 \mathrm{~m}$ deep with near-vertical sides. Both contained silty upper fills overlying more gravelly lower fills, both with charcoal. F16 was wider, at $0.4 \mathrm{~m}$, but was of a similar depth, with a flat base. It contained a similar sequence of fills to those in F12 and F13, but included coarse stone tools in the lower fill, perhaps re-used as packing stones. Lithic artefacts were recovered from all three features.

\subsubsection{North Aldie Farm: isolated features, Grid K and pit F81}

A watching brief during the removal of topsoil in the remainder of the field resulted in the discovery and excavation of five additional, isolated features of archaeological interest (F70, F81-F83, F88). F70 and F81 contained prehistoric pottery, whereas the remainder produced lithic artefacts, charcoal (with hazelnut shell in F81 and F88) and, in the case of F88, fire-cracked stones.

F70 (illus 8, 11) was located $35 \mathrm{~m}$ to the north of the post-arc in Grid J. It was sub-circular, $0.4 \mathrm{~m}$ wide by $0.15 \mathrm{~m}$ deep, with a concave profile. In addition to 


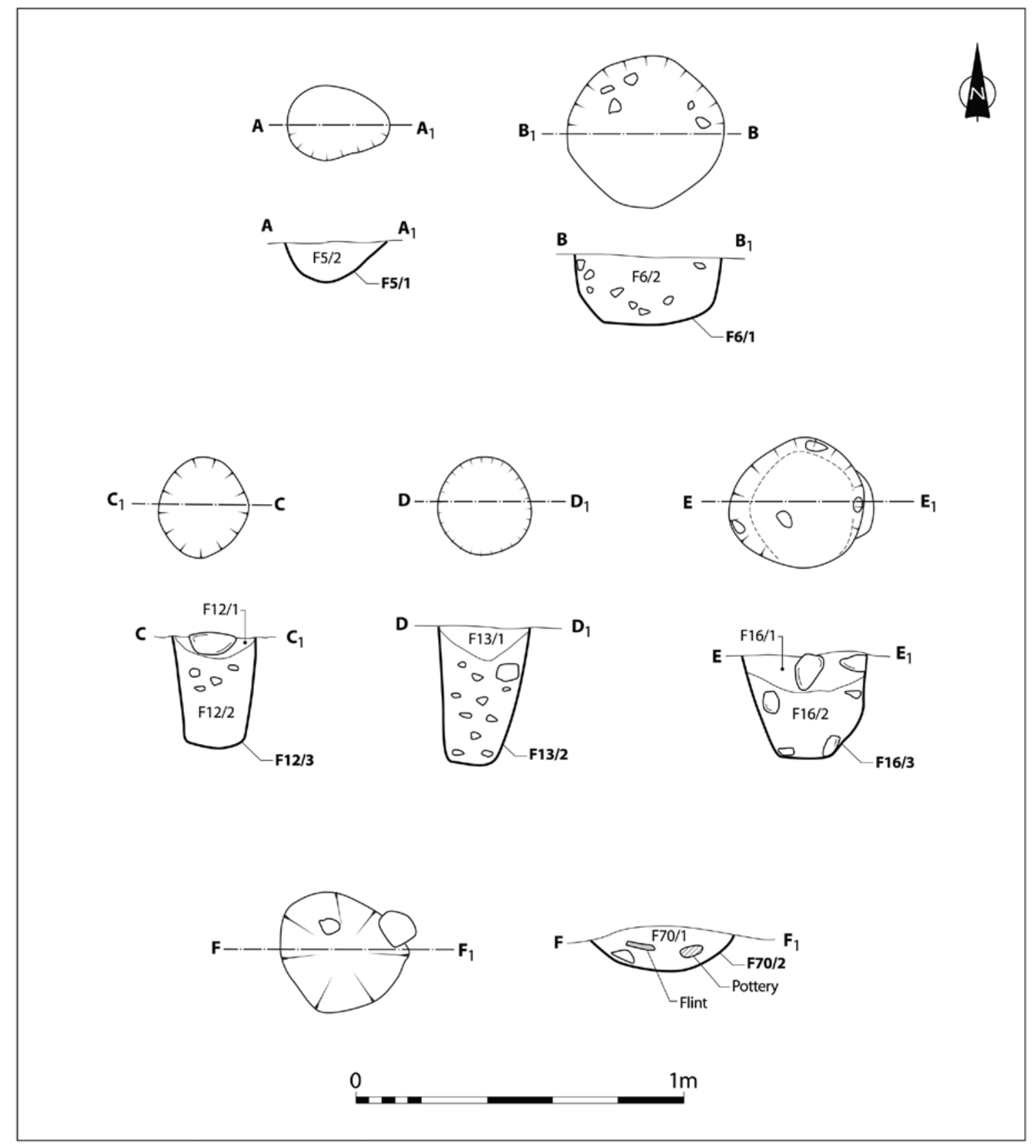

Illus 11 Sections through possible post-holes F5-F6, F12-F13 and F16 adjacent to the post-arc and through pit F70 to the north

five sherds of pottery, representing a single vessel, seventeen lithic artefacts were recovered from the sandy fill.

Some $150 \mathrm{~m}$ to the south of this feature group, a grid of nine test-pits (Grid K) was speculatively located on a prominent knoll to the east of North Aldie Farm. Eighty-three lithic artefacts were recovered from this grid and adjacent evaluation trenches, an assemblage spanning the Early Neolithic to the Early Bronze Age (Section 5.2.15).

Pit F81 (illus 12) was oval, aligned NW to SE, and was $0.8 \mathrm{~m}$ in length, $0.6 \mathrm{~m}$ in width and $0.4 \mathrm{~m}$ in depth. A deposit of black gritty silt and degraded charcoal (81/6) was recorded in the base. Above this possible hearth debris were a number of stones (81/5) which appeared to have been placed into the centre of the pit and thereby separated the intermediate fill (81/3) to the north-west from fill $81 / 3$ to the south-east. Deposits 81/3-4 consisted of dark brown gravelly silty sand and all three fills were overlain by the upper fill 81/2, a brown silty sand. A small pit (81/9) was later cut into the upper fill (81/2) and this was filled with a black silty sand which may also be hearth debris. The pit produced naked barley grains, lithic items, a hammerstone and sherds of Impressed Ware pottery. 


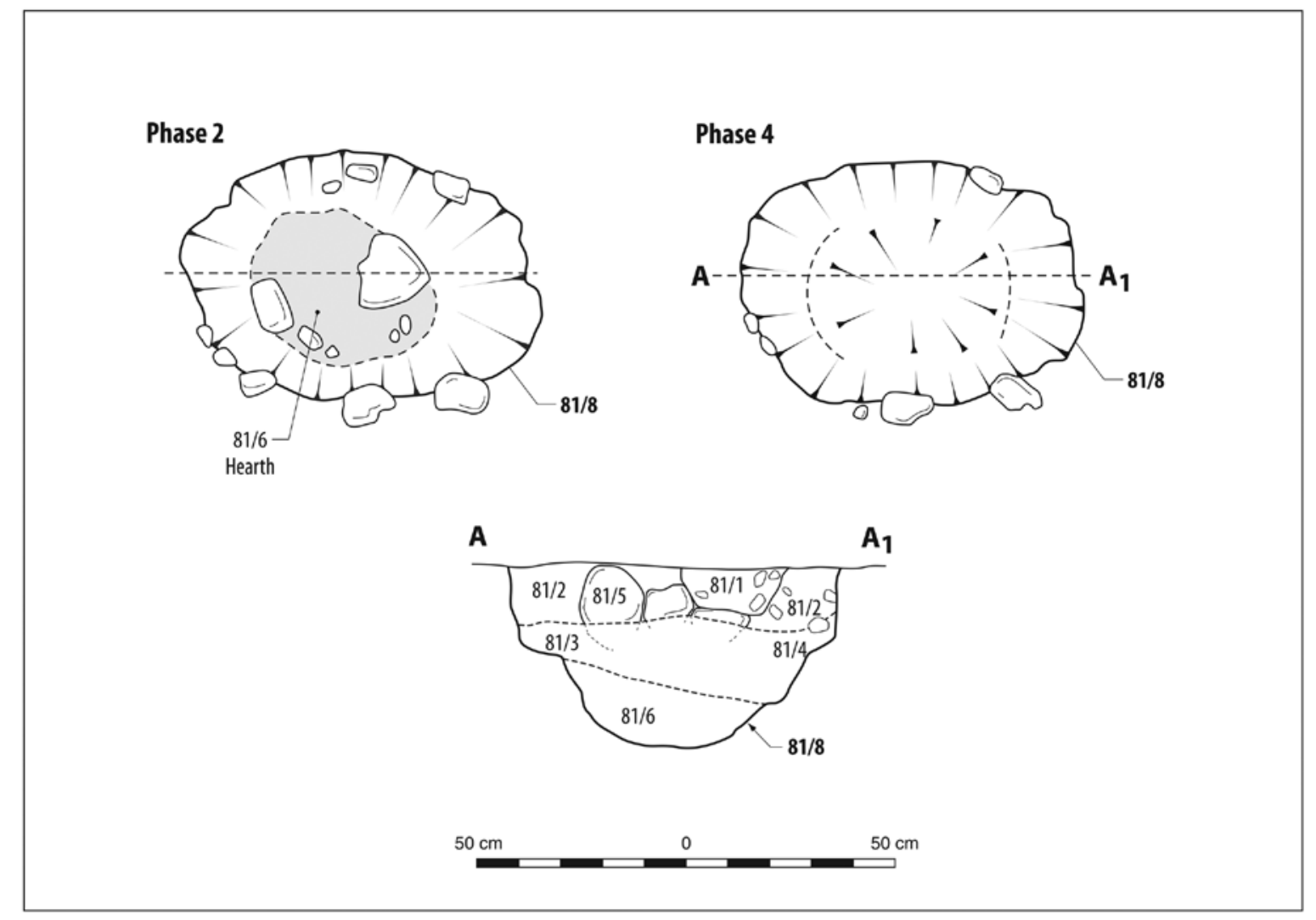

Illus 12 Section and plans of Pit F81

Samples of barley were submitted for dating (Table 7) and produced a calibrated date range of 3370-3090 вс.
A boulder saddle quern, fashioned from a block of sandstone, was recovered from topsoil on the southern flank of the knoll (Section 5.3). 


\section{PREHISTORIC FINDS AND ENVIRONMENTAL EVIDENCE}

\subsection{Prehistoric pottery, by Melanie Johnson}

\subsubsection{Introduction}

Three hundred and sixty-four sherds of prehistoric pottery, weighing $3.623 \mathrm{~kg}$, were recovered. A maximum of 29 individual vessels are represented, some of which are represented by only one sherd; few of the pots have substantial portions of their profiles surviving. A full catalogue has been prepared for the site archive.

Pottery was recovered from Cairn 7/17 and from several pits at the North Aldie Farm excavations; the assemblage is quantified in Table 2.

\subsubsection{Cairn 7/17}

The remains of three beaker vessels (P3-P5) were recovered from the cairn. Two are All-Over Cord (AOC) decorated and the third has a geometric combimpressed motif. Each vessel was found in a discrete area which, despite the later truncation and disturbance of the cairn, is likely to reflect reasonably accurately the location of the original deposition of the pots, despite none of them being whole. The AOC vessels were found lying on top of the stones (7180) that filled Pit 7181. The pit appears to pre-date the construction of the cairn so it may be coincidence that the AOC Beakers have ended up on top of this pit rather than having been redeposited from within it. The associated lithic assemblages date to the Early Neolithic, Late Neolithic and Bronze Age, with some distinction between contexts (Sections 5.2.6-7).
There have been a number of major categorisations of beaker vessels - Clarke's styles (1970), Lanting and van der Waals steps (1972), Case's styles and stages (1977; 1993) - with a variety of regional, chronological and stylistic associations. Since the British Museum radiocarbon dating programme (Kinnes et al 1991), further dating programmes of Scottish Beakers have been undertaken (Shepherd 2005; Sheridan 2007; Sheridan et al 2006 and 2007), and Needham (2005) has published a comprehensive review of Beakers, suggesting a new scheme for understanding their development. Needham's scheme is used here to categorise the vessels found.

Sherds of P3 were found in contexts 7171 and 7174 . The vessel comprises two rim sherds, four base sherds and twenty-nine body sherds. Too little survives of the profile to get a complete picture, but the vessel has a pedestal base with a convex profile to the base plate interior and a slightly flaring rounded rim. It is very finely made, dark brown to dark grey in colour, with a base diameter of $100 \mathrm{~mm}$ and a wall thickness of $6 \mathrm{~mm}$. It is decorated with an all-over motif produced by a square-toothed comb, forming panels of decoration alternating with blank areas. The panels are delineated by horizontal lines (usually one or two parallel) and contain vertical lines at the rim and body, with chevrons at the base. Lines of zig-zag hang just beneath and above the panels and in some places are superimposed over the top of the vertical lines. A variety of comb lengths appear to have been used. The condition is poor, the vessel is very fragmented and crumbly, and has suffered some surface loss.

P4 (illus 13) was found in context 7178 and comprises eleven rim sherds, four base sherds and

Table 2 Quantification of pottery assemblage

\begin{tabular}{|c|c|c|c|c|}
\hline Area & Context & Vessels & No. sherds & Weight (g) \\
\hline \multirow[t]{3}{*}{ Cairn 7/17 } & $7171 \& 7174$ & P3 & 35 & 176 \\
\hline & 7178 & $\mathrm{P} 4$ & 45 & 221 \\
\hline & 7179 & P5 & 43 & 314 \\
\hline \multirow[t]{9}{*}{ North Aldie } & 4401 & P20-P27, P29 & 36 & 406 \\
\hline & 4406 & P28 & 5 & 92 \\
\hline & F70/1 & $\mathrm{P} 1$ & 5 & 58 \\
\hline & $\mathrm{F} 81 / 2$ & P6, P18 & 12 & 208 \\
\hline & $\mathrm{F} 81 / 3$ & P8-P16 & 57 & 1195 \\
\hline & F81/4 & P7 & 1 & 65 \\
\hline & F81/6 & P17 & 25 & 421 \\
\hline & F81/3 \& F81/6 & P19 & 99 & 439 \\
\hline & $\mathrm{U} / \mathrm{S}$ & P2 & 1 & 28 \\
\hline Totals & & & 364 & 3623 \\
\hline
\end{tabular}



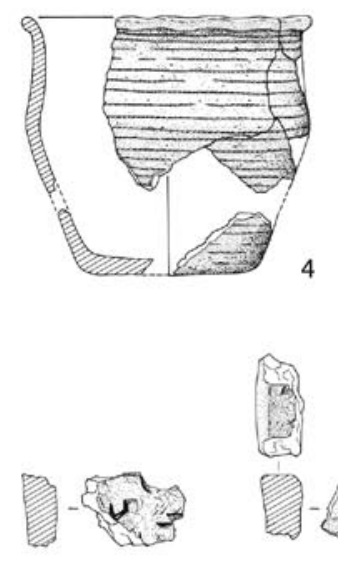

11

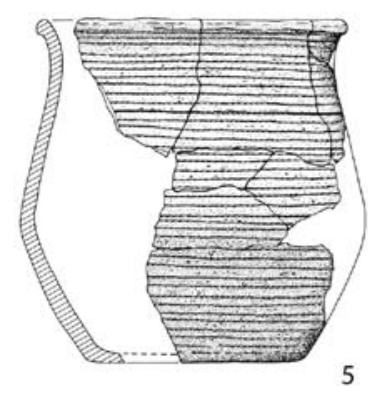

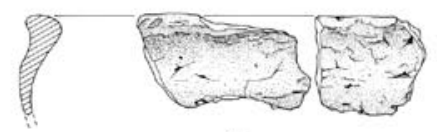

9

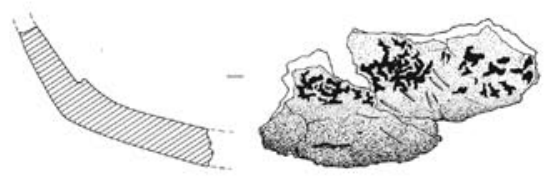

10
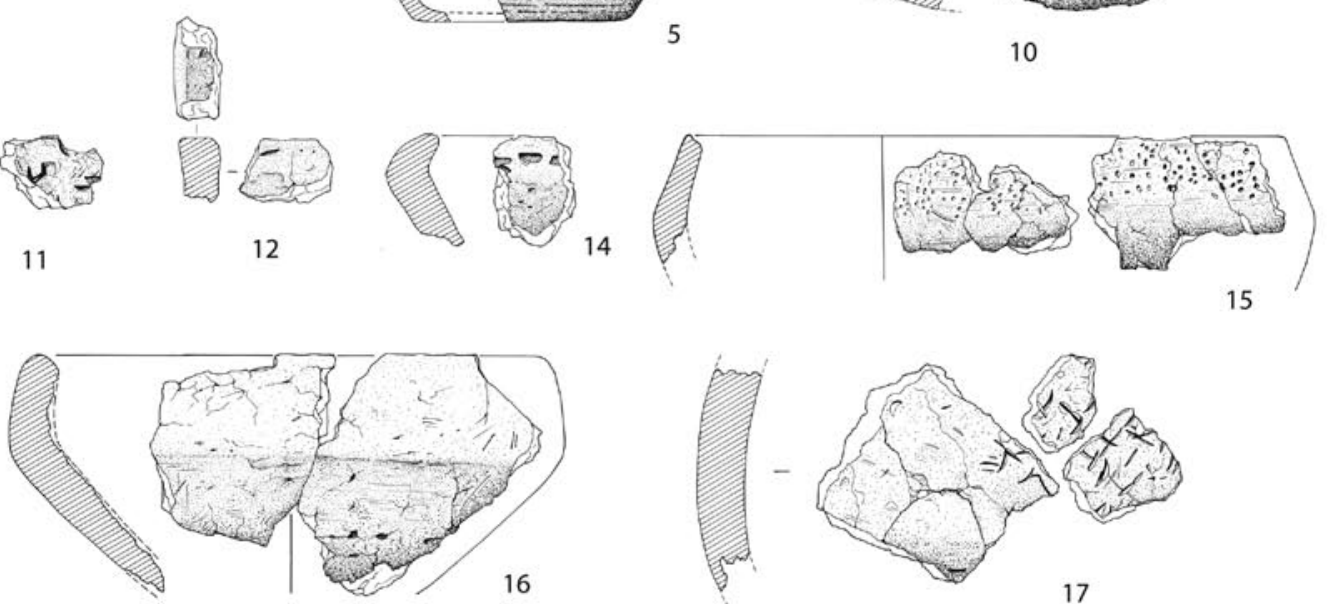

17

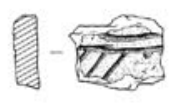

21

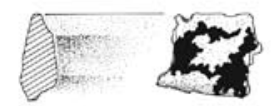

28

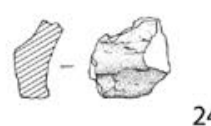

24

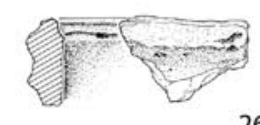

26

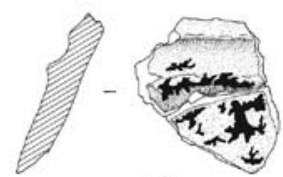

29

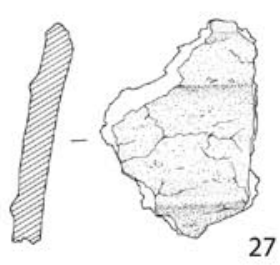

27

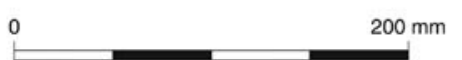

Illus 13 Pottery illustrations

thirty body sherds. Some of the sherds are very badly abraded. It has a base diameter of $80 \mathrm{~mm}$ and a rim diameter of $110 \mathrm{~mm}$. It has a fine, very hard, slightly corky fabric, dark brown to dark grey in colour, with walls $5 \mathrm{~mm}$ thick. It is decorated with AOC. P5 (illus 13), from context 7179 , comprises five rim sherds, two base sherds and thirty-six body sherds. It is very similar to $\mathrm{P} 4$ in terms of fabric and has a base diameter of $80 \mathrm{~mm}$ and a rim diameter of $120 \mathrm{~mm}$. It is also decorated with $\mathrm{AOC}$, and has slight charred residue adhering to both surfaces.

Extensive re-dating of Beakers is currently underway with two major, inter-related research projects, the 'Beaker People Project' and the 'Beakers and Bodies Project' (Sheridan 2007, Sheridan et al 2006 and 2007, Curtis et al 2007), the latter specifically dealing with the north-east of Scotland. Unfortunately, there are no dates associated with the cairn at Stoneyhill.
However, Sheridan's (2007) review of Scottish Beaker dates suggests that All Over Cord-decorated Low Carinated Beakers, to which vessels P4 and P5 here belong, date to the period 2500/2400 BC to 2200/2100 BC, comprising the earliest Beaker types found in Scotland, and Sheridan has observed that Beaker use could have started in Scotland as early as the 25th century BC (Sheridan 2007, 96). The comb-impressed Beaker would traditionally have been seen as later in date than the AOC; however, the Beaker dating programmes (Sheridan 2007) indicate that there are a number of comb-impressed Beakers in the north-east with reliable dates in the general range of 2480-2200 BC (ibid), forming some of the earliest dated Scottish Beakers: for example Keabog cist 2, Broomend of Crichie cist 2, and Borrowstone cist 1, 2 and 6 (ibid).

AOC Beakers are found in a variety of funerary and non-funerary contexts, and many Beakers in 
this region accompany individual burials, but there are parallels for AOC Beakers being found with comb-impressed Beakers in a similar context, for example at Forglen in Banffshire (Callander 1906). At this site, three Beakers were found beneath and within an earthen burial mound, two of which were decorated with comb and incision and one with AOC. There appears to have been a sequence of burials, with the AOC Beaker being earliest. There are no radiocarbon dates associated with this material.

It therefore seems possible that the combimpressed and AOC beakers from this cairn derive from a similar or the same period of activity, rather than inferring a later insertion into the cairn for P3, which is probably within the date range $2500-2200$ $\mathrm{BC}$, the earlier part of the Beaker period in the Late Neolithic.

\subsubsection{North Aldie Farm}

The fills of two pits in the U-shaped setting (4401, 4406) contained pottery (P20-P29); the majority in 4401 with only five sherds recovered from 4406 (P28). No radiocarbon dates are available and the pottery is not readily datable. The ten vessels form a relatively homogeneous group, with the exception of $\mathrm{P} 21$, and include base and rim sherds, the majority of which are decorated (illus 13, nos 21, 24, 26-9). Both rims recovered (P26 and P28) are upright rounded rims.

P21 was decorated with an incised motif of two parallel horizontal lines, with three diagonal parallel lines springing from one of the horizontal lines. The fabric of this sherd was not sandy, unlike the others, and it seems to be out of place within this sub-assemblage. It is difficult to assign a date or ware to a solitary sherd, but incised decoration like this is most likely to be Late Neolithic or Early Bronze Age in date.

The remaining decorated vessels (P24-P29) are decorated with cordons/ridges. Rim P26 has at least one and probably two ridges/cordons below the rim on the exterior, with a deep incised line placed on the interior of the rim and incised lines along the rim top; the rim top was heavily abraded. P28 has two ridges/cordons on the exterior and there is slight fluting on the rim's interior. P27 has three ridges visible on the body, two of which are more closely spaced. P24 has a cordon at the shoulder and P25 has a single cordon on the body. P29 also has an incised line and the possible remnant of a cordon. The rims were upright and rounded, giving little opportunity to discern the overall form of the vessel. It is difficult to place this pottery. The vessels' bodies appear to be plain apart from the presence of cordons/ridges, which is unusual for any wares of the Late Neolithic or Early Bronze Age, the presumed date for this pottery. A possible similar vessel was found at Balfarg and identified as Beaker (vessel 153; Barclay \& Russell-White 1993). The vessels also have echoes of Grooved Ware.
Five undiagnostic sherds from a single vessel (P1) were recovered from the fill of F70. It is difficult to suggest a date for this pottery but it is more likely to be earlier prehistoric than later, and has similarities with the beaker fabrics found in Cairn 7/17.

Fourteen vessels (P6-P19) were recovered from the fill of Pit F81 (illus 13, nos 9-12, 14-17), and appear to be Neolithic Impressed Wares and protoUnstan bowls. Sherds were recovered from contexts F81/2, F81/3, F81/4 and F81/6, with the majority of the pottery being from $\mathrm{F} 81 / 3$. Radiocarbon dates from F81/3 (Poz-14557-8) calibrate to the middle Neolithic 3370-3090 BC.

\section{Impressed wares}

P7 is a single large body sherd (F81/4) which is decorated with two or three possible fingernail impressions and a larger deeper curved impression. P11 is also a single body sherd decorated with a couple of fingernail impressions and one large deep stab made with a square-ended implement. A further vessel is decorated with fingernail impressions; P17 has a random arrangement of fingernail impressions on the body exterior, some are deeper, some fainter, with no overall motif visible. A pedestalfooted base (P18) may be the same vessel as P17. Several undecorated, undiagnostic sherds were also found (P2, P6, P13, P19).

P9 is a flat-topped rim, slightly necked with a round body, with possible impressed short lines on the outer edge of the rim top. P12 is a square flat-topped rim, probably upright, decorated with a single small slash on the exterior near the rim and a possible stab on the top of the rim. P14 is an internally expanded rim, curving to form a closed-mouth bowl. It is decorated with stabs along the top of the rim.

Mid to late Neolithic Impressed Wares are typified by a number of known assemblages including Balfarg, Fife (Barclay \& Russell-White 1993) and Meldon Bridge, Peeblesshire (Speak \& Burgess 1999). The presence of impressed and incised decoration, including twisted cord, stab, fingernail and lattice, are characteristic of this pottery. Pit scatters are a common context for the recovery of late Neolithic Impressed Wares, and these are known across many parts of Scotland, from Aberdeenshire to Dumfries \& Galloway, including Balfarg, Fife (Barclay \& Russell-White 1993), Grandtully, Perthshire (Simpson \& Coles 1990) and Dubton, Brechin (Cameron 2002).

This ware is now thought to date to the second half of the 4th millennium and the first half of the 3rd millennium BC; in recent years the range has been extended following new radiocarbon dates (Barclay et al 2001; Johnston 1997; Speak \& Burgess 1999; Strachan et al 1998; White et al 2009). The origins and development of Impressed Ware have been discussed previously (Cowie 1993; Johnston 1997; Speak \& Burgess 1999; Cameron 2002). There appear to be some differences between excavated 
assemblages, in terms of dominant vessel forms and decorative techniques, but the style is varied and regional groupings are not readily apparent. However, a north-east Scottish regional style has been proposed (Barclay et al 2001), which includes Unstan-type vessels, and the inclusion of those types in this assemblage would suggest that the pottery dates to the period 3500-3000 BC, which correlates well with the radiocarbon dating.

\section{Proto-Unstan Wares}

A decorated vessel (P15) is represented by two rim sherds and seven body sherds. The collar of the vessel has been decorated with small stabs in a random pattern, with some of the stabs shallow and faint, some like pinpricks and some larger stabs.

P16 comprises at least two rim sherds and thirty sherds from the collar of an undecorated bowl. The vessel is in a poor condition; it appears to have been poorly fired and is very crumbly, with a lot of surface loss. The vessel appears to be slightly sprung.

Two further vessels may also be proto-Unstan. Vessel P8 comprises a large rim sherd from a coarse, heavy vessel with an upright collar and an angled rim top. There is some abrasion and surface loss as the fabric is crumbly and soft, with lots of cracking. The sherd is not decorated. A coarse, thick-walled vessel (P10) survives as an undecorated carination.

Unstan bowls in their classic form are generally characteristic of the earlier Neolithic on Orkney and are also known from the Western Isles. Radiocarbon dates (Kinnes 1985), suggest a date range of at least the mid fourth millennium to the earlier third millennium BC for the classic Unstan bowl; the radiocarbon dates from this pit (F81) suggest a later third millennium $\mathrm{BC}$ date, so the vessels may be a local development or an adaptation from true Unstan ware; there is an increasing recognition of Unstan or what is termed proto-Unstan bowls - biconical or collared bowls - recovered from pits in eastern and north-eastern Scotland. For example, pits at Grandtully, Perthshire (Simpson \& Coles 1990) produced Late Neolithic pottery, of which one is Unstan-like in form; it is a bowl with a pronounced collar and internally bevelled rim, decorated with vertical and horizontal bands of stab and drag. The remainder of the assemblage is Impressed Ware.

The vessel from the pit at Spurryhillock, Aberdeenshire (Alexander 1997), has incised decoration on the collar and may be considered to be a classic example of Unstan Ware. There were no dates obtained from the pit in which it was found, and very little other material. A pit at Brackmont Mill, Fife (Longworth 1967) produced decorated biconical and collared bowls with similarities to Unstan and to the Stoneyhill vessels, which were interpreted as being a local variant on Late Neolithic wares. It was also noted in the assemblage that there were far more rim sherds than there should be in a normal domestic rubbish deposit and that a large number of vessels were represented by a few sherds each, and deliberate selection and deposition of the sherds is posited.

Easterton of Roseisle and Easterton, Aberdeenshire, and Urquhart, Moray (Henshall 1983) also produced a small number of decorated and undecorated shallow collared bowls with similarities to Unstan Ware. There are also decorated biconical vessels from Balbridie (Ralston 1982) in an assemblage of Early Neolithic carinated bowls; Cowie (1993) suggested that these have a close relationship with Unstan bowls

\subsubsection{Conclusions}

The various sub-assemblages of pottery from Stoneyhill are an important and valuable contribution to the corpus of Neolithic and Early Bronze Age pottery from the north-east of Scotland. The association of both AOC and comb-impressed Beaker pottery with the remains of the cairn and an important assemblage of lithic artefacts adds to our understanding of such funerary/ritual monuments of this period. The finds from the isolated pits and pit setting, taken as a group, suggest that the picture of Neolithic ceramics in the north-east is still far from being clearly understood: there may be local variants of both Impressed Ware and Unstan Ware, and pit deposition is a common theme; the depositional context at Stoneyhill in an isolated pit, and the combination of Impressed Ware and proto-Unstan Ware has many similarities with Brackmont Mill and Grandtully.

\subsection{Lithic artefacts, by Torben Ballin}

\subsubsection{Introduction and aims}

During the various stages of fieldwork 2788 individual artefacts were recovered. Due to the size of the project area, the number of sites and subassemblages, the recovery methods and the funding allocated, it was chosen not to attempt in-depth interpretation of the individual sites/sub-assemblages. Instead, the aims of the report were to:

- define precisely sites and sub-assemblages as discrete chronological units

- characterise and date these sites and their lithic collections

- assess the research potential of all sites and sub-assemblages

During the lithic analysis, it became clear that it would not be possible to date all assemblages by reference to diagnostic types, and it was chosen to attempt relative dating of the assemblages by comparison of the industries' operational schemas ('chaîne opératoire'; Leroi-Gourhan 1965; Lemonnier 1976). To allow this, it was necessary to carry out attribute analysis of suitable samples. 
Table 3

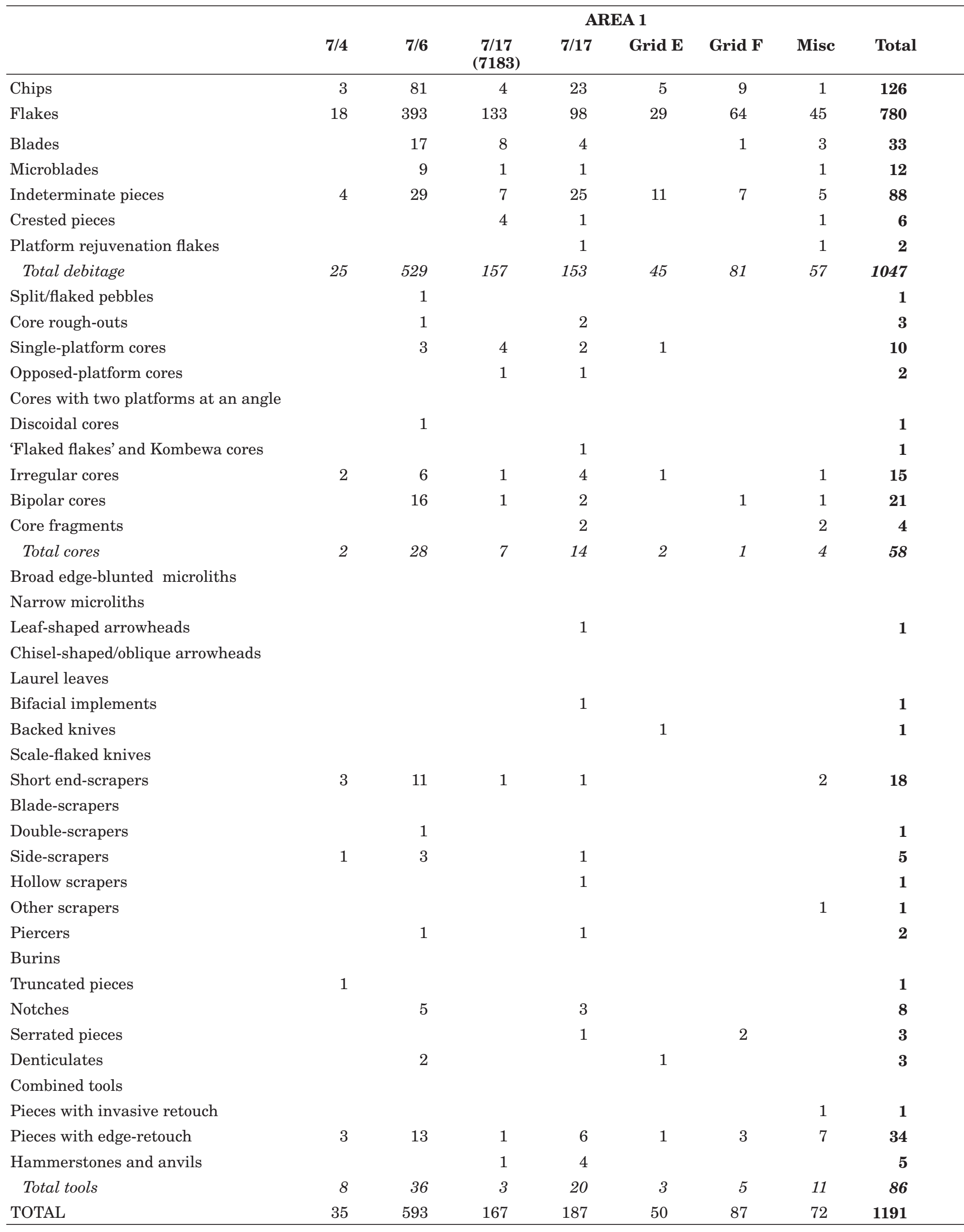


Lithic artefacts by area

\begin{tabular}{|c|c|c|c|c|c|c|c|}
\hline \multicolumn{8}{|c|}{ AREA 2} \\
\hline Site 4 & $\begin{array}{c}\text { Site } 12+ \\
\text { Grid B }\end{array}$ & $\begin{array}{l}\text { Dun na } \\
\text { Cluaich }\end{array}$ & $\begin{array}{l}\text { Tr. 1 + } \\
\text { Grid J }\end{array}$ & $\begin{array}{l}\text { Knoll/ } \\
\text { Grid K }\end{array}$ & Misc & Total & TOTAL \\
\hline 2 & 14 & 11 & 51 & & 22 & 100 & 226 \\
\hline 25 & 78 & 201 & 536 & 54 & 105 & 999 & 1779 \\
\hline 1 & 2 & 27 & 35 & & 8 & 73 & 106 \\
\hline 1 & 3 & 1 & 6 & & 4 & 15 & 27 \\
\hline \multirow[t]{3}{*}{4} & 21 & 7 & 45 & 3 & 10 & 90 & 178 \\
\hline & & 13 & 11 & 1 & 3 & 28 & 34 \\
\hline & & 1 & 4 & & & 5 & 7 \\
\hline \multirow[t]{7}{*}{33} & 118 & 261 & 688 & 58 & 152 & 1310 & 2357 \\
\hline & & & 1 & & & 1 & 2 \\
\hline & & & 1 & & & 1 & 4 \\
\hline & 1 & 1 & 23 & & 3 & 25 & 35 \\
\hline & & & 9 & & 1 & $\mathbf{9}$ & 11 \\
\hline & & & 1 & 1 & 2 & 5 & 5 \\
\hline & & & & & & & 1 \\
\hline 1 & & & & & 3 & 6 & 7 \\
\hline \multirow[t]{3}{*}{1} & 1 & 1 & 4 & 1 & 1 & 9 & 24 \\
\hline & & & 1 & & 1 & 2 & 23 \\
\hline & & 3 & 6 & 1 & & 11 & 15 \\
\hline \multirow[t]{9}{*}{2} & 2 & 5 & 46 & 3 & 11 & 69 & 127 \\
\hline & & 3 & & & & 3 & 3 \\
\hline & & & 1 & & & 1 & 1 \\
\hline & & & & & & & 1 \\
\hline & & & 2 & & 1 & 3 & 3 \\
\hline & & 1 & & & & 1 & 1 \\
\hline & & & 2 & & & 2 & 3 \\
\hline & & & & & & & 1 \\
\hline & 1 & 1 & & 1 & 1 & 4 & 4 \\
\hline \multirow[t]{3}{*}{2} & 4 & 3 & 20 & 4 & 2 & 35 & 53 \\
\hline & & 1 & 1 & & & 2 & 2 \\
\hline & & & 2 & & 1 & 3 & 4 \\
\hline \multirow[t]{5}{*}{1} & & & 1 & 1 & 3 & 6 & 11 \\
\hline & 1 & 1 & & & 1 & 3 & 4 \\
\hline & & & & & & & 1 \\
\hline & & 1 & & 1 & 1 & 3 & 5 \\
\hline & & & & & 1 & 1 & 1 \\
\hline \multirow[t]{8}{*}{1} & & 4 & 1 & & & 6 & 7 \\
\hline & & 8 & 12 & 1 & 1 & 22 & 30 \\
\hline & & 1 & 2 & & & 3 & 6 \\
\hline & & & & & & & 3 \\
\hline & & 3 & & & & 3 & 3 \\
\hline & 1 & 1 & 2 & 1 & & 5 & 6 \\
\hline & 3 & 16 & 67 & 11 & 9 & 106 & 140 \\
\hline & & & 3 & 2 & 1 & 6 & 11 \\
\hline 4 & 10 & 44 & 116 & 22 & 22 & 218 & 304 \\
\hline 39 & 130 & 310 & 850 & 83 & 185 & 1597 & 2788 \\
\hline
\end{tabular}


Adetailed catalogue of the finds forms part of the site archive and the artefacts in this report are referred to by their number (CAT no.) in the catalogue.

\subsubsection{Methodology}

The artefact groups from each area vary in size between 35 pieces (Cairn 7/4) and 850 pieces (Grid J) (Table 3). The assemblage sizes, as well as the find contexts of the individual artefact groups, define these assemblages as having more or less research potential. This report focuses on the more promising sites and artefact groups, with large assemblage size and single-period status being perceived as positive attributes.

On this basis, the assemblages were subdivided into two main categories: artefact groups with assumed high research potential, and groups with low research potential. The former encompass the finds from Cairn 7/6, Cairn 7/17, Site 12, Dun na Cluaich and Grid J. Though several of the other artefact groups are also potentially interesting (eg Cairn 7/4 and F81/Grid K), these assemblages are generally too small, or include insufficient numbers of surviving proximal ends, to allow the construction of representative operational schemas.

The assemblages of low research potential are characterised in a basic fashion involving standard classification of typology, technology and raw materials, whereas the assemblages of high research potential are characterised in more detail, for example by the application of comprehensive attribute analyses.

A distinction is made between earlier prehistoric (Mesolithic and Early Neolithic) and later prehistoric (Late Neolithic and Bronze Age), based on technological differences. The former period embraces microblade and blade industries, and the latter flake/blade or plain flake industries (Ballin forthcoming a). The Early Bronze Age is defined as the period encompassing the pottery styles Beakers, Food Vessels and Urns, and their accompanying, more or less diagnostic, barbed-and-tanged arrowhead types (Green 1980, 121-3). The Later Bronze Age is defined as the remaining part of the Bronze Age, with its subsequent pottery styles and lacking artefacts manufactured by the application of invasive retouch (Clark 1936, 47).

\subsubsection{Overview of the recovered raw materials}

Virtually all finds from Stoneyhill are in flint $(2,756$ pieces, or c 99\%), supplemented by 32 pieces in other types of raw material (c 1\%), such as quartz, quartzite, jasper and sandstone. As the colour of the flint artefacts apparently co-varies with general flint quality and flaking properties, the colours of the preparation flakes, cores and tools were classified according to a detailed colour scheme. Three main flint types were recovered from the project area: 1) flint of red/orange/honey-brown colours (orange group); 2) grey flint; and 3) flint of other colours (light olive-green group).

It is possible further to subdivide the flint of the orange group into two varieties, namely I) finegrained, homogeneous, relatively pure flint, frequently associated with a superficial sheen, and II) somewhat coarser flint characterised by the same impurities and weaknesses as flint of the light olive-green group, and with a fresh appearance (ie no sheen); grey flint is generally fresh, fine- to medium-grained and relatively homogeneous, and flint of the light olive-green group is mostly fine- to coarse-grained, fresh and with abundant impurities and weaknesses.

Grey flint dominated the finds in Pit 7183 beneath Cairn 7/17, with the odd grey piece of debitage in Cairn 7/17's general fill. The cores and tools from Pit 7183 include approximately $72 \%$ of grey flint, but the debitage from this feature is almost exclusively in grey flint. Flint of orange group I tends to be associated with early prehistoric material (eg Dun na Cluaich), and light olive-green flint (eg Grid J) and orange group II (eg Cairn 7/6) is mainly associated with later prehistoric material.

The exact provenance of the three flint types is uncertain. As indicated by Saville's work at the Den of Boddam and Skelmuir Hill (Saville 1995; 2005; 2008; Bridgland et al 1997), the colour of the flint in the local Buchan Ridge Gravels varies from browny hues to a grey colour, possibly depending on ultralocal differences in matrix composition: a higher content of kaolin in the matrix seems to result in greyer colour tones. Most likely, the coarser flint forms, and those with multiple impurities and structural weaknesses, derive from secondary deposits within the general Buchan Ridge Gravel area (see Section 2.2 above), whereas the finer, less impure orange flints may have been imported into the area from coastal sources, such as the North Sea shores.

The presently available evidence (Saville 1995, 365 ) suggests that extensive exploitation (eg in the form of mining) of the Buchan Ridge flint deposits is a mainly late prehistoric activity.

\subsubsection{Cairn 7/4}

This assemblage comprises twenty-five pieces of debitage, two cores and eight tools, all flint. The colour scheme of the flints suggests that, most likely, all were procured from the local Buchan Ridge Gravels.

The debitage is composed of three chips, eighteen flakes and four indeterminate pieces, with blades and preparation flakes being absent. Only two cores were retrieved during the investigation of Cairn 7/4, both of which are irregular cores.

The tools comprise four scrapers, one piece with an oblique truncation and three pieces with edge-retouch, all expedient pieces. Three of the four scrapers are short end-scrapers, and one is a side-scraper. A small, relatively narrow hardhammer blade has fine oblique retouch at the 
distal end. Three pieces with edge-retouch were also recovered.

In terms of dating, the lithic finds from Cairn 7/4 include no diagnostic artefacts, and the assemblage is too small to allow attribute analysis of the debitage. However, a number of traits are consistent with a later prehistoric date: the dominance of the debitage by flakes, and the absence of blades, suggest a date later than the Early/Late Neolithic transition (Ballin forthcoming a). The choice of blanks for the scrapers (a nodule, a split pebble, a 'flaked flake' and an indeterminate piece) indicates a possible later Bronze Age date (Ballin 2002a; forthcoming a). The fact that most of the lithic items were recovered from beneath the cairn suggests that the assemblage pre-dates the construction of the monument, but it is not possible to determine whether this was by days or centuries.

\subsubsection{Lithic artefacts beneath Cairn 7/6}

This assemblage probably represents one brief prehistoric episode. Two concentrations $(769,770)$ suggest the possible presence of two knappers, and the debitage was therefore selected for detailed attribute analysis.

Of the 593 lithic artefacts recovered, 529 were pieces of debitage, 28 were cores and 36 were tools. Apart from one flake and one irregular core in quartz, all finds are in flint. Approximately $60 \%$ of the assemblage is in flint of the orange group (in this case, mostly of a honey-brown colour), with $c$ $40 \%$ being in flint of the light olive-green group. Though some of the honey-brown pieces are in raw material of a homogeneous fine-grained quality, many are not, and it is thought that the major part of this assemblage was acquired locally. The better honey-brown flint may have been traded in from coastal sources.

The debitage includes 81 chips, 393 flakes, 17 blades, 9 microblades and 29 indeterminate pieces. An attribute analysis revealed that the flakes and blades are dominated by bipolar material (platform: bipolar ratio 35:65). The industry is clearly flake-dominated.

Of the 28 cores, 16 , or almost $60 \%$ of the core group, were produced in bipolar technique, with single-platform cores and irregular cores numbering three and six pieces respectively. Split pebbles, core rough-outs and discoidal cores are each represented by a single specimen. The split pebble was most likely produced in bipolar technique; from this small core two elongated flakes were detached. The corerough-out has a prepared faceted platform and a broad flaking-front, but after the detachment of only two flakes, multiple impurities caused the piece to disintegrate.

The three single-platform cores form a group of relatively squat pieces. CAT613 (illus 14.1) and CAT601 both have faceted, trimmed platforms and their 'back-sides' are fully corticated. CAT613 has a surviving crest along one lateral side, where flaking-front and cortex meet. The other lateral side is characterised by numerous incipient cones, suggesting that an attempt was made to produce either a secondary platform or an additional crest. CAT601 has two surviving crests. This core was most likely abandoned when impurities caused the formation of a series of deep step-fractures. CAT624 is a broad expedient single-platform core with a plain untrimmed platform.

One flat discoidal core has had flakes detached from the entire circumference of one face. The detachment of flakes from the opposite face was abandoned at an early stage when impurities created a deep step-fracture. The six irregular cores form a heterogeneous group, and they appear to have been reduced in a completely unsystematic manner. Their sizes differ considerably, with the largest one (CAT615) having dimensions of $89 \times 86 \times 53 \mathrm{~mm}$, and the smallest (CAT619) $30 \times 27 \times 26 \mathrm{~mm}$. These specimens only have one thing in common, namely their being based on low-grade flint (in the case of CAT619: quartz) with poor flaking properties. Their 'demotion' to unsystematic reduction was in most cases necessitated by the presence of impurities and frost-cracks.

The bipolar cores differ considerably in size, with the smallest one measuring $23 \times 14 \times 6 \mathrm{~mm}$, and the largest $86 \times 71 \times 37 \mathrm{~mm}$ (eg CAT579, illus 14.2 ; 585 , illus $14.3 ; 600$, illus 14.4 ). Three were long and slender specimens, whereas the remainder are relatively flat, broad pieces.

The large sizes of the bipolar cores define the industry as relatively wasteful (in comparison, the bipolar cores from Lussa River on Jura measure $27 \times 19 \times 11 \mathrm{~mm}$, or approximately half the size of the Stoneyhill cores; Ballin 2002b). Though a number of bipolar cores were abandoned due to the presence of chalk balls and fossils, several are in fine, flawless flint and could have been reduced further. Most likely, this raw material economy reflects the abundance of flint on the Buchan Ridge Gravels.

The tools are heavily dominated by a small number of categories, with 15 scrapers (42\%), 7 notches/denticulates (19\%), 13 edge-retouched pieces (36\%) and 1 other tool (3\%). The scrapers include 11 short endscrapers, 1 double-scraper and 3 side-scrapers. One large short end-scraper (CAT603) is based on a disintegrated irregular core, and has a convex, steep scraper-edge at one corner. Three small end-scrapers (eg CAT588, illus 14.5; 607, illus 14.6) have relatively carefully formed convex working-edges, and of those CAT588 and 607 are typical Early Bronze Age thumbnail-scrapers (av. dim.: $24 \times 28 \times 7 \mathrm{~mm}$ ). The remainder of the end-scrapers are small expedient pieces with convex, steep working-edges produced by the application of minimal retouch: in three cases (eg CAT608, illus 14.7), the retouch is inverse. The blanks for these scrapers are nine flakes, one indeterminate piece and one irregular core, with the flakes being four hard-hammer flakes, four bipolar flakes and one indeterminate flake.

Three side-scrapers form a natural continuum 


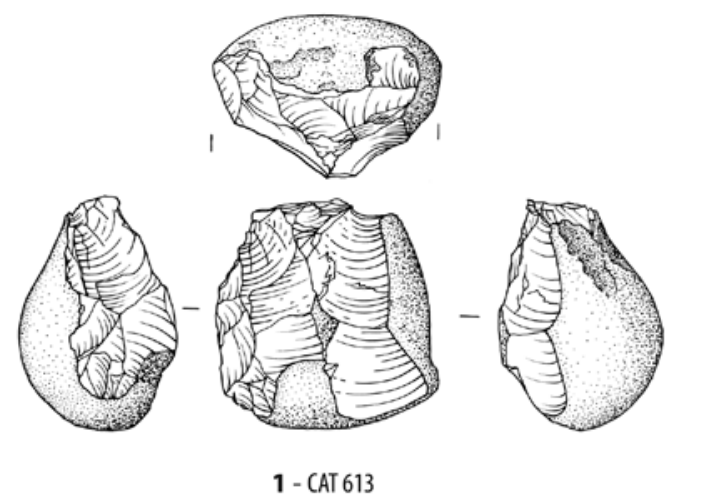

\section{Trench 9}

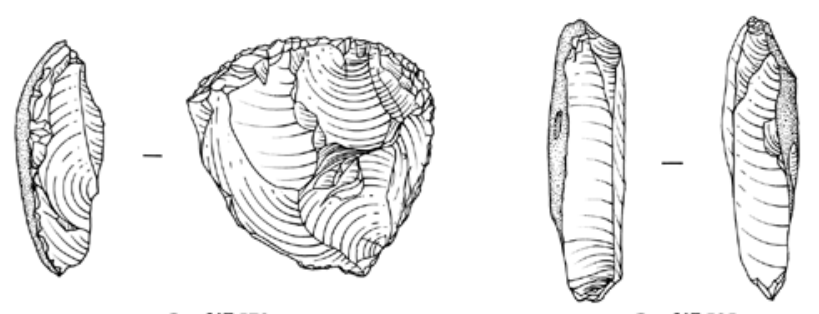

2 - CAT 579

3 - CAT 585
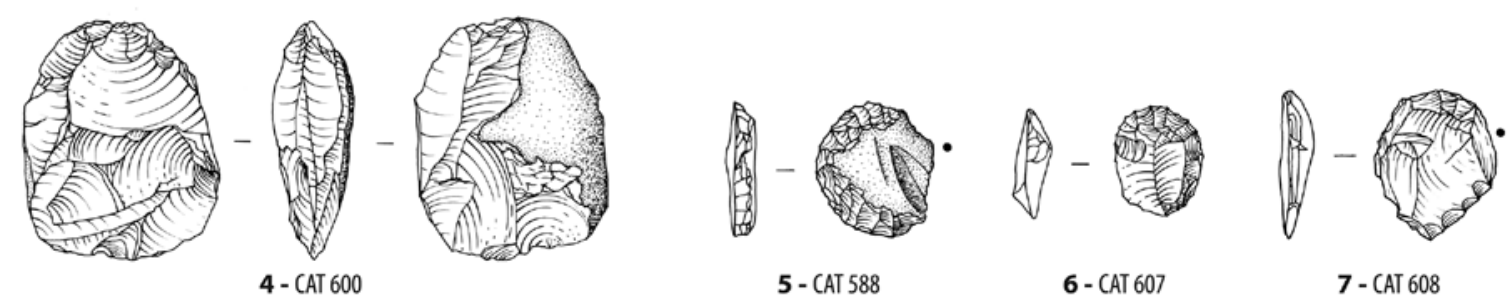

$$
\text { 5- CAT } 588 \quad \text { 6- CAT } 607 \quad 7 \text { - CAT } 608
$$

Cairn 7/17: 7183

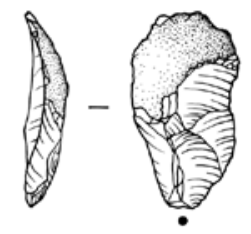

8 - CAT 551
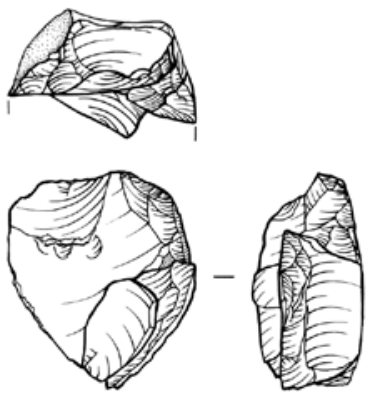

11 - CAT 555
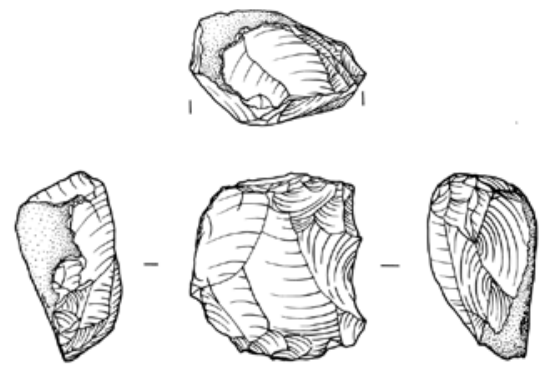

9- CAT 548

$5 \mathrm{~cm}$

\section{Cairn 7/17: Cairn fill}

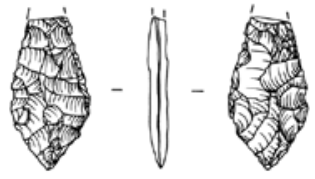

12 - CAT 521

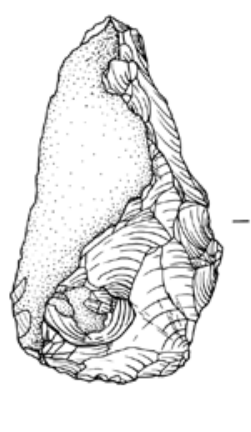

15 - CAT 540
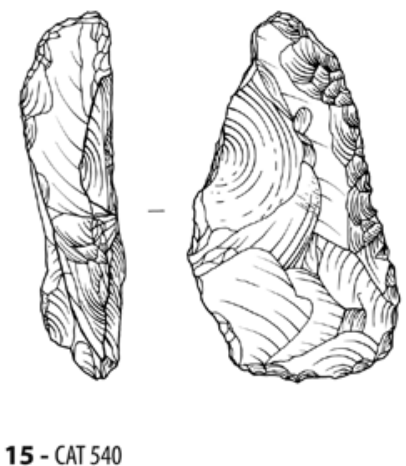

14 - CAT 514

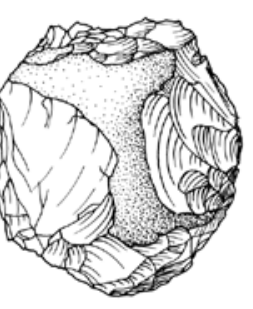

Illus 14 Lithic artefacts from Trench 9, Cairn $7 / 17$ (7183) and Cairn $7 / 17$ fill
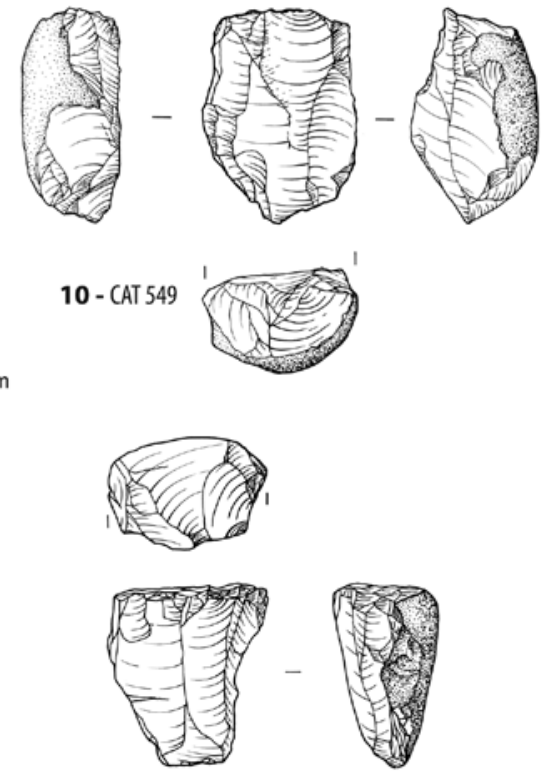

13 - CAT 528

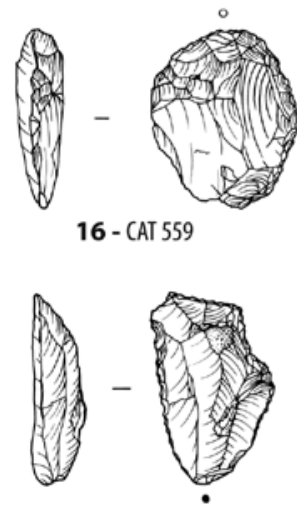

17 - CAT 533 
with the short end-scrapers. They are of approximately the same general size, and they all have an expedient appearance. They are based on one fragment of a plano-convex nodule (CAT609), one hard-hammer flake (CAT587) and one indeterminate piece (CAT586). CAT587 has inverse retouch, like three of the above-mentioned end-scrapers. The working-edge of CAT587 is convex and relatively acute, whereas the edge of CAT586 is convex and steep, and that of CAT609 straight and steep. The double-scraper (CAT598) is a small hard-hammer flake with a neat, convex, steep scraper-edge at either end; its size, combined with the quality of its execution, defines it as a thumbnail-scraper.

The piercer (CAT612) is an expedient piece, formed on the chunky proximal fragment of a hard-hammer flake. It has crude, sporadic retouch along three merging edges (the tip), as well as some blunting at the opposite end. The five notched specimens probably represent pieces with different functions. Four of those are on bipolar or indeterminate blades (CAT566, 570, 597, 622), whereas one is on a hardhammer flake (CAT591). The notches have chords between $3 \mathrm{~mm}$ and $8 \mathrm{~mm}$, and they are positioned at either end, or in the middle, of the lateral edges. Two denticulated pieces (CAT590, 604) differ considerably in appearance and, probably, in function. CAT590 is a distal flake-fragment with two small adjacent notches in the left lateral side; its function is uncertain. CAT604 is a large thermal flake with cruder, more irregular denticulation along one lateral side; it is possibly a denticulated side-scraper. The rolled, abraded edges of the latter suggest that it may pre-date most of the Trench 9 assemblage. The 13 edge-retouched pieces were manufactured on a combination of hard-hammer, bipolar and indeterminate flakes, and it is not possible to define any of them more precisely.

Apart from two Early Bronze Age thumbnailscrapers (CAT588, 607; illus 14.5-6), no diagnostic core or tool types were recovered. The fact that the artefacts are the products of a flake industry suggests a later prehistoric date, after the Early/Late Neolithic transition. The composition of the tool group, with practically all tools belonging to one of three groups (scrapers, notches/denticulates, and simple edgeretouched pieces), also indicates a late date (Ballin 2002a, 5-6), most likely in the Bronze Age. Though 'absence of evidence is not evidence of absence', the complete lack of bifacial tools, or any use of invasive retouch whatsoever, may indicate production of most of the assemblage in the Middle or Late Bronze Age - the two Early Bronze Age thumbnail scrapers may be residual, as one was found in the general cairn fill and the other one at the eastern periphery of the trench.

\subsubsection{Cairn 7/17 (deposit 7183)}

A cache of 167 lithic artefacts had been deposited near a boulder on the west lip of Pit 7181 (illus 6).
As the pit assemblage clearly represents one brief episode, it was selected for attribute analysis of its blanks, the details of which are presented in the discussion (Section 5.2.17). Too few surviving proximal ends from the cairn fill were present to carry out similar analysis on these.

The group comprises 157 pieces of debitage, 7 cores and 3 tools. Apart from one chip in quartz and one hammerstone/grindstone in quartzite, all lithic finds are in flint, with grey being the dominant colour. The presence of several different colours and textures of cortex indicate that a number of nodules were reduced to produce the assemblage. With its relatively fine-grained character and its deviant colour (ie not flint of the more common orange or light olive-green groups), it is possible that the grey flint represents selective collection from the local gravel deposits. Most likely, the grey flint was procured for reduction in association with the construction of the pit, and the flint's colour may have had symbolic connotations. It was possible to refit a number of artefacts from 7183 (ten pieces, or a refit ratio of $c$ $6 \%$ ), but the fact that so relatively few pieces were conjoinable indicates that some blanks and cores may have been removed before deposition.

The debitage includes 4 chips, 133 flakes, 8 blades, 1 microblade, 7 indeterminate pieces and 4 crested pieces. Attribute analysis of a random selection of blanks suggested that this industry is based exclusively on the use of hard percussion, though a solitary bipolar core is evidence that hammerand-anvil approaches were applied in exceptional circumstances. The blades are best perceived as longer-than-average flakes, and the industry was evidently aiming at producing flakes and not blades. Four crested pieces (eg CAT551, illus 14.8) are relatively short and, combined with their irregular features, they appear distinctly simpler than the long, slender crested blades from, for example, Grid $\mathrm{J}$ (below), with their parallel lateral sides.

The seven cores are composed of four singleplatform cores, one opposed-platform core, one irregular core, and one bipolar core. Cores CAT543 and 544 are in flint of the light olive-green group and may not be contemporary with the bulk of this small assemblage. The four single-platform cores (eg CAT548, illus 14.9) are relatively flat, short and stocky specimens (av. dim. of intact pieces: $35 \times 47 \times 32 \mathrm{~mm}$ ), and the corticated 'under-side' combined with the faceted platforms of CAT543, 548 and 554, suggest that they may be related to the "flat cores' described in connection with the assemblage from Grid J.

The opposed-platform core (CAT549, illus 14.10) is also characterised by a corticated 'under-side', and a small stretch of surviving platform-edge with fine platform faceting links this core to the same 'flat cores'. The irregular core (CAT544) is likely to be a completely exhausted 'flat core'. The bipolar core (CAT550) is a relatively simple and small piece.

Only three tools were recovered from Pit 7183, namely one short end-scraper (CAT542), one piece 
with edge-retouch (CAT555, illus 14.11) and one hammerstone/grindstone (CAT545). The hammerstone is in quartzite, whereas the scraper is in brown flint, and the retouched piece in grey flint. The brown colour of the end-scraper suggests that it may not be contemporary with the almost exclusively grey-coloured pit assemblage.

CAT542 is a relatively large end-scraper on an indeterminate primary flake. The proximal end has broken off, and the implement has a regular, semi-circular, steep scraper-edge at the distal end. The piece is similar to the Category I end-scrapers from Grid J, and is almost certainly Late Neolithic. CAT555 is a large core-side flake, which has had its proximal end removed, followed by expedient blunting of the right proximal corner and the right lateral side. The right distal corner had broken off, and after this incident the distal part of the break facet was blunted or transformed into an expedient scraper-edge. It was possible to conjoin a flake fragment to the ventral face of this tool. CAT545 is a flat elongated quartzite pebble with noticeable crushing at its most pointed end, and sporadic battering at the other. One flat face has been ground smooth.

The assemblage from 7183 is likely to represent material deposited largely as a single event. First of all, the flint is of a deviating grey colour (see Section 5.2.3); secondly, only $1 \%$ of the assemblage has macroscopic use-wear, indicating that the pit assemblage may have been produced specifically for deposition; and thirdly, only $2 \%$ of the finds from the pit are tools (Table 3). As one of the three tools from Pit 7183 is in brown flint (CAT542), and therefore likely not to be contemporary with the bulk of grey flints, and one is a hammerstone, which may be have been used to manufacture the pit assemblage, the 'grey collection' only includes one expedient tool (CAT555).

The pit assemblage includes no diagnostic core or tool types, but the technological attributes of its cores and flakes do allow an approximate date to be put forward (see discussion section). The finds represent a flake industry, with true blades being absent, suggesting a date after the Early/Late Neolithic transition, when fewer blades were produced (Ballin forthcoming a). Many attributes are shared with the operational schema defined for the Grid J industry, such as finely faceted platform remnants and abraded platform-edges (below). Combined with the fact that the cores appear to be more squat versions of Grid J's 'flat cores', a date at the end of the Late Neolithic period seems likely.

\subsubsection{Cairn 7/17 (cairn fill) (illus 14)}

From the cairn above Pit 7183, 187 lithic artefacts were recovered. For recording of these finds, the burial monument was subdivided into ten approximately equal grid units, five on either side of a central axis. Seventy per cent of the lithic finds came from the grid above Pit 7183, with a flint concentration (7177) roughly on the cairn's central axis towards its north-eastern end, and the slight rise in find frequency immediately to the west of this concentration probably represents material associated with this small flint deposit.

The 187 lithic finds from the cairn fill included 153 pieces of debitage, 14 cores and 20 tools. Apart from two flakes, one indeterminate piece, one opposed-platform core (CAT524), one irregular core (CAT515), one hammerstone in quartz (CAT557) and two hammerstones (CAT529, 534) and one hammerstone/grindstone (CAT518) in quartzite, all finds are in flint. The flint assemblage was produced in a much more diverse selection of flint colours and qualities than the grey collection from Pit 7181. Approximately $60 \%$ of the flints are in colours of the light-olive-green group, whereas $c 40 \%$ are in flint of the orange group (in this case mainly in red nuances). The finds from the cairn indicate that the assemblage represents a palimpsest with artefacts of Neolithic and Bronze Age dates (eg one leafshaped arrowhead (CAT521, illus 14.12); see dating section, below).

In general, the red flint artefacts appear to be slightly thinner and more refined than the flint artefacts in other colours, and the homogeneous nature of this raw material characterises it as orange flint of group I. As suggested in the general raw material section (Section 5.2.3), flint artefacts of this variety are mainly Early Neolithic, and possibly imported from coastal areas, whereas artefacts of the light olive-green group are mainly later prehistoric, and local.

The debitage includes 23 chips, 98 flakes, 4 blades, 1 microblade, 25 indeterminate pieces, 1 crested piece and 1 platform rejuvenation flake. The few blades are generally simple hard-hammer blanks, and they are most likely to belong to the group of later finds. The probable dominance of the assemblage by later material is also supported by the many indeterminate pieces in relatively coarse flint (16\% of the debitage), supporting the impression of more careless selection of raw material in the Stoneyhill area in later prehistory. One fragmented crested blade (CAT511) and one simple platform rejuvenation flake (CAT539) were also recovered.

The cores include two core rough-outs, two singleplatform cores, one opposed-platform core, one 'flaked flake' (Ashton et al 1991), four irregular cores, two bipolar cores and two core fragments. One of the two core rough-outs (CAT535) is fairly large (greatest dimension (GD) 92mm) and the other (CAT525) is of medium size (GD 53mm). CAT535 has had a number of flakes removed from either end, possibly by the application of hard percussion, and a simple crest was formed across one of the decorticated faces. Without producing a proper platform, it was attempted to detach this crest, but the corticated platform collapsed without releasing a flake and the nodule was abandoned. CAT525 was formed by detaching two flakes at a perpendicular angle to 
each other, thus creating a 'proto' flaking-front and a plain platform. Crushed areas along the intended platform-edge demonstrate that the knapper tried to detach flakes from the core rough-out, but the platform was damaged and the piece subsequently abandoned.

Two single-platform cores are relatively small specimens (GD 39mm). They are both knapped along $c$ two-thirds of the circumference and trimmed. CAT527 is roughly cubical and has a plain platform, whereas CAT528 (illus 14.13) is sub-conical and has a faceted platform. The four irregular cores may be sub-divided into two groups, namely cores reduced in a completely unsystematic fashion (CAT515, 537), and cores which represent the final stages of a more systematic operational schema. The only opposed-platform core is in quartz $(46 \times 40 \times 26 \mathrm{~mm})$, and it has two plain platforms and two trimmed platform-edges.

CAT531 is a 'flaked flake' which has had one flake removed from its ventral face. With its crudely denticulated edge, it comes across as a typical late prehistoric core (eg Ashton et al 1991; Ballin 2002a). The two bipolar cores differ considerably, with CAT520 being very small (GD 24mm), and in pure fine-grained flint, whereas CAT514 (illus 14.14) is large (GD 52mm) and in coarse-grained impure flint. One of the two core fragments (CAT536) is a large piece at an advanced stage of disintegration, whereas the other (CAT530) is a small piece with the surviving remains of one trimmed platform-edge.

The tools comprise one leaf-shaped arrowhead, one other bifacial implement, three scrapers, one piercer, three notched pieces, one serrated piece, six pieces with edge-retouch and four hammerstones. The site's solitary leaf-shaped arrowhead (CAT521, illus 14.12) is a small double-pointed specimen (GD 30mm). In Green's classification system (1980, 6972 ), it fits his Type 3Cs best, but where Green's Type $3 \mathrm{Cs}$ has clearly convex lateral sides, CAT521 is kiteshaped. The outermost part of the tip has broken off. CAT540 (illus 14.15) is an abandoned rough-out for a relatively large biface (GD 73mm). It was manufactured on a robust flake and it was discarded when attempts at thinning one face created a large concavity in that surface. One end is pointed and one convex, suggesting that the piece may be a rough-out for a leaf-shaped arrowhead, but it is also possible that CAT540 represents an early stage in the production of a bifacial scale-flaked knife.

The scraper category includes three expedient implements, namely one short end-scraper, one side-scraper and one hollow scraper. CAT559 (illus 14.16) is a short end-scraper on a hard-hammer flake. It has a short convex, steep working-edge at the proximal end. CAT541 is the fragment of a side-scraper on a large indeterminate piece with a straight lateral scraper-edge. It disintegrated as a result of several intersecting frost cracks or planes of weakness. CAT517 is a small indeterminate piece with a distinct retouched concavity at one end, and plain blunting along one lateral edge.
Only one piercer (CAT516) was found. It was manufactured on a small flake with a discrete bulb-of-percussion, and its expedient distal tip was formed by merging two concave lateral retouches. Three notched pieces are all on small flake fragments: CAT523 and 560 are on distal fragments, and CAT526 is on the proximal fragment of a hardhammer flake. The chords of the notched pieces vary between $3 \mathrm{~mm}$ and $5 \mathrm{~mm}$. CAT533 (illus 14.17) is a serrated piece on a robust hard-hammer flake, and the serration is relatively coarse $(c 3-4$ teeth per $\mathrm{cm})$. The lateral side opposite the working-edge has been blunted by rough rubbing. The six edge-retouched pieces were manufactured on a combination of hardhammer flakes and indeterminate pieces, and it is not possible to define any of them more precisely. The serrated flake (CAT533) and one edge-retouched flake (CAT532) conjoin, indicating that these two pieces are contemporary.

Four hammerstones are all fragmented to varying degrees. CAT557 is a small angular fragment of a quartz pebble with one surviving battered end. CAT529 and 534 are both medium-sized irregular quartzite cobbles with one main worked end. Attempts at using other points, corners or faces for hammering caused the pieces to disintegrate. CAT518 is a large oval quartzite cobble with one slightly battered end and two smooth, ground faces. Discrete facets characterise the edges of both ground surfaces, and parts of both lateral sides have broken off.

The combination of diagnostic lithic types, technological attributes and diagnostic pottery clearly demonstrates that the finds from the cairn fill represent a palimpsest. A leaf-shaped arrowhead (CAT521) in red flint, and slightly thinner and more delicate debitage and tools in the same type and colour of raw material, are likely to be of an Early Neolithic date, whereas the majority of somewhat cruder debitage and tools in flint of the light olivegreen group are likely to have been deposited during either the Late Neolithic or Bronze Age periods. Beaker sherds from the centre of the cairn, as well as from the area around Pit 7183, are evidence of later prehistoric activity, with the vessels dated to the earlier part of the Beaker period, 2500/2400 BC to $2200 / 2100$ BC (Section 5.2.2).

\subsubsection{Test-pit Grid E}

The finds were evenly distributed across the grid and 50 worked lithic artefacts were retrieved, including 45 pieces of debitage, 2 cores and 3 tools. Most finds are in flint. The colour scheme and the general quality of the raw material suggests procurement from the local gravel resources.

The debitage includes 5 chips, 29 flakes and 11 indeterminate pieces, with blades and preparation flakes being absent. The two cores are a singleplatform flake core (CAT629) and an irregular core (CAT628). The latter is the only jasper artefact in 
the Stoneyhill collection. Three tools were also recovered. CAT625 is a typical backed flake knife with robust blunting along its left lateral side. Abrasion of the distal tip suggests secondary use as a strike-a-light. CAT626 is a flake with crude denticulation along the right lateral edge. CAT627 is a chip with inverse retouch of one lateral side.

No strictly diagnostic artefacts were identified, but the combination of a number of less diagnostic types and attributes indicate a later prehistoric date. The dominance of the debitage by flakes and the absence of blades, suggest a relatively late date (Ballin forthcoming a). The plain single-platform core (CAT629) is undiagnostic, but denticulated cores (CAT628) and tools (CAT626) are generally indicative of later prehistoric industries (eg Saville 1981; Herne 1991)

\subsubsection{Test-pit Grid F}

Lithic artefacts were mainly recovered from the northern half of the grid. Test-pits near Cairn 7/17 were all sterile, and the Grid $\mathrm{F}$ assemblage does not appear to be associated with this cairn.

Eighty-seven worked lithic artefacts were recovered, including 81 pieces of debitage, 1 core and 5 tools. Most lithic finds from this site are thought to be local flint from Buchan, but the homogeneous nature of the flint of the blade blanks suggests careful selection. The debitage includes 9 chips, 64 flakes, 1 blade and 7 indeterminate pieces. The solitary blade is a fairly simple piece. The only core retrieved is a bipolar core (CAT634) on an exhausted platform core.

The tools include two serrated pieces and three pieces with edge-retouch. The two serrated pieces and edge-retouched piece (CAT633) are all on regular trimmed blades, whereas the remaining edge-retouched pieces are on simple flakes. Serrated piece CAT630 has fine serration (c 17 teeth per $\mathrm{cm}$ ) along its entire left lateral side. The other serrated piece (CAT631) has slightly less fine serration along its left lateral side ( $c$ 8-9 teeth per $\mathrm{cm}$ ), but these teeth have been rounded by use.

The combination of regular broad blades and finely serrated pieces indicates a date within the period embracing the Early Neolithic and the earlier part of the Late Neolithic. As demonstrated by Manby's (1974) research on the Late Neolithic period in Yorkshire and the analysis of the Area 1/Grid J assemblage (Section 5.2.14), stout blades are produced well into the Late Neolithic on flat Levallois-like platform cores. Finely serrated pieces are mainly associated with the Early Neolithic (eg Saville 2002), and they may be most numerous during this period, but they also form natural parts of Late Neolithic assemblages (Manby 1974; Grid J Section 5.2.14).

\subsubsection{Various other Area 1 contexts}

Seventy-two lithic artefacts, all flint, were recovered from other Area 1 contexts; relatively insignificant assemblages of between one and eighteen artefacts were recovered: Cairn 7/1 (2), Cairn 7/8 (1), Cairn 7/11 (2), Grid G (1), Grid H (5), Evaluation Trenches 1 (4), 2 (1), 3 (9), 4 (18), 5 (13), 14 (1), Test-pit $2 /$ Site 43 (3), SW of Grid E (7), and unprovenanced contexts (5). A general overview of the composition of this collection is presented in Table 3; more detailed description of individual artefacts is available in the site archive.

\subsubsection{Site 4}

Approximately $80 \%$ of the lithic finds were recovered from Cairn $4 / 1$, with the remainder having been found in, or under, cairns $4 / 2,4 / 4$ and $4 / 5$. Thirtythree pieces of debitage, two cores and four tools were found. All finds are in flint, and the colours and flaking properties of this material suggest that it may represent the same resource of gravel flint within the Buchan Ridge area.

The debitage is composed of 2 chips, 25 flakes, 1 blade, 1 microblade and 4 indeterminate pieces. The blade is a hard-hammer blade with fine faceting of the platform remnant (see Grid J, Section 5.2.14). The microblade is a bipolar product. The two cores of this small assemblage are both technologically simple. CAT653 is a small 'flaked flake' (Ashton et al 1991), whereas irregular core CAT654 may be the remains of an untrimmed, relatively crude single-platform core which, at a late stage of the reduction process, had flakes struck from a number of secondary directions.

The small group of tools include two end-scrapers, one side-scraper and one piece with an oblique truncation. Both end-scrapers are expedient flake tools. CAT972, the side-scraper, is the distal fragment of an originally much longer piece, and it is possible that its two lateral scraper-edges met to form a stout piercer tip. CAT655 is a short hard-hammer flake with an oblique, slightly concave distal truncation. Most likely, CAT655 is an expedient knife.

None of the cores and tools are diagnostic, and the small size of the debitage group prevents attribute analysis of this material. A broad date is suggested by the basic composition of the debitage and blanks, with flake dominance indicating a later prehistoric date. The general character of the unmodified blade fragment, not least its finely faceted platform remnant, indicate that this assemblage may include Late Neolithic material (Grid J, Section 5.2.14), but it is by no means certain that the finds from Site 4 were deposited at one occasion, or over a short span of time.

\subsubsection{Site 12/Test-pit Grid B}

Site 12 included Cairns 12/1-3 and Test-pit Grid $\mathrm{B}$ (Section 4.2.2). Most of the finds were recovered from Cairn 12/2 and Grid B. 
The assemblage includes 118 pieces of debitage, 2 cores and 10 tools. Apart from one quartz flake from Cairn 12/2, and a quartz flake and an indeterminate piece in quartz from Grid B, all lithic objects are in flint. Approximately $40 \%$ of the assemblage is in flint of the orange group, and $60 \%$ in flint of the light olive-green group. This colour distribution most likely reflects the chronologically mixed status of the assemblage (below). The light olive-green group clearly represents locally procured gravel flint, but the site's finer red, orange and honey-brown flint artefacts may represent importation from coastal deposits.

The debitage includes 14 chips, 78 flakes, 2 blades, 3 microblades and 21 indeterminate pieces. The high proportion of indeterminate pieces (18\% of the debitage) indicates that a large proportion of the raw material is locally procured gravel flint, with impurities, frost cracks and inherent planes of weakness lowering the flaking properties of this resource. The two blades are both soft-percussion blanks in red flint, whereas the three microblades are bipolar pieces, and they are all in light olivegreen flint. The two cores are one fragmented flat single-platform core (CAT665), and one disintegrated irregular core (CAT660). The former is relatively small, and it has lost its apex; it may be a variant of the flat Late Neolithic cores discussed in connection with the assemblage from Grid J. The latter was originally considerably larger but, owing to internal impurities (large chalk balls), it disintegrated.

The tools comprise one scale-flaked knife (CAT663), four short end-scrapers (CAT658, 662, 664, 666), one hollow scraper (CAT659), one piece with invasive retouch (CAT668) and three retouched pieces. CAT663 is a scale-flaked knife on a relatively thin, regular blade. The proximal end has broken off, and the implement has two parallel edges, one of which was sharpened by invasive retouch. Both cutting edges are worn.

End-scraper CAT664 is a small scraper with a regularly convex, steep scraper-edge at the distal end. It is on a thick primary hard-hammer flake, and its general shape and type of blank relates it to the robust regular scrapers found in Grid J. CAT666 is a naturally rolled thermal flake, which has been supplied with a convex, steep scraper-edge at one end. This natural flake may have been selected as a blank due to the large fossil of a shell adorning its flat 'under-side'. CAT658 and 662 are both small expedient pieces. The former is a distal flake fragment with a convex, steep, inverse scraperedge, and the latter is a medial flake fragment with a similar scraper-edge at the proximal end. It has blunting along the right lateral side.

Hollow scraper CAT659 is a highly irregular primary hard-hammer flake in impure, coarse flint. It has a concave, steep scraper-edge along its right lateral side. The invasively retouched piece (CAT668) is most likely a fragmented chisel-shaped arrowhead. The implement is based on a relatively thin flake, and is missing its proximal end. Along its oblique distal end, as well as at its likely base, it has bifacial invasive retouch. CAT668 may have been a chisel-shaped arrowhead of Clark's Type C2 or D (Clark 1934a, 34). The three edge-retouched pieces were manufactured on two flakes and one abandoned bipolar core (CAT667), and it is not possible to define any of them more precisely.

This assemblage includes a number of diagnostic elements, such as the scale-flaked knife (CAT663) and the chisel-shaped arrowhead (CAT668). Scaleflaked knives occur in the Neolithic period, as well as the Early Bronze Age, but the regular blade blank of CAT663 indicates a date no later than the earlier part of the Late Neolithic period (Manby 1974, 88-9; also Grid J, Section 5.2.14). If the invasively retouched piece (CAT668) is in fact a broken chiselshaped arrowhead, this supports a Late Neolithic date (Ballin forthcoming b). The shape and general character of end-scraper CAT664 is consistent with a Late Neolithic date (Grid J). If single-platform core CAT665 is, as suggested, a variant of the 'flat cores' described in connection with the Grid J assemblage, this also supports a Late Neolithic date. The simplicity of many flakes indicates some activity in the later part of the Bronze Age (Ballin 2002a).

\subsubsection{Dun na Cluaich}

Most lithic artefacts were collected from the surface south-east of the quarry, with a small number being recovered north-west of Dun na Cluaich in the area of Site 17 (Section 4.2.3). It was decided to include the small sub-assemblage from Site 17 in the much bigger assemblage from the summit as: 1) the location of Sites 14 and 17 on either side of the quarry suggests that the two sites formed parts of the same original settlement; 2) the type and colour of flint is the same (fine-grained flint of the orange group), suggesting an Early Neolithic date; and 3) both assemblages contain relatively thin, narrow blades of a quality consistent with an Early Neolithic date. Unfortunately, too few proximal ends had survived in this assemblage to allow attribute analysis.

The assemblage includes 261 pieces of debitage, 5 cores and 44 tools. Apart from one quartz flake, all finds are in flint. Three-quarters of the assemblage is in flint of the orange group, with the remainder belonging to the light olive-green group. The red, orange and honey-brown flint is generally fine-grained, homogeneous and flawless and may represent importation from coastal gravel deposits. The light olive-green flint is generally coarser and more impure, and dominance of this material is usually consistent with a late prehistoric date (see for example Grid J, Section 5.2.14).

The debitage includes 11 chips, 201 flakes, 27 blades, 1 microblade, 7 indeterminate pieces, 13 crested pieces (mostly blades; eg CAT683 (illus 15.18)) and one platform rejuvenation flake. Although the assemblage is clearly the product of 


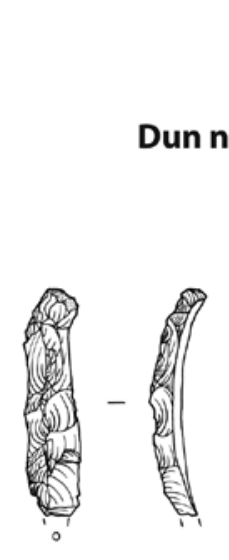

18 - CAT 683

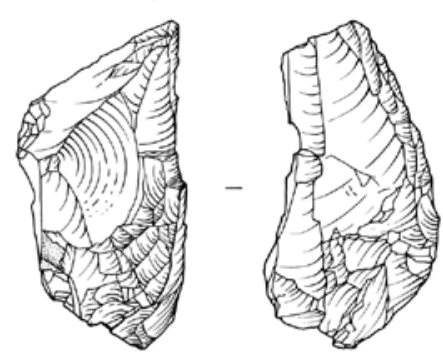

19 - CAT 708

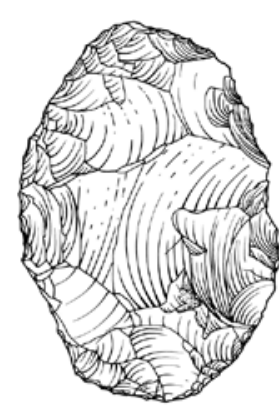

20 - CAT 728

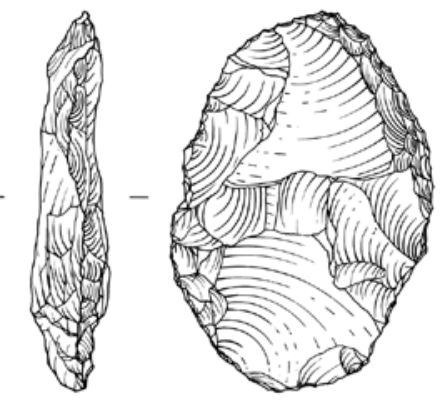

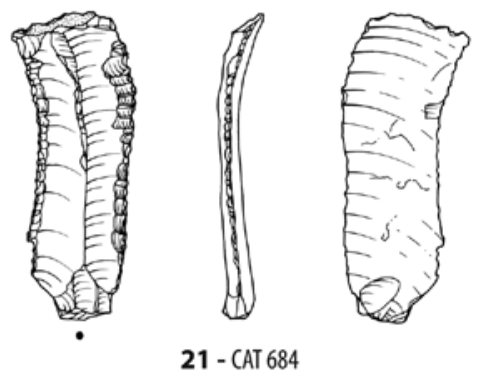

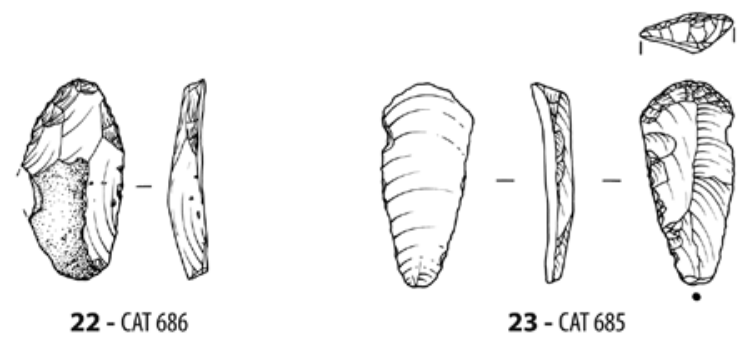

Grid J: Trench 1
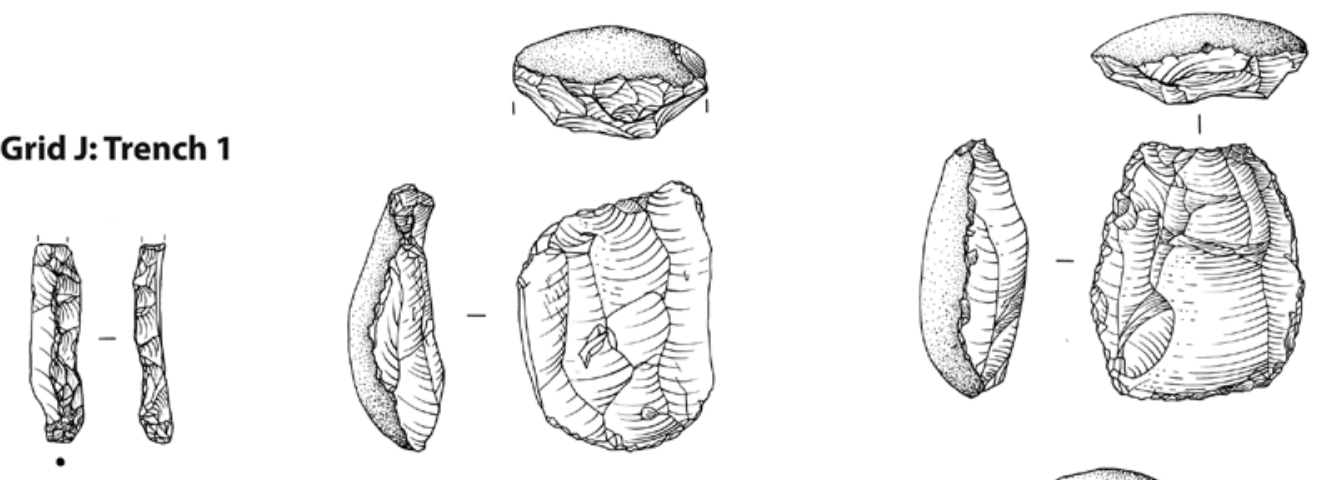

24 - CAT 850
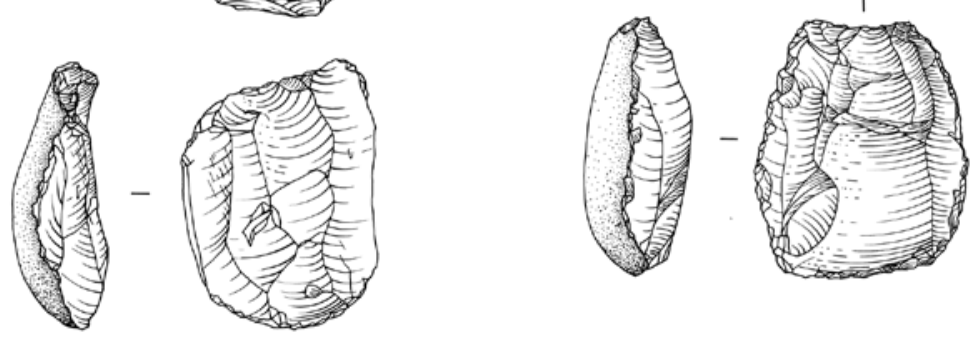

25 - CAT 775

26 - CAT 803
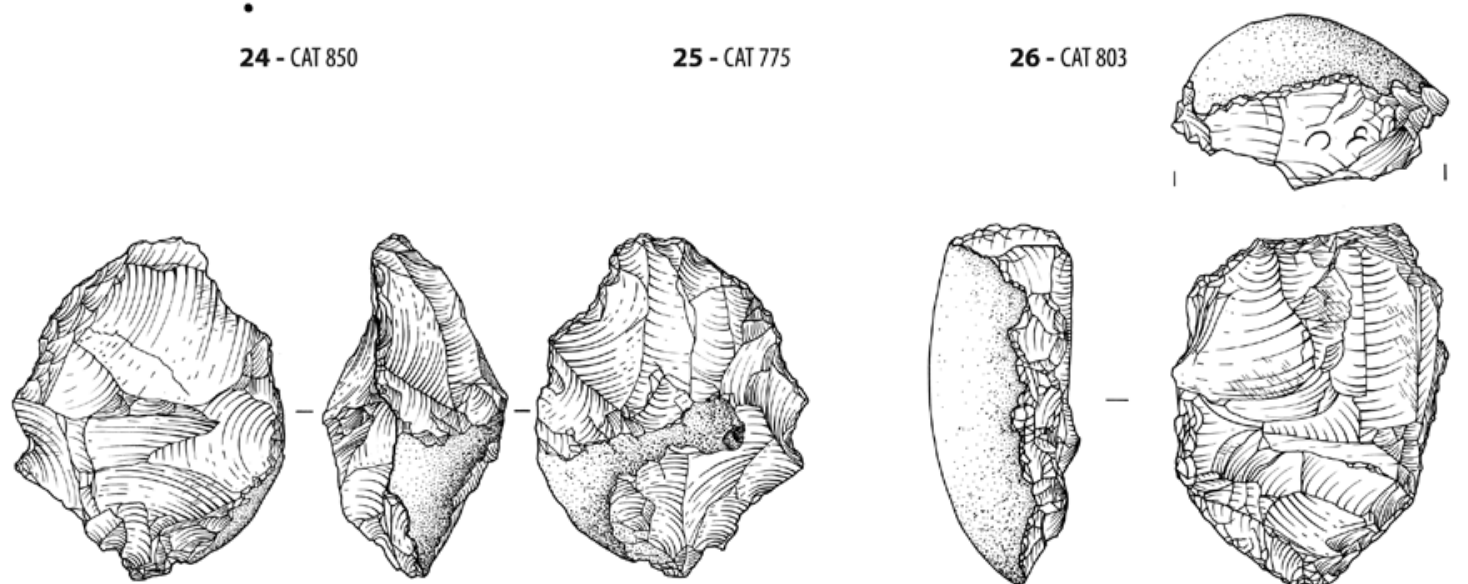

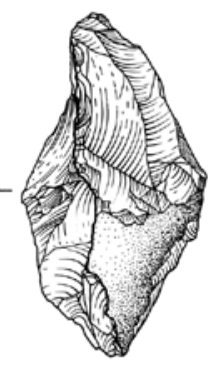

27 - CAT 798

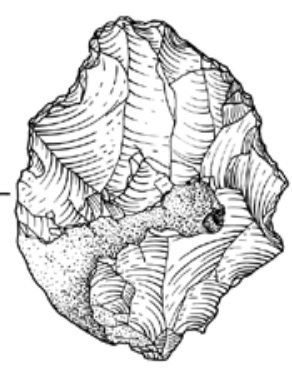

$5 \mathrm{~cm}$

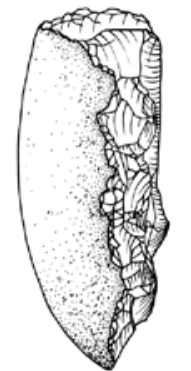

(n)

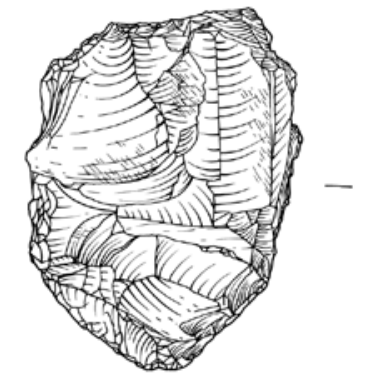

28 - CAT 738

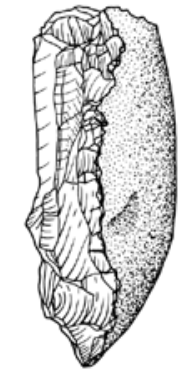

$$
\text { . }
$$


a blade industry, only $c 10 \%$ of the debitage are blades, supporting the impression of this assemblage as being that of a truncated site. The debitage of blade industries is usually expected to include higher numbers of blades (eg Bordes \& Gaussen 1970), and it is possible that the finds from Dun na Cluaich represent parts of a settlement where other activities than knapping dominated. Though this suggestion is supported by the relatively high tool ratio (almost 15\%), the presence of 13 crested pieces and 1 core tablet is evidence of primary production (CAT723). It may not be possible to explain these contradictory ratios. In comparison with several of the late prehistoric assemblages from the Stoneyhill area, the relatively early Dun na Cluaich collection contains relatively few indeterminate pieces $(c$ $2.5 \%$, against ratios of $25 \%$ (Grid E) and $18 \%$ (Site $12)$ ). This is most likely a result of the exploitation of better, less flawed flint, and more vigorous core preparation.

Only five cores were found on Dun na Cluaich, namely one single-platform core, one irregular core and three core fragments. CAT708 (illus 15.19) is a large single-platform core, from which blades were detached along approximately half of the circumference. The other half of the core's circumference is characterised by either cortex or flake scars from the initial decortication process and production of its crests. The platform-edge is trimmed, and careful faceting of the platform surface nearest the platform-edge has been carried out. However, this platform-faceting differs considerably from the much finer faceting undertaken to produce the Late Neolithic assemblages from Pit 7183 underneath Cairn 7/17 (Section 5.2.6) and Grid J (Section 5.2.14).

CAT721 is an irregular core from which flakes have been detached along three flaking axes. The three core fragments are all remains of much larger disintegrated cores. CAT670 is a large core-side (GD $72 \mathrm{~mm}$ ) and its surviving characteristics suggest that it may have formed part of a single-platform core. CAT679 is much smaller (GD $35 \mathrm{~mm}$ ), and the combination of perpendicular flaking directions and many incipient cones across its surfaces indicates that it may be a fragment of an expedient irregular core. CAT692 is a small detached apex, and its regular conical shape suggests that it may be the apex of a single-platform blade core.

The tools include 3 microliths, 1 laurel leaf, 1 scaleflaked knife, 3 short end-scrapers, 1 blade-scraper, 1 hollow scraper, 1 piercer, 4 truncated pieces, 8 notched pieces, 1 serrated piece, 3 combined tools, 1 piece with invasive retouch and 16 pieces with edge-retouch.

Three microliths are on regular, thin macroblades, and they are all edge-blunted pieces with the tip at the proximal end. CAT701 $(35 \times 11 \times 4 \mathrm{~mm})$ and CAT702 $(22 \times 10 \times 3 \mathrm{~mm})$ both have one side fully retouched, and the blunted edges are straight. Their general size and shape suggest that they may be microliths of Deepcar type (Reynier 2005, 14).
CAT690 $(26 \times 12 \times 3 \mathrm{~mm})$ has curved backing of one lateral side, with a tiny notch at the basal (distal) end. As the corner opposite this notch has broken off, the piece acquires a tanged appearance, but the 'tang' is probably an illusion based on the character of the fracture. It is not entirely certain whether CAT690 is a microlith or a diminutive backed knife.

CAT728 (illus 15.20) has been characterised as a laurel leaf (eg Clark 1960, 221, 223). It is a relatively large $(77 \times 52 \times 18 \mathrm{~mm})$ bifacial rough-out, most likely for a slender leaf-shaped point with a rounded base. The knapper seems to have been unable to thin a central raised area and, as a consequence, the piece was abandoned. CAT684 (illus 15.21) is a fine scaleflaked knife on a long and thin, regular blade. Of the two parallel lateral sides, one is slightly concave and one slightly convex. Both sides have been sharpened by invasive retouch.

The three combined tools are all scraper-knives. CAT729 is a scraper-knife on a large flake. It was thinned by the application of crude bifacial retouch, and it has a slightly convex, steep scraper-edge at one end. CAT685 (illus 15.23) and CAT713 are both scraper-knives on blades, with one scale-flaked lateral cutting edge, and a convex, steep scraperedge at the distal end.

Three short end-scrapers form a heterogeneous group. CAT686 (illus 15.22) is a short end-scraper on an elongated hard-hammer flake (GD 40mm) and it has been severely burnt. It has a regularly convex, steep scraper-edge at the distal end. CAT691 is a much larger (GD $68 \mathrm{~mm}$ ) thermal flake with full cortex-cover. It has been supplied with a somewhat uneven, convex, steep scraper-edge at one end. CAT694 is a broad platform rejuvenation flake with a straight, steep scraper-edge along its left lateral side. CAT734 is the burnt distal end of a blade scraper; it has a convex, steep working-edge at the distal end, but the left corner of the scraper-edge disintegrated due to the exposure to fire. CAT731 is a hollow scraper on the proximal fragment of a blade. It has a distinctly concave working-edge at the proximal end. Its entire left lateral side has been blunted.

Only one piercer (CAT706) was recovered from Dun na Cluaich. It is a small hard-hammer flake with short stretches of retouch on either side of a distal tip. The piece has sporadic blunting along the right lateral side, and a small notch in the opposite side, most probably to facilitate hafting. Four truncated pieces form a small group of expedient tools. The truncations of CAT676, 712 and 718 are oblique, whereas that of CAT673 is straight. Fine use-wear along one or more lateral edges reveals that, in functional terms, all four implements are knives. CAT676 was manufactured on a large indeterminate piece, the robust truncation of which may have had a scraping function in addition to the function as blunting. CAT673 is on a small hard-hammer flake, whereas CAT712 is on a long, slender blade. CAT718 is the distal fragment of a small indeterminate flake. 
CAT688 is the medial fragment of a serrated blade. The implement has fine, quite worn serration along its right lateral side ( $c 10$ teeth per $\mathrm{cm}$ ), whereas the left lateral side displays flat use-wear of a type usually associated with cutting activities. The eight notched pieces are on either regular hard-hammer blades (CAT687, 707, 720) or hard-hammer flakes (CAT677, 678, 681, 714, 719), and the chords of the small retouched notches vary between $4 \mathrm{~mm}$ and $12 \mathrm{~mm}$. Most of the pieces in this group have lateral edge-wear suggesting use as cutting implements. The notches of the blades are usually towards one end and appear to be hafting notches, but the notches of the flakes are more difficult to interpret as they are frequently located in more obscure parts of the various edges, such as the central area, or at corners.

One chunky proximal fragment of a hard-hammer flake has regular invasive blunting along its left lateral side. The sixteen edge-retouched pieces were manufactured on one nodule, one abandoned irregular core, four blades, nine flakes and one crested blade. It is not possible to define any of these tools more precisely.

The assemblage includes several diagnostic types, such as three microliths, a laurel leaf, a scale-flaked knife, three scraper-knives, a finely serrated blade and a piece with invasive retouch. The diagnosticity of these tools varies, with some indicating a date within a single period, whereas others are indicative of more than one period. The microliths are all on broad blades and probably date to the earlier part of the Mesolithic period (Reynier 2005). The general lack of Mesolithic types in the project area, such as burins, suggests that the Stoneyhill microliths may be stray artefacts, possibly relating to hunting trips or brief retooling activities (Keeley 1982). Though scale-flaked knives occur throughout most of the Neolithic and Early Bronze Age periods, and serrated pieces in the Early and Late Neolithic periods (Saville 2002), the specimens from Dun na Cluaich are mainly on regular broad blades, suggesting a Neolithic date. Laurel leaves are mainly associated with the earlier part of this period (Clark 1960; Smith 1965, 100). The flake with invasive retouch can only be broadly dated to the period Early Neolithic to Early Bronze Age (cf Clark 1936, 47).

The present assemblage is heavily dominated by the 'orange' type of flint and, in conjunction with the diagnostic tool types discussed above, this suggests that the assemblage from Dun na Cluaich may be almost entirely Early Neolithic. The only artefacts indicating a presence at any other time are the three, probably stray, Early Mesolithic microliths.

\subsubsection{Test-pit Grid J}

The contour map (illus 8) shows that the finds are concentrated roughly along the central north-south axis, this being the location of a slight elongated knoll. There are three 5-7m long concentrations and, as the southernmost concentration is truncated by the margin of the grid, it must be assumed that the flint distribution continued in this direction. East of Grid J, lithic finds were primarily found in F18 (27 pieces) and its neighbouring features, as well as in F15 (eight pieces) and its surroundings, again forming a north-south line of concentrations.

As the assemblage seems to be chronologically 'clean', in the sense that it probably consists almost exclusively of Late Neolithic artefacts, it was selected for detailed attribute analysis. By this means, the author hoped to produce a diagnostic technological profile, describing the operational schema of the responsible industry, and hopefully shed light on the slightly enigmatic 'Levallois-like' cores reported from Late Neolithic sites throughout Britain (eg Moore 1963; Manby 1974; Saville 1981; Healy 1993; Durden 1995; Healy 1995).

The collection comprises 688 pieces of debitage, 46 cores and 116 tools. Apart from one flake and a hammerstone (CAT761) in quartz, a hammerstone in sandstone (CAT760) and a hammerstone/anvil in quartzite (CAT743), all finds are in flint, with flint of the light olive-green group dominating (approximately two-thirds of all worked flint). The character of the flint suggests that, in this case, almost all the raw material was procured locally.

The debitage includes 51 chips, 536 flakes, 35 blades, 6 microblades, 45 indeterminate pieces, 11 crested pieces and 4 platform rejuvenation flakes. Attribute analysis of a random selection of flakes and blades showed that this industry is based entirely on hard percussion. The aim of the industry was clearly to produce elongated flakes and robust blades, though blades from the first production series (particularly from the removal of crests) occasionally turned out long and slender. In the discussion section (below), this industry is compared with two other later prehistoric industries, and an attempt is made at distinguishing between the blanks of apparently similar later prehistoric material cultures. The operational schema of the present material culture is obviously similar to that of Late Neolithic assemblages throughout Britain (see references above), for which reason the characterisation of the industry has been given some priority.

Eleven intact or fragmented crested blades (eg CAT850, illus 15.24) are relatively slender pieces. Four pieces have been classified as platform rejuvenation flakes, as they are short irregular flakes with fine modification of the platform remnants. However, where this would usually characterise a traditional core tablet, with the fine modification being surviving trimming, this modification may be the fine platform faceting recognised on many ordinary Late Neolithic flakes (see Section 5.2.17). Or in other words, these 'platform rejuvenation flakes' may be irregular, shorter-than-intended, ordinary flakes, rather than preparation flakes.

The cores form an exceedingly homogeneous group, with almost $60 \%$ of the cores representing 
different stages of the same core type. The core group includes 1 split pebble, 1 core-rough-out, 23 single-platform cores, 9 opposed-platform cores, 1 core with 2 platforms at an angle, 4 irregular cores, 1 bipolar core and 6 core fragments. In the present case, the traditionally applied core typology does not group the objects appropriately, and 26 single- and opposed-platform cores, as well as irregular cores, form a group of 'flat cores' with many similarities (CAT775 and 803 (illus 15.25-6) are archetypal examples of this category). The average dimensions of these 'flat cores' are $52 \times 44 \times 23 \mathrm{~mm}$, and the average LW and WTh ratios are 1.21 and 1.95. This indicates that, at the time of abandonment, these cores were slightly longer than their width, and almost twice as broad as they were thick.

Most likely, the first step of this operational schema was to produce thick discoidal, or 'tortoiseshaped', rough-outs, such as CAT798 (illus 15.27). This rough-out was probably discarded as a result of the creation of several deep step-fractures. Contrary to CAT798, which has been almost completely decorticated, most tortoise rough-outs would have had fully cortex-covered, domed 'under-sides' and slightly arched, decorticated 'top-sides' (the prospective flaking-fronts). Mostly, flakes and blades were only detached from one face of the parent piece ( $\mathrm{cf}$ Moore 1963, 194).

As best indicated by CAT738 (illus 15.28) (which was discarded shortly after commencement of production), these special cores were prepared by first detaching small flakes around the entire circumference, at a perpendicular angle to the flaking-front. Then one end was transformed into a faceted platform, which would be faceted more finely before the first flakes or blades were struck off (basically, this corresponds to horizontal trimming). Occasionally, the cores were trimmed in the traditional manner (vertical trimming), and in many cases the trimming, or the fine faceting, was combined with abrasion of the platform-edge. A crest flanked either side of the flaking front, from platform to apex. The morphology of the 'flat cores' reveals some of the weaknesses of this approach, the main one being the tendency of blanks to become rather broad due to the flatness of the flaking fronts. The longest blanks are the crested pieces, which were detached from more distinctly ridged parts of the cores. Blanks from the central part of the cores frequently removed the core apexes by plunging. The tendency of many flakes to terminate in step- or hinge-fractures reflects the properties of the flint, as well as the approach (ie the application of insufficient force). In a number of cases, it was attempted to revive the cores by adding a secondary (opposed-platform cores) or tertiary platform (irregular cores).

Seven more traditional single-platform cores were also recovered. CAT765 and 827 are coresides of conventional single-platform cores (av. dim.: $43 \times 38 \times 19 \mathrm{~mm}$ ), and they probably broke off their parent pieces due to the presence of planes of weakness or frost cracks. CAT860 is a small rolled single-platform core $(32 \times 25 \times 16 \mathrm{~mm})$ which may pre-date the bulk of the Grid J assemblage. The remaining four single-platform cores (eg CAT736, illus 16.29) are considerably bulkier than the 'flat cores', but they also share attributes with this category, such as faceting/fine faceting of the platforms. The latter suggests that the 'flat cores' and these four single-platform cores are products of the same technological tradition.

Traditional opposed-platform cores are few, with one (CAT792) being a stocky, relatively irregular specimen $(53 \times 44 \times 32 \mathrm{~mm})$. It has massive stepfractures at one end, which probably caused it to be abandoned. CAT910 is somewhat thicker than most 'flat cores' $(53 \times 46 \times 34 \mathrm{~mm})$, but its general shape (in particular its flat cortical 'under-side') suggests that it may be an 'outsider' of the 'flat core' group. One core with two platforms at an angle (CAT744) $(58 \times 35 \times 27 \mathrm{~mm})$ is probably a 'flat single-platform core' which split due to an unexpected plane of weakness. After having split along its long axis, a secondary platform was created perpendicular to the original one. Two relatively cubic irregular cores have three or more platforms or flaking axes; one (CAT767) is relatively small (GD $49 \mathrm{~mm}$ ) and one (CAT748) considerably larger (GD 56mm). A bipolar core (CAT851) is a 'flat core' $(55 \times 42 \times 25 \mathrm{~mm})$, which was exhausted completely by the application of hammer-and-anvil technique, whereas a split pebble (CAT907) is an early-stage bipolar core $(68 \times$ $51 \times 38 \mathrm{~mm})$. It was not possible to classify six core fragments (CAT843, 848, 868, 869, 877, 879) more precisely. They all disintegrated due to either frost cracks/planes of weakness or exposure to fire.

The 116 tools include 1 microlith, 2 chisel-shaped arrowheads, 2 bifacial implements, 24 scrapers, 1 truncated piece, 12 notched pieces, 2 serrated pieces, 2 fragments with bifacial/invasive retouch, 67 pieces with edge-retouch and 3 hammerstones. The three largest tool groups are scrapers (21\%), notched pieces $(10 \%)$ and retouched pieces $(59 \%)$. The solitary microlith (CAT754) is a narrow specimen $(12 \times 3 \times$ $1 \mathrm{~mm}$ ) and generally much smaller than the microliths recovered from Dun na Cluaich (Section 5.2.13) with their average width of $11 \mathrm{~mm}$. The left lateral side is fully retouched, and the oblique retouch at the distal end defines the piece as either a narrow scalene, rhomboid or trapezoidal microlith. The proximal end has broken off.

Two modified pieces (CAT881, 890, illus 16.30) are the remains of chisel-shaped or oblique arrowheads (Clark 1934a, 34-5). CAT881 is the lateral fragment of an arrowhead with regular concave retouch. This piece may belong to Clark's Type D. CAT890 has robust bifacial retouch of one edge, removing the bulbar area of the flake blank, and sporadic edgeretouch of the other. This modification gave the implement an approximately wedge-shaped outline, and the piece probably fits best into Clark's Type C1. Two bifacial implements (CAT764 (illus 16.31), 768) appear to be unfinished pieces, and they may be rough-outs for leaf-shaped implements or, in the case 


\section{Grid J: Trench 1}

(continued)
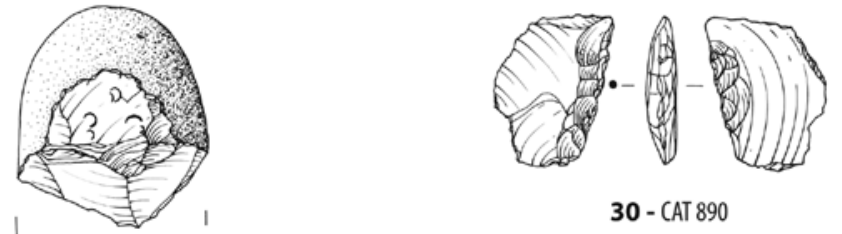

30 - CAT 890

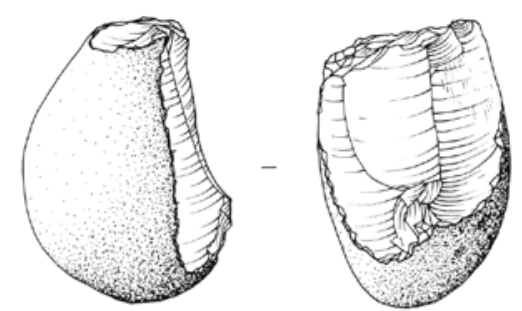

29 - CAT 736

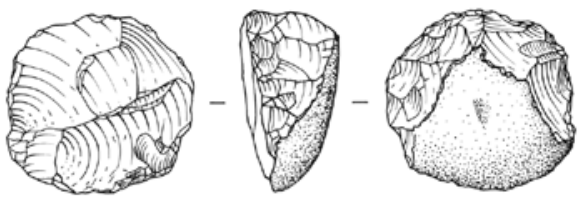

32 - CAT 777

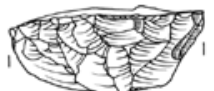

34 - CAT 906
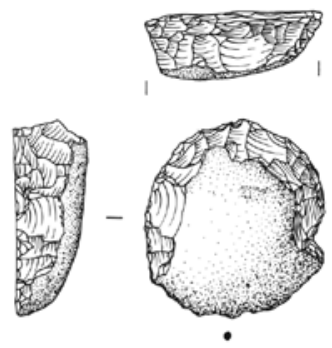

\section{Dun na Cluaich}

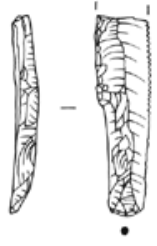

35 - CAT 741
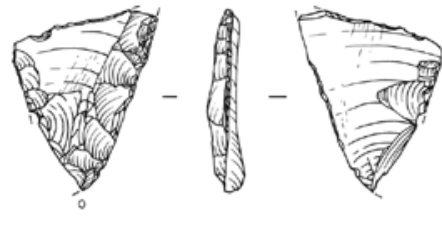

36 - CAT 948

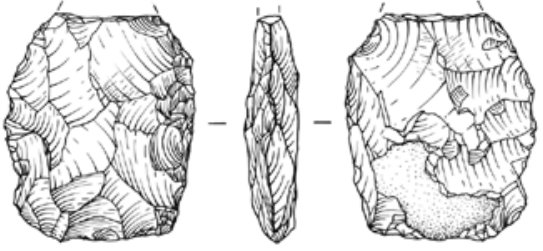

31 - CAT 764
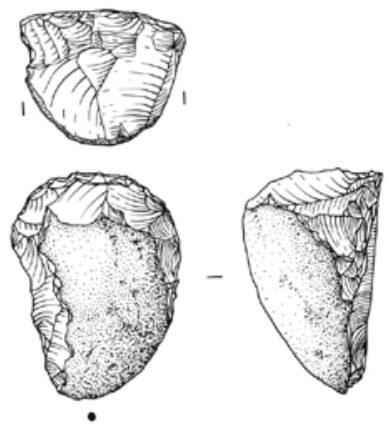

33 - CAT 826

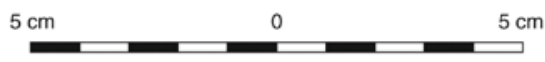

Illus 16 Lithic artefacts from Dun na Cluaich and Grid $J$

of CAT764, possibly a pre-form for a discoidal knife (Clark 1932). They have either convex (CAT768) or straight bases (CAT764), and they are both missing one apparently pointed end.

The 20 short end-scrapers were sub-divided into two major categories: I) 12 pieces representing regular specimens (eg CAT777 illus 16.32, CAT826 illus 16.33, CAT906 illus 16.34); and II) eight pieces representing expedient pieces with more varied shapes and edge-morphologies. The end-scrapers of
Category I are, with a few exceptions, thick pieces (av. dim.: $40 \times 32 \times 17 \mathrm{~mm}$ ), and their defining attribute is an exceedingly regular convex workingedge, forming an approximate semicircle. Very few of the Category I scrapers display shoulders where the scraper-edge meets a lateral side (eg CAT791). CAT791 is on a crested flake, CAT824, 828, 899 and 900 are on secondary flakes, whereas the remainder are on either primary flakes (CAT826, 887, 897, 906) or abandoned cortical 'flat cores' (CAT776, 
$777,870)$. The secondary pieces are generally hardhammer flakes, whereas the primary pieces appear to have been detached by the application of bipolar technique. As mentioned above, the Grid J industry is characterised by the almost exclusive use of hard percussion, and it is possible that these isolated cases of applied bipolar technique are associated with the process of splitting or decorticating nodules to form rough-outs for 'flat cores' (see for example Saville 2006, 452). Several of the Category I scrapers have blunting of one or more lateral sides, with two implements having been defined as horseshoe-scrapers (CAT828, 906).

The scrapers of Category II form a strongly heterogeneous tool group, with varying sizes, shapes and working-edges. Some are small (eg CAT863; GD $20 \times 22 \times 8 \mathrm{~mm}$ ), and some are large (eg CAT737; $59 \times 38 \times 18 \mathrm{~mm}$ ); some are thick (eg CAT876; $44 \times 40 \times 17 \mathrm{~mm}$ ), and some are thin (eg CAT872; $28 \times 19 \times 7 \mathrm{~mm}$ ); and the blanks seem to be a completely random selection of flakes and cores: CAT737, 806, 820, 863 and 872 are hard-hammer flakes (GD: $22-59 \mathrm{~mm}$ ); CAT746 and 876 are raw nodules or thermal flakes; and CAT801 may be a 'flaked flake' (Ashton et al 1991) or a completely exhausted 'flat core'. The scraper-edges are generally expedient and convex (CAT801, 806, 820), straight (CAT746, 863, $872,876)$, or denticulated (CAT737). CAT820 has a knapping seam running from platform remnant to apex, and the blank is clearly a crested piece from a 'flat core'.

The main difference between the two types of short end-scrapers is the fact that scrapers of Category I are consistently robust, with well-executed semi-circular working-edges which were never manufactured in fine retouch, whereas the simpler scrapers of Category II may have any thickness with working-edges of any delineation or fineness. Many of the working-edges of Category I scrapers have distinct overhangs, suggesting that these implements are used and discarded pieces.

A small blade-scraper (CAT829) was manufactured on a relatively narrow hard-hammer blade (W $14 \mathrm{~mm}$ ), with the remains of a trimmed platform at the distal end. The scraper-edge is slightly convex, steep and expedient. Two thick double-scrapers (CAT830, 838) are related to short end-scrapers of Category I, and they only differ from implements of this group by having two opposed working-edges; CAT838 is burnt, and both pieces are on indeterminate flakes. One side-scraper (CAT844) is on a short hard-hammer flake with a steep uneven scraper-edge on the right lateral side, whereas the left lateral side has been blunted by the application of fine retouch.

Only one truncated piece was recovered from the site, namely CAT769. This piece is a broad hardhammer blade (W 19mm) which has had its distal end broken off. The facet of the break has been blunted by sporadic curved retouch, partly from the ventral face and partly from the dorsal face. The right lateral side is blunted by surviving cortex, whereas the left lateral side is sharp. Flat use-wear of the sharp edge suggests that the implement is a knife. Twelve notched pieces (CAT756, 758, 762, $766,783,802,807,808,823,834,880,911)$ are a heterogeneous category, which most likely served a number of different functions. The pieces may have one or two notches, the notches may be at either end or in the medial part of a lateral edge, and the chords of the notches are between $4 \mathrm{~mm}$ and $9 \mathrm{~mm}$. The blanks of the notched pieces are eight flakes, three blades and one indeterminate piece, and the flakes and blades were detached by the application of either hard percussion or bipolar technique; only CAT756 has a discrete bulb-of-percussion.

Two serrated pieces (CAT741 illus 16.35, 874) are on thin and slender soft-percussion blades. CAT741 is on a narrow crested blade, and its distal end has broken off. Serrated pieces are particularly common in Early Neolithic contexts (Saville 2002) but, as demonstrated by Manby (1974), they also form part of typical late Neolithic inventories. It is possible that some soft percussion was applied in connection with the detachment of crests as well as blades near the crested parts of the 'flat cores'. The serration is exceedingly fine (13-14 teeth per $\mathrm{cm}$ ) and runs along one entire lateral edge. The opposite edge of CAT741 is blunted by surviving cortex, whereas the opposite edge of CAT874 has been blunted by rubbing with a hammerstone.

Two pieces (CAT796, 840) are fragments with bifacial or invasive retouch. CAT840 is the fragment of a robust flake which has had its bulbar area removed by bifacial retouch, and CAT796 is a large indeterminate piece with a short stretch of flat invasive retouch along one edge. The 67 edgeretouched pieces were manufactured on 2 nodules, 1 irregular core-fragment, 10 blades, 46 flakes, 5 indeterminate pieces and 3 crested pieces. It is not possible to define any of these tools more precisely.

Two hammerstones (CAT760, 761) and one hammerstone/anvil (CAT743) were recovered. CAT760 is a large elongated hammerstone in sandstone with two crushed ends. The battered ends have been worn flat. CAT761 is a much smaller flat and oval piece in quartz with two crushed terminals. The used area of the most pointed end extends along one lateral side, whereas the other end is damaged. CAT743 is a large flat and oval piece in quartzite with two battered ends and one battered lateral side. At the centre of either face is a pitted area from bipolar reduction of flint nodules.

The assemblage includes few strictly diagnostic types, but in terms of technological approach it appears homogeneous. The bulk of the lithic artefacts are likely to be contemporary and, though the finds were not necessarily deposited during the same occupation of the site, they were most likely abandoned in the area during one prehistoric period. The narrow microlith is a solitary stray find, and may have been lost during a Late Mesolithic hunting episode.

A chisel-shaped arrowhead (CAT890), and the 
probable fragment of another (CAT881), suggest a general Late Neolithic date for the assemblage (Clark 1934a; Manby 1974; Green 1980). This date is supported by the distinctive operational schema followed by the knappers, including the reduction of tortoise-shaped rough-outs into characteristic 'flat cores' and, not least, the application of fine faceting of the platform and abrasion of the platform-edge (see discussion section, below). This particular technological approach has frequently been referred to in the archaeological literature as 'Levallois-like', and tortoise cores or rough-outs and 'Levalloislike' cores have been reported from Late Neolithic contexts throughout Britain (eg Moore 1963; Manby 1974; Saville 1981; Healy 1993; Durden 1995; Healy 1995).

Manby $(1974,83)$ defines a typical Late Neolithic lithic tool kit, which combines the above-mentioned cores with chisel-shaped/oblique arrowheads, discoidal flint knives, various forms of edge-ground tools, plano-convex knives on blades (where the Bronze Age variant would be on flakes), finely serrated flakes and blades, and robust wellexecuted scrapers. Several of these implements are relatively uncommon on settlement sites, such as discoidal and plano-convex knives, but with its characteristic cores, chisel-shaped points, finely serrated pieces and robust scrapers, the assemblage from Grid $J$ presents itself as typically Late Neolithic. The two bifacial pieces (CAT764, 768) are unquestionably post-Mesolithic, but their shapes are too indistinct to allow precise classification and thereby dating.

\subsubsection{Grid K, Pit F81, with adjacent areas}

This group includes lithic finds from Test-pit Grid K (illus 3), Trenches 49-51 (north-east and east of Grid K), and other topsoil finds from the immediate area. Approximately $80 \%$ of the lithic artefacts were recovered from a prominent knoll, whereas the remaining $20 \%$ of the finds were distributed evenly across the remainder of this general area.

The assemblage includes 58 pieces of debitage, 3 cores and 22 tools. With a tool ratio of $27 \%$, this assemblage differs from most other Stoneyhill assemblages (ratios between $5 \%$ and 15\%). The Stoneyhill tool ratios are generally relatively high, which may be due to the lack of consistent sieving (which usually results in the recovery of large numbers of chips). The relatively high tool ratio of this assemblage indicates that this area may have been the focus of slightly different activities from those characterising the other Stoneyhill sites.

Apart from four artefacts in quartz and quartzite, the lithic finds are all in flint. The flints are almost evenly distributed across the orange and light olivegreen groups. The light olive-green group clearly represents locally procured gravel flint, but the red, orange and honey-brown flint is characterised by having fewer impurities and, consequently, better flaking properties than the average Buchan Ridge material.

The debitage is heavily dominated by 54 flakes, supplemented by 3 indeterminate pieces and 1 unilaterally crested blade. The latter may be a crest from a flat Late Neolithic core. The cores are: one core with two platforms at an angle, one irregular core and one core fragment.

The 22 tools include 1 scale-flaked knife, 1 fragment of a bifacial implement, 4 short end-scrapers, 1 side-scraper, 1 piercer, 1 notched piece, 2 hammerstones and 11 pieces with edge-retouch. CAT928 has been classified as the fragment of a bifacial implement, and it may originally have formed part of a relatively large Early Bronze Age tool, such as a sickle (Clark 1934b), a dagger (Grimes 1932) or a foliate knife (Ballin forthcoming c). One end constitutes a rounded point or butt, whereas the other end is a diagonal fracture facet. The end-scrapers form a heterogeneous group of tools, including one regular horseshoe-shaped specimen as well as three expedient pieces on suitable blanks.

This small assemblage includes several diagnostic elements, suggesting that it is chronologically mixed. The scale-flaked blade knife was most likely produced in the later part of the Early Neolithic, or in the earliest part of the Late Neolithic (Ballin forthcoming a); the bifacial piece may be a fragment of a sickle, a dagger or a foliate knife, all of which are datable to the Early Bronze Age period. Most of the red, orange and honey-brown flint are of a quality (eg the scale-flaked knife) which supports the indication of an earlier prehistoric presence.

\subsubsection{Other Area 2 contexts}

Elsewhere in Area 2 (illus 3), 185 lithic artefacts were recovered, with relatively insignificant assemblages of between 1 and 47 artefacts being recovered. These were: Grid A (22) and Trench 7 (2), on the east flank of Dun na Cluaich; Grid C (12) and Trench 22 (27) on flat ground between Dun na Cluaich and Northfield; Trench 17 (1) adjacent to Grid B; Trench 29 (1) to the south-west of Dun na Cluaich; Trench 31 (1) to the south of Grid B; Trenches 44 (47) and 48 (8), by Grid J; The Field (46) and south-east corner (8), both non-specific parts of the field containing Grid J etc; Test-pit 1 (3), in the peat by the Laeca Burn to the south of Dun na Cluaich; and unprovenanced (7). Apart from four artefacts in quartz and quartzite, all finds are in flint.

To a degree, these artefacts represent general background noise to the above-mentioned more substantial assemblages, but a number of the 'various' contexts probably form extensions of Site 12, Dun na Cluaich, Grid J and Grid K. Information on these groups is available in the archive.

Only two artefacts deserve to be mentioned specifically, namely a scale-flaked knife on a flake (CAT959) and a chisel-shaped arrowhead of Clark's Type C (CAT948 illus 16.36). Both derive from topsoil in the 
Table 4 Dates and characterisation of the various Stoneyhill sub-assemblages. The colour-coding suggests major or minor chronological elements, with black indicating dominance of material from a specific period.

\begin{tabular}{|c|c|c|c|c|c|c|}
\hline Area & Assemblage characterisation & Meso & EN & $\mathbf{L N}$ & EBA & LBA \\
\hline Cairn 7/4 & In situ domestic assemblage & & & & & \\
\hline Cairn 7/6 & In situ domestic assemblage & & & & & \\
\hline Cairn 7/17 (7183) & Ritual/burial assemblage & & & & $(?)$ & \\
\hline Cairn 7/17 (cairn fill) & Mainly redeposited domestic material & & & & & \\
\hline Test Pit Grid E & In situ domestic assemblage & & & $?$ & $?$ & \\
\hline Test Pit Grid F & In situ domestic assemblage & & $?$ & $?$ & & \\
\hline Site 4 & Redeposited domestic material & & & & $?$ & $?$ \\
\hline Site 12 (incl. Grid B) & In situ domestic assemblage & & & & & $?$ \\
\hline Dun na Cluaich & Redeposited domestic material & & & & & \\
\hline Trench 1/Grid J & In situ domestic assemblage & & & & & \\
\hline The Knoll + adjacent areas & In situ domestic assemblage & & & & & \\
\hline
\end{tabular}

same field as both Grid J and Grid K. CAT959 is registered as having been found in 'the SE Corner' and CAT948 was recovered from an unspecified location; they represent activity in the period from the later part of the Early Neolithic to the Early Bronze Age.

\subsubsection{Conclusion: overview; assemblage date and character}

The 2,788 lithic artefacts were distributed across a number of settlement sites, burial monuments and disturbed or mixed contexts, and the sub-assemblages listed in the introduction were defined. These assemblages were then subjected to traditional typo-technological analysis, analysis of assemblage raw material composition, and attribute analysis of selected groups of debitage, allowing the various groups of finds to be characterised and dated. Some assemblages were proven to be almost chronologically 'clean' (eg Cairn 7/6/Trench 9 Ext, Cairn 7/17 (Pit 7183), Site 12, Dun na Cluaich and Grid J), whereas others turned out to represent multi-period activity. Table 4 gives an overview of the sites' dates and general character.

As shown in Table 4, assemblages from Area 1 tend to be relatively late, with a strong Later Bronze Age presence (eg Cairns 7/4 and 7/6/Trench 9 ), whereas assemblages from Area 2 tend to be relatively early, including one almost exclusively Early Neolithic assemblage (Dun na Cluaich), and one almost exclusively Late Neolithic assemblage (Grid J). Late Neolithic material dominates the Stoneyhill area in general (Cairn 7/17, Site 12 and Grid J), and Mesolithic finds are only present in the form of four stray microliths. Early Bronze Age material is probably present, but as no assem- blages are dominated by finds from this period, it has not been possible to gain precise information on the lithic typology, technology and raw material preference.

The composition of the main assemblages defines these as either in situ domestic assemblages, redeposited domestic assemblages or ritual/burial assemblages. Most are in situ domestic assemblages from settlement sites (Cairn 7/4, Cairn 7/6, Grid E, Grid F, Site 12, Grid J and Grid K), with the assemblages from Cairns 7/4 and 7/6 representing pre-cairn material. Cairn $7 / 4$ was most likely a prehistoric cairn, albeit of uncertain function, and Cairn $7 / 6$ was a modern clearance cairn. Three assemblages probably represent redeposited domestic material (Cairn 7/17 (cairn fill), Site 4 and Dun na Cluaich), although it is quite possible that the finds from Cairn 7/17 include small numbers of flint artefacts inserted with Beaker burials. The assemblage from Site 4 was recovered from around and under a number of probably post-medieval clearance cairns, whereas the Dun na Cluaich assemblage was redeposited during the recent exploitation of the Dun na Cluaich gravel quarry. Deviating flint type, tool ratio and use-wear ratio, as well as association with a rock-cut 'cist', suggest that the assemblage from Cairn 7/17 (Pit 7183) is a ritual or burial assemblage.

From the outset of the lithic analysis, the assemblages were preliminarily ranked as having more or less research potential. This judgement was based on assemblage size, as well as find contexts, and the assemblages were analysed in greater or lesser detail according to this ranking. The lithic analysis subsequently proved some 'promising' assemblages to be mixed multi-period accumulations (Table 4) and therefore of less use-value to the analyst than first 
anticipated. However, a number of these collections remained useful, and the following assemblages are of great value to the understanding of the Neolithic and Bronze Age periods in eastern Scotland: 1) Cairn 7/6/Trench 9; 2) Cairn 7/17 (Pit 7183); 3) Dun na Cluaich; and 4) Grid J. They shed light on the lithic industries of the local Early Neolithic (Dun na Cluaich), Late Neolithic (Grid J; possibly Cairn 7/17 (Pit 7183)) and Later Bronze Age periods (Cairn 7/6/Trench 9). As the finds from Trench 9 (knapping floor) and Grid J (substantial settlement area) were recovered approximately in situ, these assemblages may also prove valuable as part of future spatial analyses. In the present report, spatial analyses were cursory and only served to test the internal chronology of a limited number of assemblages (Trench 9, Cairn 7/17 and Grid J).

The greatest value of these assemblages undoubtedly regards the understanding of the lithicindustries of prehistoric eastern Scotland, and, by the construction of precise technological profiles, the formation of a supplementary dating tool for this period and region. As noted by other analysts (eg Warren 2006), Neolithic (and, for that matter Bronze Age) assemblages are relatively rare in eastern Scotland, and they are usually quite small. As demonstrated by Warren (2006, table 1), most Neolithic assemblages number a few tens or hundreds, and, generally, the post-Mesolithic assemblages from Stoneyhill are of similar sizes, or slightly larger. However, the largest Stoneyhill collection was recovered from Grid J, and it totals 850 lithic pieces, or approximately $40 \%$ more than the hitherto largest Neolithic assemblage from eastern Scotland (Deer's Den, Kintore: 633 pieces; Alexander 2000).

\section{The prehistoric industries of the Stoneyhill area}

The author originally hoped that it would be possible to produce precise characterisations (operational schemas) of early as well as late prehistoric industries. Unfortunately, Mesolithic finds are limited to four stray microliths, and the Early Neolithic assemblage from Dun na Cluaich did not include sufficient numbers of proximal ends to allow this. Only from Cairn 7/6, Cairn 7/17 (7183) and Grid J was it possible to produce statistically sound samples for attribute analysis.

These three samples have been provided with preliminary dates, based mainly on technological attributes, such as dimensions, proportions, percussion methods and preparation styles, and association with diagnostic types, or the absence of certain attributes and types. The main feature of all three assemblages is that they represent industries dominated by the production of flakes, and as the Early/Late Neolithic transition appears to correspond to a technological 'water-shed' with blade industries on one side and flake/blade and flake industries on the other (Ballin forthcoming a). The two ends of the Late Neolithic-Bronze Age period are relatively well defined (Manby 1974;
Ballin 2002a), showing how the Late Neolithic is a relatively sophisticated industry aiming at the production of robust blades/elongated flakes, whereas the Later Bronze Age is a simplistic industry aiming at the production of squat flakes.

As the finds from Grid $J$ include many of the types and attributes described by Manby (1974) in his discussion of the Yorkshire Late Neolithic, and frequently reported from Late Neolithic sites throughout Britain, this assemblage clearly dates to the beginning of the later prehistoric period. The flakes and cores from Cairn 7/17 (7183) have many traits in common with the finds from Grid J, but the smaller blank sizes and the more squat appearance of the cores suggest a later date, though probably still within the Late Neolithic period. The assemblage from Cairn 7/6 is even simpler, in technological terms, as it is based mainly on bipolar technique. The composition of the tools (eg Saville 1981; Herne 1991; Ballin 2002a), as well as the complete lack of invasive retouch (Clark 1936, 47), suggests that they may date to the Later Bronze Age period.

\section{The operational schema of Grid $\boldsymbol{J}$ (the Late Neolithic period)}

This sample consists predominantly of flint of the light olive-green group, which was procured from local gravel deposits (Table 5). The blanks are mainly elongated flakes (LW ratio all blanks 1.4). The assemblage includes several high-quality blades (LW ratio 2.7), most of which are crested pieces. A plot of the widths of the blanks results in an almost bell-shaped curve which indicates that the sample is likely to be chronologically unmixed (cf Ballin \& Johnson 2005); a small secondary peak is probably largely a result of the small sample size $(\mathrm{n}=70)$.

The operational schema of this industry is obviously phased, with the first stage representing careful core preparation. Basically, the shaping of the core rough-out follows the steps described by Roe (1981, fig. 3:9) in his discussion of the Late Acheulean/Mousterian Levalloisian, resulting first in the production of a thick 'tortoise' core with a relatively flat flaking-front and a more domed 'under-side' (Roe, Steps I-II). Only one such core was recovered from Grid J (CAT798, illus 15.27). Though most Late Neolithic 'tortoise' cores would have had an almost fully cortex-covered 'under-side' (as demonstrated by the many discarded 'flat cores' from this site), CAT798 has been almost completely decorticated.

In contrast to Palaeolithic Levalloisian cores, the core rough-outs of Grid J were provided not only with a finely faceted striking-platform (Roe, Step III), but also with two lateral crests along either side of the flaking-front. Scrutiny of the platform remnants of the site's crested blades shows that the slightly curved lateral crests met the platform at almost right- or obtuse angles. When the core rough-out was fully formed, the first blade/flake series was initiated by detaching the crests. These 
Table 5 Technological key-figures for the operational schemas of the assemblages from Trench 1/Grid J, Cairn 7/17 (7183) and Cairn 7/6. For comparison, the key-figures of three LBA samples from the Raunds area, Northamptonshire, have been included (Ballin 2002a). The populations have been sequenced according to their estimated dates. (1) Per cent of platform blanks; (2) platform blanks/bipolar blanks.

\begin{tabular}{|c|c|c|c|c|c|}
\hline & $\begin{array}{r}\text { Early LN } \\
\text { Grid J } \\
\text { flakes/blades }\end{array}$ & $\begin{array}{r}\text { Early LN } \\
\text { Grid J } \\
\text { blades }\end{array}$ & $\begin{array}{r}\text { Late LN/EBA } \\
\text { Cairn 7/17 } \\
(\mathbf{7 1 8 3})\end{array}$ & $\begin{array}{r}\text { LBA } \\
\text { Cairn 7/6 }\end{array}$ & $\begin{array}{r}\text { LBA } \\
\text { Raunds }\end{array}$ \\
\hline Population & $\mathrm{n}=70$ & $\mathrm{n}=21$ & $\mathrm{n}=80$ & $\mathrm{n}=96$ & 3 samples \\
\hline Grey flint & $1 \%$ & $0 \%$ & $100 \%$ & $0 \%$ & NA \\
\hline Flint of the orange group & $4 \%$ & $29 \%$ & $0 \%$ & $77 \%$ & NA \\
\hline Flint of the light olive-green group & $95 \%$ & $71 \%$ & $0 \%$ & $23 \%$ & NA \\
\hline Primary material & $4.3 \%$ & $0 \%$ & $7.5 \%$ & $15.6 \%$ & $10-12 \%$ \\
\hline Secondary material & $42.8 \%$ & $24 \%$ & $55.0 \%$ & $46.9 \%$ & $50-65 \%$ \\
\hline Tertiary material & $52.9 \%$ & $76 \%$ & $37.5 \%$ & $37.5 \%$ & $25-38 \%$ \\
\hline Av. length & $31.8 \mathrm{~mm}$ & $43.5 \mathrm{~mm}$ & $24.6 \mathrm{~mm}$ & $24.1 / 24.6 \mathrm{~mm}(2)$ & $19-21 \mathrm{~mm}$ \\
\hline Av. width & $23.5 \mathrm{~mm}$ & $16.4 \mathrm{~mm}$ & $20.5 \mathrm{~mm}$ & 21.6/17.0mm (2) & $18-20 \mathrm{~mm}$ \\
\hline Av. thickness & $8.0 \mathrm{~mm}$ & $6.8 \mathrm{~mm}$ & $6.3 \mathrm{~mm}$ & $5.9 / 6.0 \mathrm{~mm}(2)$ & $6-7 \mathrm{~mm}$ \\
\hline Av. platform remnant width & $14.6 \mathrm{~mm}$ & $7.8 \mathrm{~mm}$ & $11.4 \mathrm{~mm}$ & $13.5 \mathrm{~mm}(1)$ & $11-13 \mathrm{~mm}$ \\
\hline Av. platform remnant depth & $5.3 \mathrm{~mm}$ & $3.3 \mathrm{~mm}$ & $4.0 \mathrm{~mm}$ & $4.2 \mathrm{~mm}(1)$ & $4-5 \mathrm{~mm}$ \\
\hline Av. flaking angle & $100.8^{\circ}$ & $103^{\circ}$ & $106.1^{\circ}$ & $106.5^{\circ}(1)$ & $109-113^{\circ}$ \\
\hline Av. no. of parallel dorsal ridges & 1.10 & 1.5 & 0.89 & 0.60 & Almost none \\
\hline $\mathrm{LW}$ ratio & 1.4 & 2.7 & 1.2 & $1.1 / 1.5(2)$ & $1.0-1.1$ \\
\hline WTh ratio & 2.9 & 2.4 & 3.3 & $3.7 / 2.8(2)$ & Not calc. \\
\hline WD ratio & 2.8 & 2.4 & 2.6 & $3.2(1)$ & $2.7-2.8$ \\
\hline Platform : bipolar technique & 100:00 & 100:00 & 100:00 & $35: 65$ & 100:00 \\
\hline Pronounced bulbs & $80.9 \%$ & $62 \%$ & $81.3 \%$ & $73.5 \%(1)$ & $72-83 \%$ \\
\hline Multiple bulbs & $25.0 \%$ & $0 \%$ & $16.3 \%$ & $8.8 \%(1)$ & $13-16 \%$ \\
\hline Platform collapse & $2.9 \%$ & $5 \%$ & $8.8 \%$ & $1.0 \%$ & $1.9 \%$ \\
\hline Split bulbs & $0.0 \%$ & $0 \%$ & $1.3 \%$ & $5.2 \%$ & $5-7 \%$ \\
\hline Impact scars & $29.4 \%$ & $10 \%$ & $45.0 \%$ & $38.2 \%(1)$ & $43-57 \%$ \\
\hline No dorsal preparation & $55.2 \%$ & $25 \%$ & $71.2 \%$ & $97.1(1)$ & $80-90 \%$ \\
\hline Trimming & $26.9 \%$ & $35 \%$ & $15.0 \%$ & $2.9 \%(1)$ & $10-20 \%$ \\
\hline Abrasion & $17.9 \%$ & $40 \%$ & $13.8 \%$ & $0.0 \%$ & $0.0 \%$ \\
\hline Cortical platform & $10.6 \%$ & $0 \%$ & $7.5 \%$ & $17.7 \%(1)$ & $31-37 \%$ \\
\hline Plain platform & $27.3 \%$ & $45 \%$ & $33.8 \%$ & $61.8 \%(1)$ & $42-45 \%$ \\
\hline Faceted platform & $36.4 \%$ & $25 \%$ & $36.3 \%$ & $20.6 \%(1)$ & $19-21 \%$ \\
\hline Finely faceted platform & $25.8 \%$ & $30 \%$ & $16.3 \%$ & $0 \%(1)$ & $0.0 \%$ \\
\hline Hinged terminations & $17.8 \%$ & $20 \%$ & $16.4 \%$ & $16.7 \%$ & $40-48 \%$ \\
\hline
\end{tabular}

blanks were long, elegant blades (not uncommonly with LW ratios of four or more), due to the welldefined dorsal guide ridge. As blanks were detached further and further towards the centre of the flat, or slightly domed, flaking-front, these blanks grew increasingly shorter and broader. Due to the flat flaking-fronts, the broad central flakes frequently removed the cores' apex by plunging. Considering this 'design flaw', it is puzzling that a 'Levallois-like' approach into the British Late Neolithic was introduced. It is possible that this particular technique was perceived as beneficial, as it allowed the production of long blades for, for example, serrated pieces (eg CAT741 illus 16.35 and 874) and broad flakes for chisel-shaped arrowheads (eg CAT881, 890, illus 16.30) within the same operational schema.

Before and during the detachment of flakes, the platform-edge was prepared. This primarily took the form of fine faceting of the platform surface immediately behind the platform-edge (horizontal trimming), occasionally combined with, or replaced by, traditional vertical trimming and/or abrasion of 
the platform-edge. The flakes and blades were then detached by the application of mainly hard percussion, as demonstrated by the many pronounced bulbs, multiple bulbs and incipient cones or impact scars. As demonstrated by the average flaking angle of the assemblage $\left(c 100^{\circ}\right)$, the hammerstone met the platform at an almost right angle.

As noted by Manby (1974), Late Neolithic blanks are characterised by having finely faceted platform remnants, which is a direct consequence of the choice of core shape and the applied systematic core preparation. Most likely, platforms were not rejuvenated by detaching traditional core tablets, and the 'core tablets' recovered in connection with this assemblage are most likely ordinary flakes which have been erroneously classified as a consequence of their finely faceted platform remnants (incorrectly perceived as traditional trimming) and their likeness to traditional platform rejuvenation flakes.

Occasionally, the 'flat cores' were re-orientated in an attempt to exhaust the cores completely. First, they were provided with a second, opposed platform and, later, possibly even a third platform, transforming them into irregular 'flat cores'. Only in one case (CAT885) was it attempted to exhaust a 'flat core' by flaking its secondary face (the 'under-side'). The Late Neolithic 'flat cores' were supplemented by a small number of traditional single-platform, opposed-platform and irregular cores.

This operational schema is to be discussed further in a forthcoming paper (Ballin forthcoming d).

The operational schema of Cairn $7 / 17$ (Pit 7183) (the later Late Neolithic period)

As argued in connection with the general characterisation of this assemblage, the finds from deposit 7183 and its immediate surroundings are likely to have been produced and deposited as a single event, and they are contemporary in the stricter sense of the word. This is clearly demonstrated by the regular and symmetrical bell-shaped curve produced by plotting the widths of the blanks.

The sample is completely dominated by homogeneous grey flint, which probably represents careful selection of local pebbles and cobbles. This selection process would have included not only consideration of flint quality, as the grey flint is finer and more homogeneous than for example flint of the light olive-green group, but also consideration of colour, as grey flint is less common at Stoneyhill than flint of the orange and light olive-green groups (cf Lebour 1914; Darvill 2002).

The operational schema seems to be a slightly less strict version of the one defined for Grid J. Core rough-outs were produced in a similar manner, but resulting in somewhat chubbier, less elegant 'flat cores' (CAT543, 547, 548, 554), with shorter, more irregular lateral crests (CAT546, 551, 552, 553) than the long straight crests characterising the collection from Grid J. The blanks themselves are also notably smaller, more irregular and shorter (LW ratio 1.2).
The preparation of the cores' platforms and platform-edges followed the same general schema as in Grid J, although with less extensive fine faceting (16.3\% against $25-30 \%)$, trimming (15.0\% against $27-35 \%$ ) and abrasion (13.8\% against 18 $40 \%$ ) and, consequently, more specimens without dorsal preparation $(71.2 \%$ against $25-55 \%)$. The flakes were then detached by the application of hard percussion, as demonstrated by the many pronounced bulbs, multiple bulbs and incipient cones or impact scars. Compared to the sample from Grid J, the hammerstone met the platform at a more acute angle, generally producing more obtuse angles between the flakes' ventral faces and platforms $\left(106.1^{\circ}\right.$ against $\left.100-103^{\circ}\right)$. The flakes are sub-divided into two groups with either approximately right flaking angles or obtuse flaking angles, possibly representing flakes from the decortication process (obtuse angles) and actual target flakes (right angles).

\section{The operational schema of Cairn 7/6/Trench 9 (the Later Bronze Age period)}

This sample differs from the previous two by being predominantly in flint of the orange group. In the present case, the mainly honey-brown flint is of a relatively impure sort (group 2, Section 5.2.3) which is likely to be local pebble flint. The material formed part of a discrete knapping floor, suggesting general contemporaneity. Plotting the widths of platform flakes and bipolar flakes results in two asymmetrical, single-peaked bell-shapes.

This sample is clearly dominated by the application of bipolar technique, with some use of platform technique (platform:bipolar ratio 35:65). The two subsamples differ considerably in size and proportions, with platform flakes being as squat as flakes from other Later Bronze Age assemblages (eg Raunds, Ballin 2002a), whereas the bipolar flakes tend to be more elongated (LW ratios, 1.1 and 1.5, respectively). The latter is probably a function of many nodules splitting in a manner creating so-called 'orange-segment flakes' when worked in hammerand-anvil technique (see Ballin 1999). These flakes tend to retain the length of the original nodule, but they are only approximately half as wide as that nodule, thereby acquiring an elongated shape.

The flakes from the small sub-sample of platform flakes (34 pieces) were generally prepared in a very simplistic manner, or not at all. The platforms are mostly cortical $(17.7 \%)$ or plain $(61.8 \%)$, with few faceted (20.6\%) and no finely faceted platforms; the platform-edges are generally unprepared (97.1\%), supplemented by as little as $2.9 \%$ trimmed edges. The platform cores were reduced by the application of hard percussion, as demonstrated by pronounced bulbs, multiple bulbs and incipient cones or impact scars. The flaking angle $\left(106.5^{\circ}\right)$ of this sample corresponds to that of the Cairn 7/17 sample. The presence $(5.2 \%)$ of split bulbs is a direct result of a robust percussion technique. 


\section{Comparison}

As argued in a number of papers (eg Ballin 2002a; 2004), operational schemas of lithic industries (technological profiles) tend to be highly diagnostic, and they usually allow clear distinction between assemblages from different periods or phases.

The chronological sequencing of the three samples is based on several sets of attributes, but the LW ratio appears to be a practical point of departure. The combined flakes and blades from Grid $J$ have a LW ratio of 1.4 (the blades alone have a ratio of 2.7), suggesting that they are elongated and probably not much later than the Early/Late Neolithic transition, when blade industries were replaced by flake/blade, and later flake, industries (Ballin forthcoming a). The platform blanks of the sample from Cairn 7/6 have a LW ratio of 1.1, that is, they are squat. As demonstrated in Ballin (2002a), squat platform flakes characterise Later Bronze Age assemblages. With a LW ratio of 1.2, the flakes from Cairn 7/17 (7183) are likely to post-date the blanks from Grid $\mathrm{J}$, and pre-date the blanks from Cairn 7/6.

This impression of gradual degeneration is supported by other attributes, such as the average number of parallel dorsal ridges (the ridge index or ratio). This parameter is, indirectly, a measure for the regularity of blanks, and the three samples develop from having a ridge index of 1.1 (2.7 for the Grid J blades) over 0.89 to 0.6 . The most elegant prehistoric blades may have up to three or four parallel dorsal ridges, whereas the much simpler and more unsystematically manufactured blanks of British later prehistory generally have ridge indexes around or below 1 . The index of the sample from Cairn 7/6/ Trench 9 (0.6) indicate that only every second flake from this assemblage had a dorsal ridge running roughly parallel to its edges.

Other chronological indicators of this development are increasing numbers of primary flakes $(4.3 \% \Rightarrow 7.5 \% \Rightarrow 15.6 \%)$, and simpler preparation of platforms (plain platforms: $27.3 \% \Rightarrow 33.8 \% \Rightarrow$ $61.8 \%$ ) and platform-edges (no dorsal preparation: $55.2 \% \Rightarrow 71.2 \% \Rightarrow 97.1 \%$ ). Usually, indicators of robust techniques (eg multiple bulbs and incipient cones) and the numbers of hinged terminations also increase during the later prehistoric period, but this is not the case in the project area. The reason for this situation is most likely the small sample sizes, such as the size of the platform flake sub-assemblage from Cairn 7/6. Though the general sample from this location numbers 96 flakes, which is statistically acceptable, the sub-assemblages (platform and bipolar flakes) are smaller and of critical numerical sizes ( 34 and 62 flakes, respectively).

The finely faceted platform remnants of the Late Neolithic samples are obviously functions of the particular 'Levallois-like' core types produced on those sites.

Results and future perspectives

The Stoneyhill Project provides a snap-shot of the east of Scotland post-Mesolithic lithic industries. Its assemblages complement the already available, traditionally quite small assemblages assigned to this region's Neolithic and Bronze Age periods (cf Warren 2006), but they also expand our understanding of the associated industries by allowing the construction of the first detailed technological profiles. The Late Neolithic profile for Grid J may be valid throughout Britain (cf Ballin forthcoming d), whereas the profiles for Cairn 7/17 (7183), and Cairn 7/6 may only have regional validity. Though it was not possible to carry out an attribute analysis of the blanks from Dun na Cluaich, this assemblage does represent a valuable supplement to present knowledge on the Early Neolithic blade industries of east Scotland (since the production of the present report, additional Early Neolithic assemblages have been excavated, shedding new light on the period's lithic technology; eg Warren 2009 and Ballin forthcoming a).

Combined, the debitage, cores and tools found at Stoneyhill provide a representative picture of not only the technology of post-Mesolithic industries of eastern Scotland, but they also shed light on the period's lithic typology and raw material preferences and, to a degree, procurement strategies. The latter mainly include local procurement, but possible importation is also suggested.

It is the author's hope that, in the future, it will be possible to build up a sequence of securely dated technological profiles, linked to lithic typologies and different procurement patterns (Ballin forthcoming a represents a first step in this direction). This set of chronologically well-defined profiles and inventories would be an invaluable resource in the future dating of assemblages which cannot be dated by radiocarbon dating or pottery association. Some of these profiles and inventories may have national validity (like that of Grid J), whereas many may only be of local relevance. The technological profile of the Grid $\mathrm{J}$ industry is to become the focus of a more detailed future paper (Ballin forthcoming d).

As indicated above, several of the Stoneyhill assemblages have high research potential. Further typo-technological scrutiny may add more details on the lithic industries per se, but these assemblages may also add to the understanding of the Buchan Ridge area and its flint mines (procurement strategies). Intra-site spatial analysis of sites, such as Cairn 7/6 and Grid J (illus 3 and 4) may shed light on settlement organisation and on-site human behaviour.

\subsection{Coarse stone, by Adam Jackson}

A single coarse stone object was recovered from topsoil close to North Aldie Farm. The object is a sandstone boulder saddle quern, with a single dished work surface caused by heavy grinding. The quern is of crude and expedient form, showing no evidence of any modification other than that caused during 
Table 6 Composition of carbonised cereal remains and other plant remains

\begin{tabular}{|c|c|c|c|c|c|c|c|c|}
\hline \multirow[t]{4}{*}{ Latin name } & \multirow[t]{4}{*}{ Plant part } & \multicolumn{7}{|l|}{ Common name } \\
\hline & & Feature no. & $7 / 1$ & $16 / 1+2$ & $81 / 1$ & $81 / 2$ & $81 / 3$ & 7182 \\
\hline & & Sample no. & 8 & 10 & 27 & 29 & 30 & 38 \\
\hline & & Volume (litres) & 4 & 14 & 3 & 12 & 4 & 12 \\
\hline Avena sp. & caryopsis & oat & 1 & & & & & \\
\hline Hordeum vulgare var. nudum & caryopsis & naked barley & & 1 & 111 & 584 & 128 & \\
\hline Hordeum sp. & caryopsis & barley & & & & 1 & & \\
\hline Cereal indet & caryopsis & indeterminate & & & & 1 & & \\
\hline Corylus avellana $\mathrm{L}$ & nutshell & hazel & & & + & + & & \\
\hline Monocotyledon & rhizome & & & & & & & 2 \\
\hline Non-cereal remains & internode & & & & & & 1 & \\
\hline
\end{tabular}

use. Saddle querns are found on sites of prehistoric and later date throughout Scotland.

\subsection{Charcoal and charred plant remains, by Mhairi Hastie and Mike Cressey}

Thirty-four bulk soil samples were subjected to flotation and wet sieving. The quantity of carbonised remains present in the samples was extremely low, with only six samples containing any cereal grain (Table 6).

The most common component by far was cereal grain. Grains of barley were the most frequently encountered and the better preserved of these were identified as the naked variety (Hordeum vulgare var. nudum). Of significance is the large concentration of well-preserved naked barley grain recovered from the fill of Pit F81. The cache of naked barley (823 grains) suggests a Bronze Age or earlier date for the feature, naked barley being principally replaced as a main crop by hulled barley during the Iron Age. Two grains were extracted for radiocarbon dating (Section 5.5 below) and produced a Neolithic date. This date is consistent with the flint and pottery assemblages it was associated with.

The amount of cereal grain present was high, with over 40 grains per litre of soil recovered from F81/2, and the plant assemblage was formed principally of cereal grain, with no cereal chaff or agricultural weed seeds recovered. The quantity and composition of the assemblage suggests that the remains originated from a store of clean grain.

The majority of grains were extremely well preserved and showed little sign of abrasion, indicating that they were unlikely to have undergone much movement once charred or after burial. This suggests either that the grains were burnt in situ or the material had been dumped into the pit immediately following charring.

No other high concentrations of cereal grains or other carbonised plant remains were uncovered during the excavation. One oat grain was recovered from F7/1 (post-hole within arc), but in the absence of accompanying well-preserved florets the grain could not be identified to species level. Fragments of hazelnut shell (Corylus avellana) were recovered from F81 and F88/1, the fill of an isolated Pit 60m to the north of F81.

The level of preservation within the charcoal assemblage was good, with only minimal abrasion recorded, indicating that the assemblage had not been subjected to mass-movement once buried. One fragment had wormholes, a common feature of dead branchwood. Virtually all of the charcoal was amorphous, suggesting that taphonomical processes had modified the charcoal after firing. Only a single context (7182, Cairn 7/17) contained roundwood fragments, of slender hazel twigs. The rest of the samples were dominated by non-round material. Occasional larger blocky fragments of charcoal were present. Only one fragment of charcoal had evidence of trimming (F81/3).

Four wood species are represented in the charcoal assemblage. Hazel (Corylus avellana) dominates (11.8g, 141 identifications), birch (Betula sp.) and oak (Quercus sp.) share the same frequency (44 identifications each, $2.9 \mathrm{~g}$ and $2.2 \mathrm{~g}$ respectively), with willow (Salix sp.) present in trace amounts (0.35g, five identifications)

All species of wood charcoal present are native to Scotland and would have grown within the locality of the site during prehistory. Owing to the low frequency of the charcoal assemblage any attempt to assess the species composition in terms of woodland exploitation would be meaningless.

\subsection{Radiocarbon dating}

The paucity of ecofacts restricted the opportunities for radiocarbon dating. The site as a whole contained few negative features within which suitable organic remains were preserved and although none contained clearly in-situ deposits, pit F81 appeared to contain 
Table 7 Radiocarbon dates (calibrations, Bronk Ramsey 2005)

\begin{tabular}{llllll}
\hline Context & Sample & Sample Material & Date BP & Calibrated date (1 $\boldsymbol{\sigma})$ & Calibrated date 2 $\boldsymbol{\sigma}$ \\
\hline 762 & SUERC-9742 (GU-13907) & Humic acid & $155 \pm 35$ & Recent & Recent \\
F81/3 & Poz-14557 & Naked barley & $4540 \pm 40$ & $3370-3090 \mathrm{BC}$ & $3370-3110 \mathrm{BC}$ \\
F81/3 & Poz-14558 & Naked barley & $4490 \pm 35$ & $3350-3030 \mathrm{BC}$ & $3340-3090 \mathrm{BC}$ \\
\hline
\end{tabular}

rapidly infilled material derived, if not from in-situ burning, then from nearby cereal processing. The date (Table 7) calibrates to the second half (or fourth quarter) of the fourth millennium BC, around the transition from the early to middle Neolithic. The pottery has been identified as Impressed/Unstan Ware and the radiocarbon determination is in agreement with existing dates for such wares.
In an attempt to date the lithic scatter in Trench 9 , a sample of humic acid was extracted from a Kubiena tin sample covering context 762 . This was submitted for dating but the result (Table 7) was clearly anomalous. Humic acid dating (and the associated dating of humin and fulvic acid) have previously been found to be unreliable (Shore et al 1995) but no alternative media were available. 


\section{DISCUSSION AND CONCLUSIONS}

\subsection{Introduction}

The fieldwork at Stoneyhill was spread over a year and provided a rare opportunity for the in-depth study of an apparently inauspicious part of a small Buchan valley. This area was the subject of a commercial development so the archaeological remains described above are not the result of favourable site or location selection by archaeologists. The results may therefore be seen as a truer reflection of the actual picture of past human activities in the landscape than the results of selected-site excavations could be.

An overview of the impact of developer-led archaeology in Scotland between 1990 and 2003 (Philips \& Bradley 2004) includes a map-based summary of the evidence from Buchan (ibid, Figs 3-5). Mesolithic evidence was not forthcoming, and the Neolithic was represented by a single site. Better represented is the Bronze Age, but still only three sites are highlighted. Stoneyhill is clearly an important addition to the baseline archaeological evidence from Buchan investigated through developer funding, and should assist in informing future work in the area.

Within Stoneyhill, the widespread extent and varied nature of the remains detailed above entirely justified the requirement from Aberdeenshire Council, Planning and Development for the extensive archaeological survey, evaluation, excavation and monitoring of the development, even where the baseline archaeological resource tended to suggest low potential.

The extent of the work, and the geography of the site, in particular encompassing both sides of a valley, has allowed an insight into the inter-relationships between monuments over time, observations that greatly increase their potential for interpretation. This may throw up problems, but also allows preconceived theories to be challenged.

\subsection{Prehistoric activity}

The prehistoric structures at Stoneyhill consist of two cairns $(7 / 4,7 / 17)$, one apparently a result of field clearance and one of a funerary nature, a postsetting/arc with nearby post-holes/pits, and two isolated pits. The field clearance cairn is assumed to be prehistoric on the basis of soil stratigraphy, morphology, lichen growth and the recovery of lithic artefacts from amongst and under the stones. It is possible that these cairns were once part of a much larger site, recorded on the OS First Edition, which were removed by the 1950s Stoneyhill Quarry.

Some, at least, of these sites may have been clearance cairns. Whilst the reliability of the accounts may be questioned, the OS Name Book (1868) is of assistance in this regard as it notes that neither bones nor artefacts were recovered when they were 'opened'(Site 7).Although containing some large stones, similar to those forming the modern cairns, Cairn 7/4 was partially grassed over and the exposed stones were lichen-covered. Cairn 7/17 was distinguished by its low profile, gorse covering and, when exposed, by smaller cobbles.

Prehistoric clearance cairns and other types of cleared stone accumulations are widespread in Scotland. They are often formed around, or in, an obstacle to cultivation, for example a large stone, surface bedrock or a wet area. The former was the case at Stoneyhill. Such a monument would naturally be, or become, the focus for later events, knapping for instance, even if only by virtue of a place to sit whilst undertaking the task. This being the case, the Late Bronze Age lithic artefacts may provide a terminus ante quem for the cairn. Indirect supporting evidence for cultivation in the area comes from the cartographic evidence for the missing cairns and potentially direct evidence from the ard-mark near Cairn 7/17. On the other hand, the well-defined nature of the lithic scatter under Cairn 7/6 (providing a terminus post quem date for the covering cairn) suggests there has been minimal cultivation since the Late Bronze Age.

Prehistoric burial cairns are also widespread in Scotland. They may be formed on an obstacle to cultivation (which may also be a point of visibility) or adjacent to an existing landmark or monument, which may often be destroyed in the process.

In the case of Cairn 7/17, the presence of lithic artefacts and pottery ensures some survival of the evidence. The deposition of the grey flint assemblage by Pit 7181, suggested by Ballin to be one episode and likely to have been specifically produced for deposition, is dated to the Late Neolithic. The Beakers date to the period 2500/2400-2200/2100 $\mathrm{BC}$, which accords with the latest part of the Late Neolithic, and so it seems reasonable to assume that both assemblages were inserted at the same time for a funerary or other ritual purpose. It seems unlikely that the cist is significantly earlier than the construction of the cairn. The cairn material incorporates lithic artefacts of Early Neolithic, Late Neolithic and Early Bronze Age date which form a more diverse, redeposited domestic assemblage, probably a result of the disturbance and reworking of domestic material in the vicinity during the construction and maintenance of the cairn.

What is without doubt is that the rock-cut cist represents the only example of its type in Buchan (I 
Shepherd, pers comm). Similar examples of rock-cut funerary pits occur at Ferndale in Orkney (Duffy 2005) and at Craigscorry near Beauly (Callander 1925). At neither are the side slabs of conventional cists mimicked in the construction, and it may be that the particular geology and angle of the strata at Stoneyhill provided a rare opportunity for this feature.

On the western side of the valley, the pits and post-holes under ploughsoil have no ready parallels in the area. The fills of the features interpreted as post-holes suggest that the structure(s) may have been dismantled. No evidence for the function of the post-setting was forthcoming. With the open end facing across the valley to Cairn 7/17, an association either with the cairn or a previous monument on the site may be inferred. Assumed to be Late Neolithic or Early Bronze Age, the pottery from the post-setting is of a similar date to the finds from the cairn. Unlikely to be merely a windbreak, were the post-holes to form the base for a solid screen any occupant would have their view directed towards the monument on the horizon and be isolated from the remaining landscape, a concept recalling the isolation experienced within henges.

Within the post-setting, the recovery of pottery and hammerstones solely from the features at the terminals of the arc may indicate deliberate or structured deposition. There was unfortunately insufficient charcoal for dating purposes and in any case the taphonomy of the carbonised material is uncertain. Although possessing a close spatial relationship, the nucleus of the Late Neolithic lithic scatter did not overlie the post-setting and may therefore be unrelated to the features. In addition, the scatter is domestic in character and the features less obviously so by dint of their aspect, facing across the valley to the cairn. The pottery would be closely related in date to both lithic assemblages. Little can be said about nearby Pit F70 other than it may contain pottery similar in character to the Beaker ceramics in the cairn, but its presence strengthens the connection between the west and east sides of the valley. F81 appears to be an isolated Mid/Late Neolithic feature which may have been associated with some aspect of cereal drying or processing and the Impressed Ware/Unstan Ware pottery is a useful addition to the insubstantial corpus of sites containing this material in the north-east of Scotland.

Any discussion of the archaeology in this part of Buchan cannot escape from the presence of flint. John Milne, writing in 1892, recognised its dominance over 'all other types of surface stones' $(1892,189)$ between the Water of Cruden, $5 \mathrm{~km}$ to the south of Stoneyhill and the River Ugie, $7 \mathrm{~km}$ to the north near Peterhead. The Stoneyhill site is in the centre of this area. Several general observations about the results of the fieldwork at Stoneyhill in relation to the lithic assemblage can be made:

- Worked flint was remarkably commonplace within the topsoil across the site, with significant numbers of the overall assemblage (the 11 subassemblages) being found in widely spread parts of the development.

- Useful assemblages were most common in those areas not recently cultivated, but the most important assemblage was recovered from an annually cultivated field.

- Seven of the eleven sub-assemblages have the character of in-situ domestic assemblages and five of these were recovered from areas not subjected to modern, or perhaps any, ploughing. In none of these cases were they associated with surviving structural remains. This observation has implications for the assumption that assemblages of domestic character in ploughed fields were associated with shallow-founded or vestigial structures.

Conversely and surprisingly, the only in situ domestic sub-assemblage to be associated with anything that could be described as a structure at Stoneyhill was recorded in an annually ploughed field.

The lithic scatters recorded at Stoneyhill vary from what may be single knapping events (Trench $9 ; 769,770,771)$ to scatters representing extended periods of activity (Dun na Cluaich; Grid J). They have suffered varying degrees of post-depositional disturbance, with those in Trench 9 being apparently undisturbed and others in Area 1 being the result of casual (if frequent) loss or discard. Much of the remainder derives from disturbed contexts which include incorporation into ploughsoil (Grid $\mathrm{J})$ or machine clearance and inclusion in bunded topsoil (Dun na Cluaich).

Flint scatters are recognised as an indicator of prehistoric occupation and, that being the case, the landscape within Stoneyhill was widely settled. Numerous flint scatters are recorded in the landscape around Stoneyhill and it should come as no surprise that extensive fieldwork of the type described here should greatly increase this number.

\subsection{Conclusions}

The conclusion resulting from the archaeological fieldwork at Stoneyhill must be that archaeological input into the development process can enable the remains present within it to be located through careful trench positioning and a knowledge of the types of site likely to be found in the area.

The input of Aberdeenshire Council in requiring extensive monitoring of topsoil removal during the watching brief was of benefit in allowing well-defined smaller sites not discovered during the evaluation to be located. Further, a willingness on the part of an interested client to modify agreed programmes of archaeological work in the light of unexpected discoveries was noteworthy.

The fieldwork revealed just how widespread were the traces of past human activity within an unpromising Buchan valley, with most of the testpit grids revealing lithic assemblages characteristic 
of prehistoric settlement-based activity, from the Mesolithic to the Bronze Age. Even in the most definitive of these locations however (Dun na Cluaich and Grid J), no clearly settlement-related features could be found.

Overall,theopportunity toinvestigatea substantial part of what may be seen as a typical flint-producing area of the Buchan landscape was an important one and the extent of the work has been justified by the recovery of nationally important lithic assemblages and by the recognition of changing procurement strategies over time in the Buchan Gravels. 


\section{ACKNOWLEDGEMENTS}

CFA wishes to thank Stoneyhill Waste Management Ltd, now part of SITA UK Ltd, for funding the project. Notable on-site assistance was provided by Glenn Jones, Alistair Speid, Dougie Kelman and Wayne the driver. We also wish to thank the late Ian Shepherd of Aberdeenshire Council, Planning and Environment Services and both Katherine Donnachie and Andy Taylor of Aberdeenshire Council, Development Control for undertaking site visits.

The site assistants who ably excavated the remains, despite the far from ideal conditions of working next to a landfill site, were John Bendicks, George Geddes, Douglas Gordon, Dave Harding, Magnus Kirby, Grant Lock, Tom McCulloch, Jennifer Marshall, Stuart Mitchell, Steven Orr, InGrid Stephenson, Andrew Stockdale and Charlotte Westoby.

Illustrations are by Kevin Hicks, George Mudie and Leeanne Whitelaw. Drafts of this report were edited by Sue Anderson and Andrew Dunwell, and an anonymous referee. Responsibility for the final form and contents of this report rests with the authors and CFA Archaeology Ltd. 


\section{REFERENCES}

\subsection{Bibliographic}

Abercromby, P 1711 The Martial Achievements of the Scots Nation. Robert Freebairn, Edinburgh.

Alexander, D 1997 'Excavation of pits containing decorated Neolithic pottery and early lithic material of possible Mesolithic date at Spurryhillock, Stonehaven, Aberdeenshire', Proc Soc Antiq Scot, 127 (1997), 17-27.

Alexander, D 1999 Stoneyhill Landfill, Peterhead - proposed extension: Archaeological Survey for Environmental Assessment. CFA Archaeology Ltd, Report No. 482.

Alexander, D 2000 'Excavations of Neolithic pits, later prehistoric structures and a Roman temporary camp along the line of the A96 Kintore and Blackburn Bypass, Aberdeenshire', Proc Soc Antiq Scot, 130, 11-75.

Anderson, A O 1922 Early Sources of Scottish History $A D$ 500-1286 (2 vols). Oliver \& Boyd, Edinburgh.

Ashton, N; Dean, P \& McNabb, J 1991 'Flaked flakes: what, when and why?', Lithics, 12, 1-11.

Ballin, T B 1999 'Bipolar Cores in Southern Norway - classification, chronology and geography', Lithics, 20 (1999), 13-22.

Ballin, T B 2002a 'Later Bronze Age flint technology: a presentation and discussion of post-barrow debitage from monuments in the Raunds area, Northamptonshire', Lithics, 23 (2002), 3-28.

Ballin, T B 2002b The quartz artefacts from Lussa River, Isle of Jura. Unpublished report.

Ballin, T B 2004 'The Mesolithic Period in Southern Norway: material culture and chronology', in A Saville (ed) Mesolithic Scotland and its Neighbours. The Early Holocene Prehistory of Scotland, its British and Irish Context, and some Northern European Perspectives, 413-38. Soc Antiq Scot, Edinburgh.

Ballin, T B forthcoming a 'Neolithic and Bronze Age lithic industries from eastern Scotland - a comparative study', Tayside \& Fife Archaeological Journal.

Ballin, T B forthcoming b 'Struck flint from West Cotton, Irthlingborough and Stanwick/Overview of the lithic evidence', in J Harding \& F Healy Raunds Area Project. The Neolithic and Bronze Age Landscapes of West Cotton, Stanwick and Irthlingborough, Northamptonshire.

Ballin, T B forthcoming c 'The lithic finds', in $\mathrm{M}$ Johnson \& K Cameron A Bronze Age Cremation Cemetery at Skilmafilly, Near Maud, Aberdeenshire, and other Prehistoric Sites in Aberdeenshire. Excavations 2001. Scottish Archaeological Internet Reports.
Ballin, T B forthcoming d 'The Levalloisian of Late Neolithic Britain, and other operational schemas of the later prehistoric period. A report from the Stoneyhill Project, Aberdeenshire', Lithics.

Ballin, T B \& Johnson, M 2005 'A Mesolithic chert assemblage from Glentaggart, South Lanarkshire, Scotland: chert technology and procurement strategies', Lithics, 26, 57-86.

Barclay, G J \& Russell-White, C J 1993 ‘Excavations in the ceremonial complex of the fourth to second millennium BC at Balfarg/Balbirnie, Glenrothes, Fife', Proc Soc Antiq Scot, 123, 43-210.

Barclay, G J; Carter, S P; Dalland, M M; Hastie, M; Holden, T G; MacSween, A \& Wickham-Jones, C R 2001 'A possible Neolithic settlement at Kinbeachie, Black Isle, Highland', Proc Soc Antiq Scot 131, 57-85.

Bordes, F \& Gaussen, J 1970 'Un Fonde de tente Magdalénien près de Mussidan (Dordogne)', Frühe Menschheit und Umwelt 1, 313-29.

Bridgeland, D R; Saville, A \& Sinclair, J M 1997 'New evidence for the origin of the Buchan Ridge Gravel, Aberdeenshire', Scottish Journal of Geology, 33 (1), 43-50.

Bronk Ramsey, C 2005 Ox-Cal version 3.10

Callander J G 1906 'Notice of three urns of the drinking-cup type and other relics discovered in a mound at Forglen, Banffshire', Proc Soc Antiq Scot, 40, 279-90.

Callander, J G 1925 'Notes on (1) A Bronze Age grave at Craigscorry, Beauly, Invernesshire, and (2) Two urns from Aberdeenshire', Proc Soc Antiq Scot, 59 (1924-5), 204-10.

Cameron, K 2002 'The excavation of Neolithic pits and Iron Age souterrains at Dubton Farm, Brechin, Angus', Tayside Fife Archaeol J, 8, 19-76.

Case, H 1977 'The Beaker culture in Britain and Ireland', in R Mercer (ed) Beakers in Britain and Ireland: Four Studies, 71-101. Oxford (=BAR Int Ser, 26).

Case, H 1993 'Beakers: deconstruction and after', Proceedings of the Prehistoric Society, 59, 241-68.

Clark, J G D 1932 'Discoidal polished flint knives, their typology and distribution', Proceedings of the Prehistoric Society, 6, 40-54.

Clark, J G D 1934a 'Derivative forms of the Petit Tranchet in Britain', Archaeological Journal, 91, $32-58$.

Clark, J G D 1934b 'The curved flint sickle blade of Britain', Proceedings of the Prehistoric Society, 7, 67-81.

Clark, J G D 1936 'Report on a Late Bronze Age Site in Mildenhall Fen, West Suffolk', Antiquaries Journal, 16, 29-50. 
Clark, J G D 1960 'Excavations at the Neolithic Site at Hurst Fen, Mildenhall, Suffolk', Proceedings of the Prehistoric Society, 26, 202-45.

Clarke, D L, 1970 Beaker Pottery of Great Britain and Ireland. Cambridge University Press, Cambridge.

Cowie, T 1993 'A survey of the Neolithic pottery of eastern and central Scotland', Proc Soc Antiq Scot, 123, 13-41.

Cressey,M 2002 Stoneyhill Windfarm,Aberdeenshire, Archaeological Assessment, CFA Archaeology Ltd, Report No. 691.1.

Curtis, N; Wilkin, N; Hutchison, M; Jay, M; Sheridan, A \& Wright, M 2007 'Radiocarbon dating results from the Beakers and Bodies Project', Discovery \& Excavation in Scotland, 223-4.

Darvill, T 2002 'White on blonde: quartz pebbles and the use of quartz at Neolithic monuments in the Isle of Man and beyond', in A Jones \& G MacGregor (eds) Colouring the Past. The Significance of Colour in Archaeological Research, 73-91. Berg, Oxford.

Duffy, P 2005 The Excavation of a Mound and Three Cist Burials at Ferndale, Rendall, Orkney. Scottish Archaeological Internet Report 16 (www.sair.org.uk/sair16/index.html).

Durden, T 1995 'The production of specialised flintwork in the later Neolithic: a case study from the Yorkshire Wolds', Proceedings of the Prehistoric Society, 61, 409-32.

Green, H S 1980 The Flint Arrowheads of the British Isles. A detailed study of material from England and Wales with comparanda from Scotland and Ireland. Parts i-ii. Oxford (=BAR Brit Ser 75).

Grimes, W F 1932 'The Early Bronze Age flint dagger in England and Wales', Proceedings of the Prehistoric Society, 6, 340-55.

Healy, F 1993 'Lithic material', in R Bradley; P Chowne; R M J Cleal; F Healy \& I Kinnes Excavations on Redgate Hill, Hunstanton, Norfolk, and at Tattershall Thorpe, Lincolnshire. East Anglian Archaeology 57.

Healy, F 1995 'Prehistoric material', in A Rogerson A Late Neolithic, Saxon and Medieval Site at Middle Harling, Norfolk. East Anglian Archaeology 74, 32-40.

Henshall, A S 1983 'The Neolithic pottery from Easterton of Roseisle, Moray', in A O'Connor \& D V Clarke (eds) From the Stone Age to the 'Forty-Five, 19-44. John Donald, Edinburgh.

Herne, A 1991 'The flint assemblage', in I Longworth; A Herne; G Varndell \& S Needham (eds) Excavations at Grimes Graves, Norfolk 1972-6. Fascicule 3, Shaft X: Bronze Age Flint, Chalk and Metal Working, 21-93. British Museum Press, London.

Johnston, D A 1997 'Biggar Common, 1987-93: an early prehistoric funerary and domestic landscape in Clydesdale, South Lanarkshire', Proc Soc Antiq Scot, 127 (1997), 185-263.

Keeley, L H 1982 'Hafting and retooling: effects of the archaeological record', American Antiquity, 47 (4), 798-809.

Kesel, R H \& Gemmel, A M D 1981 "The "Pliocene" gravels of Buchan: a reappraisal', Scottish Journal of Geology, 17, 185-203.

Kinnes, I 1985 'Circumstance not context: the Neolithic of Scotland as seen from the outside', Proc Soc Antiq Scot 115, 15-57.

Kinnes, I; Gibson, A; Ambers, J; Bowman, S; Leese, M \& Boast, R 1991 'Radiocarbon dating and British beakers: the British Museum Programme', Scottish Archaeological Review, 8, 35-68.

Lanting, J \& Waals, J van der 1972 'British beakers as seen from the Continent: a review article', Helinium, 12, 20-46.

Lebour, N 1914 'White quartz pebbles and their archaeological significance', Trans Dumfries \& Galloway Natural History \& Antiquarian Society, 2 (1913-14), 121-34.

Lemonnier, P 1976 'La Description des Chaînes Opératoires: contribution à l'analyse des systèmes techniques', Technique et Culture 1, 100-51.

Leroi-Gourhan, A 1965 Le Geste et la Parole II. La Memoire et les Rythmes. Albin Michel, Paris.

Longworth, I H 1967 'Further discoveries at Brackmont Mill, Brackmont Farm and Tentsmuir, Fife', Proc Soc Antiq Scot, 49 (1967), 60-92.

Manby, T G 1974 Grooved Ware Sites in the North of England, Oxford (=BAR Brit Ser, 9).

Merritt, J W; Connell, E R \& Bridgland, R R (eds) 2000 The Quaternary of the Banffshire Coast and Buchan: Field Guide. Quaternary Research Association, London.

Merritt, J W; Auton, C A; Connell, E R; Hall, A M \& Peacock, J D 2003 The Cainozoic geology and landscape evolution of north-east Scotland. Memoir of the British Geological Survey. British Geological Survey, Edinburgh.

Milne, J 1892 'Drift rocks in Buchan', Transactions of Buchan Field Club, 2 (1892) 181-98.

Moore, J W 1963 'Excavations at Beacon Hill, Flamborough Head, East Yorkshire', Yorkshire Archaeological Journal, 162, 191-202.

Needham, S P 2005 'Transforming Beaker Culture in North-West Europe: processes of fusion and fission', Proceedings of the Prehistoric Society, $71,171-217$.

Ordnance Survey 1868 Name Book No. 22, 7.

Philips, T \& Bradley, R 2004 'Developer-funded fieldwork in Scotland, 1990-2003: an overview of the prehistoric evidence', Proc Soc Antiq Scot, 134 (2004), 17-51.

Pratt, J B 1858 Buchan. 1981 reprint. Smith, Aberdeen \& Blackwood, Edinburgh

Ralston, I B M 1982 'A timber hall at Balbridie Farm', Aberdeen University Review, 168, 238-49.

Reynier, M J 2005 Early Mesolithic Britain. Origins, development and directions, Oxford (=British Archaeological Reports British Series 393).

Roe, D E 1981 The Lower and Middle Palaeolithic 
Periods in Britain. Routledge \& Kegan Paul, London (=The Archaeology of Britain).

Saville, A 1981 Grimes Graves, Norfolk. Excavations 1971 / 72: Volume II. The Flint Assemblage. (=DoE Archaeol Rep, 11). HMSO, London.

Saville, A 1995 'GB 20 Den of Boddam near Peterhead, Grampian Region, Scotland. GB 21 Skelmuir Hill, Grampian Region, Scotland. Prehistoric exploitation of flint from the Buchan Ridge Gravels, Grampian region, north-east Scotland', Archaeologia Polona 33, 353-68.

Saville, A 2002 'Lithic artefacts from Neolithic causewayed enclosures: character and meaning', in G Varndell \& P Topping (eds) Enclosures in Neolithic Europe. Essays on Causewayed and Non-Causewayed Sites, 91-105. Oxbow Books, Oxford.

Saville, A 2005 'Prehistoric quarrying of a secondary flint source: evidence from north-east Scotland', in $\mathrm{P}$ Topping \& $\mathrm{M}$ Lynott (eds) The Cultural Landscape of Prehistoric Mines, 1-13. Oxbow Books, Oxford.

Saville, A 2006 'Flint technology associated with extraction sites in north-east Scotland', in G Weisgerber (ed) Stone Age - Mining Age. Proceedings of the VIII International Flint Symposium, Bochum, 1999, 449-54. Veröffentlichungen aus dem Deutschen Bergbau-Museum Bochum 148. Deutsches Bergbau-Museum Bochum, Bochum.

Saville, A 2008 'Flint extraction and processing from secondary flint deposits in the north-east of Scotland in the Neolithic period', in P Allard; F Bostyn; F Giligny \& J Lech (eds) Flint Mining in Prehistoric Europe. Interpreting the Archaeological Records. European Association of Archaeologists, 12th Annual Meeting, Cracow, Poland, 19th-24th September 2006, 1-10. Oxford (=Brit Archaeol Rep Int Ser 1891).

Shepherd, I 2005 'Radiocarbon dates sponsored by Aberdeenshire Archaeology in 2004', Discovery and Excavation in Scotland 6, 184-185.

Sheridan, A 2007 'Scottish Beaker dates: the good, the bad and the ugly', in M Larsson \& M Parker Pearson (eds) From Stonehenge to the Baltic: living with cultural diversity in the third millennium $B C$, 91-123. Oxford (= BritishArchaeological Reports International Series 1692).

Sheridan, A; Parker Pearson, M; Jay, M; Richards, M \& Curtis, N 2006 'Radiocarbon dating results from the Beaker People Project: Scottish samples', Discovery \& Excavation in Scotland, 198-201.

Sheridan, A; Parker Pearson, M; Jay, M; Richards,
M \& Curtis, N 2007 'Radiocarbon dating results from the Beaker People Project, 2007: Scottish samples', Discovery \& Excavation in Scotland, 222.

Shore, J S; Bartley, D D \& Harkness, D D 1995 'Problems encountered with the ${ }^{14} \mathrm{C}$ dating of peat', Quaternary Science Reviews 14, 373-83.

Simpson, D D A \& Coles, J M 1990 'Excavations at Grandtully, Perthshire', Proc Soc Antiq Scot, $120,33-44$.

Smith, I F 1965 Windmill Hill and Avebury; Excavations by A. Keiller, 1925-1939. Clarendon Press, Oxford.

Speak, S \& Burgess, C 1999 'Meldon Bridge: a centre of the third millennium BC in Peeblesshire', Proc Soc Antiq Scot, 129 (1999), 1-118.

Strachan, R \& Dunwell, A 2003 'Excavations of Neolithic and Bronze Age sites near Peterhead, Aberdeenshire, 1998', Proc Soc Antiq Scot, 133, $137-71$.

Strachan, R; Ralston, I \& Finlayson, B 1998 'Neolithic and later prehistoric structures, and early medieval metal-working at Blairhall Burn, Amisfield, Dumfriesshire', Proc Soc Antiq Scot, 128 (1998), 55-94.

Suddaby, I 2009 Stoneyhill Farm, Longhaven, Peterhead, Aberdeenshire: the post-medieval features. Post-Excavation Archive Report. CFA Report No. 1723.

SWM 2000 Environmental Statement for the Proposed Development and Site Extension at Stoneyhill. Prepared by BMT Cordah on behalf of Stoneyhill Waste Management Ltd (SWM).

Warren, G 2006 'Chipped stone tool industries of the earlier Neolithic in Eastern Scotland', Scott Archaeol J, 28(1), 27-47.

Warren, G, with Dolan, B 2009 'Stone Tools' in H K Murray; J C Murray \& S M Fraser (eds) A Tale of the Unknown Unknowns: a Mesolithic pit alignment and a Neolithic timber hall at Warren Field, Crathes, Aberdeenshire. Oxbow, Oxford.

White, R; Richardson, P \& O'Connell, C 2009 'Prehistoric pit clusters and a rectilinear enclosure at Newton Road, Carnoustie, Angus', Tayside \& Fife Archaeological Journal, 15, 1-21.

\subsection{Cartographic}

Ordnance Survey 1872 Aberdeenshire, Sheet XXXI, First Edition, 6": 1 mile.

Ordnance Survey 1901 Aberdeenshire, Sheet XXXI NE, Second Edition, 25": 1 mile. 